Portland State University

PDXScholar

Fall 1-1-2012

\title{
Post-occupancy Evaluation at the Zoo: Behavioral and Hormonal Indicators of Welfare in Orangutans (Pongo pygmaeus abelii)
}

Leigha Tingey

Portland State University

Follow this and additional works at: https://pdxscholar.library.pdx.edu/open_access_etds

Part of the Behavior and Ethology Commons, and the Zoology Commons Let us know how access to this document benefits you.

Recommended Citation

Tingey, Leigha, "Post-occupancy Evaluation at the Zoo: Behavioral and Hormonal Indicators of Welfare in Orangutans (Pongo pygmaeus abelii)" (2012). Dissertations and Theses. Paper 901.

https://doi.org/10.15760/etd.901

This Thesis is brought to you for free and open access. It has been accepted for inclusion in Dissertations and Theses by an authorized administrator of PDXScholar. Please contact us if we can make this document more accessible: pdxscholar@pdx.edu. 
Post-occupancy Evaluation at the Zoo: Behavioral and Hormonal Indicators of Welfare in Orangutans (Pongo pygmaeus abelii)

\author{
by \\ Leigha Tingey
}

A thesis submitted in partial fulfillment of the requirements for the degree of

\author{
Master of Science \\ in \\ Biology
}

Thesis Committee:

Deborah A. Duffield, Chair

David J. Shepherdson

Brad A. Buckley

Portland State University

2012 
(C) 2012 Leigha Tingey 


\section{Abstract}

An increased understanding of species-specific behavioral needs has lead zoos to focus on providing more naturalistic and stimulating environments. Scientific assessments of how changes in habitat affect animal behavior are necessary in improving overall animal welfare. This study examined the move of three orangutans housed at the Oregon Zoo into a new and innovative exhibit. Post-occupancy evaluation (POE), which offers systematic information regarding the success or failure of the built environment (Maple \& Finlay, 1987), was utilized to effectively evaluate the results of the move. The collection of behavioral data and adrenal activity monitoring through collection of non-invasive saliva, urine and hair provided a comprehensive methodology for comparing changes in behavior and physiological functioning. Behavioral results showed that following the move to the new enclosure animals spent less time inactive, more time at higher elevations and utilized exhibit structures at a greater frequency. Hormonal results suggest that detection of cortisol in orangutan hair could be a useful tool for monitoring chronic stress. 


\section{Acknowledgements}

This thesis would not have been possible without the guidance and the help of several individuals who in one way or another contributed and extended their valuable assistance in the preparation and completion of this study. I would like to express my deepest gratitude to my advisor, Dr. Deb Duffield, for her unfailing encouragement and support throughout the entire process. Dr. David Shepherdson, for his advice as a committee member and for initially extending the opportunity for me to work with the orangutans at the Oregon Zoo; and Dr. Brad Buckley for agreeing to be on my committee, and his willingness to Skype in from Antarctica for my defense. Karen Lewis for all the insights she has shared; and my excellent interns, Kevin Lee and Katie Goodman for their hard work and dedication to my project. All the primate zookeepers at the Oregon Zoo, especially Jesus Gonzales for his enthusiasm and willingness to help with sample collection. The Endocrine services lab team: Dr. Francis Pau for his steadfast encouragement, recommendations and expertise; Steven Blue for his valuable insights and Andrea Winchell for her willingness to read my first draft. My fellow grad students who shared their advice, understanding and were there for commiseration; my parents and family members who offered both support and encouragement with their best wishes. My dear friends, Kerry Hoeschen, Heidi Haberbush Tingey, and Kacy Cullen for being the supportive core I needed to get through this program and all my other amazing friends who I haven't yet thanked. Gordon Nickel, for capturing beautiful photos of the orangutans, 
providing technical support, and believing in me when I needed it most. Thank you for standing by me this past year and being there to cheer me up. Finally, I would like to thank the orangutans at the Oregon Zoo, Inji, Kutai and Batik. Without them this study would not have been possible. 


\section{Table of Contents}

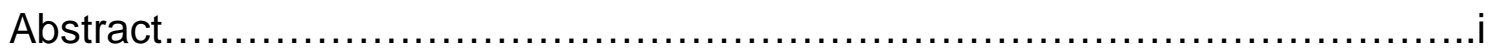

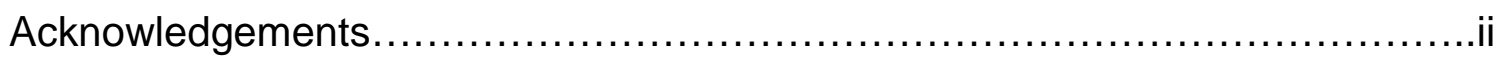

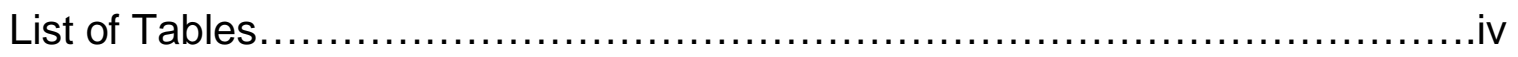

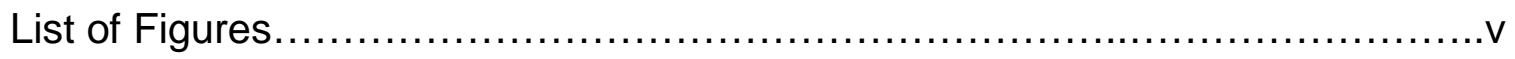

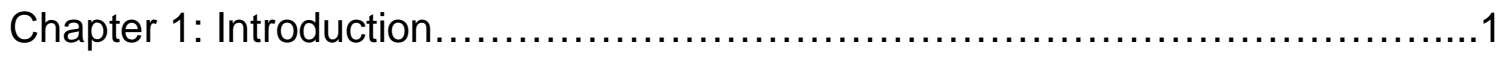

Chapter 2: Method and Procedure.......................................

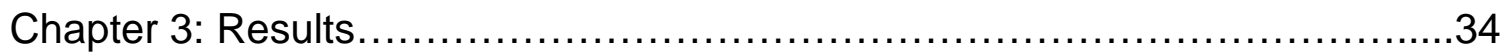

Chapter 4: Discussion and Conclusions................................64

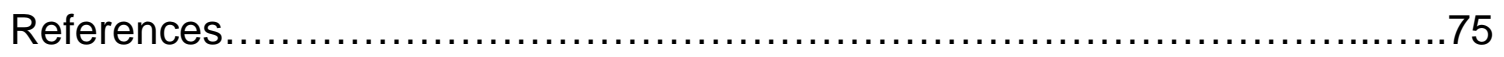

Appendices

A: Red Ape Reserve exhibit outdoor plant species....................81

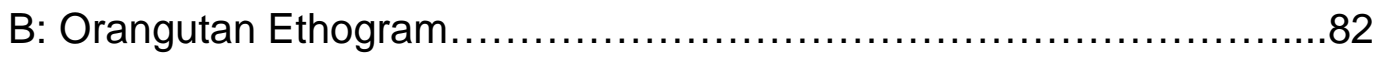

C: Behavioral data percent of observable interval totals................85 


\section{List of Tables}

Table 2.1: Individual orangutans housed at the Oregon Zoo..................17

Table 2.2: $\quad$ Pre-move observation data collection details......................24

Table $2.3 \quad$ Introductions to the new exhibit.................................25

Table 3.1 Behavioral data categories and observable intervals totals (proportion of total minutes) for Inji..............................34

Table 3.2 Behavioral data categories and observable intervals totals (proportion of total minutes) for Kutai..............................34

Table $3.3 \quad$ Inji salivary cortisol sample totals...............................57

Table 3.4 Inji mean values of salivary cortisol $(\mathrm{ng} / \mathrm{ml})$ before and after the move to the new exhibit.........................................5

Table $3.5 \quad$ Kutai salivary cortisol sample totals...............................59

Table 3.6 Kutai mean values of salivary cortisol $(\mathrm{ng} / \mathrm{ml})$ before and after the

move to the new exhibit..........................................59

Table 3.7 Inji mean values of salivary cortisol $(\mathrm{ng} / \mathrm{ml})$ before and after the

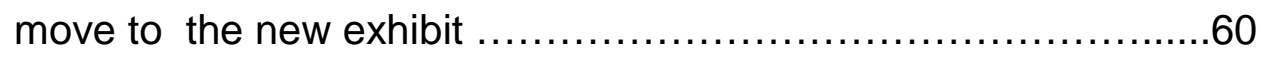

Table 3.8 Kutai urine sample totals and mean values of urinary cortisol $(\mathrm{ng} / \mathrm{ml})$ before and after the move to the new exhibit...............62

Table 3.9 Kutai's hair samples collected and analyzed for cortisol............62 


\section{List of Figures}

Figure 1.1: Time associated with hormone secretion/excretion and action as adapted from Whitten, Brockman \& Stavisky (1998).............9

Figure 1.2: Map of orangutans distribution in Southeast Asia....................10

Figure 2.1: Photograph of adult flanged male, Kutai at the Oregon Zoo........18

Figure 2.2: Photograph of old orangutan exhibit at the Oregon Zoo taken from single visitor viewing window.......................................19

Figure 2.3: Old exhibit design parameters depicting single public view window

Figure 2.4: Photograph of new Red Ape Reserve exhibit at the Oregon Zoo showing exhibit structures (including: mesh perimeter and ceiling, horizontal and vertical logs, rope, and sway poles) with animals in outside zone 1

Figure 2.5: New exhibit design parameters depicting public view windows and outside exhibit zones........................................

Figure 2.6: Serial dilution of orangutan urine samples depicting linearity $\ldots . . .28$

Figure 2.7: Distribution of saliva samples volumes..........................29

Figure 2.8: Serial dilution of orangutan saliva samples depicting

linearity.

Figure 3.1: Inji's percentage of elevations observed during the three phases

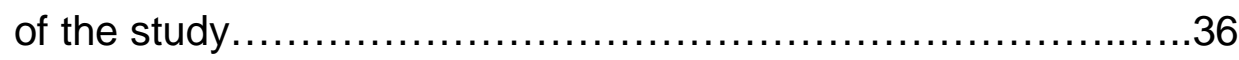


Figure 3.2: Kutai's percentage of elevations observed during the three phases of the study.

Figure 3.3: Inji's percentage of proximity observations during the three phases of the study

Figure 3.4: Kutai's percentage of proximity observations during the three phases of the study.

Figure 3.5: Inji's percentage of specific structure use observed during all three study phases

Figure 3.6: Inji's observed use of vertical and horizontal logs during habituation and post-occupany phase. .42

Figure 3.7: Inji's percentage of total structure use observed during all three study phases

Figure 3.8: Kutai's percentage of specific structure use observed during all three study phases

Figure 3.9: Kutai's observed use of vertical and horizontal logs during habituation and post-occupancy phases.

Figure 3.10: Kutai's percentage of specific structure use observed during all three study phases .44

Figure 3.11: Inji's percentage of window use observed during the three study phases .46

Figure 3.12: Kutai's percentage of window use observed during the three 
study phases.

Figure 3.13: Inji's percentage of outside use during the habituation and post-occupancy phases

Figure 3.14: Kutai's percentage of outside use during the habituation and post-occupancy phases

Figure 3.15: Inji's percentage of general locomotions observed for all study phases .50

Figure 3.16: Inji's percentage of active locomotions observed during all study phases

Figure 3.17: Kutai's percentage of general locomotion observed for all study phases .52

Figure 3.18: Kutai's percentage of active locomotions observed during all study phases.

Figure 3.19: Inji's percentage of activities observed during all study

$$
\text { phases. }
$$

Figure 3.20: Inji's percentage of object use observed during all study phases 54

Figure 3.21: Kutai's percentage of activities observed during all study phases .56

Figure 3.22: Kutai's percentage of object use observed during all study phases .56

Figure 3.23: Salivary cortisol values for Inji's morning samples compared 
across baseline and post-occupancy

Figure 3.24: Salivary cortisol values for Kutai's morning samples compared across baseline and post-occupancy

Figure 3.25: Urinary cortisol values for Inji's morning samples compared across baseline and post-occupancy

Figure 3.26: Morning and afternoon urinary cortisol values for Inji's samples collected during baseline

Figure 3.27: Batik's hair cortisol values collected during baseline prior to her death. .63 


\section{Chapter 1}

\section{INTRODUCTION:}

\subsection{Introduction}

Many zoos have shifted their objectives from a solely recreational role to one including conservation, public education, and improving the overall welfare of their animals (Little \& Sommer, 2002). The health and longevity of zoo animals is of concern, particularly in the case of endangered species who serve as viable populations for breeding in captivity. The emphasis on zoo animal welfare in the past decade has resulted in efforts to increase the understanding of speciesspecific behavioral needs and social dynamics of captive animals. These changes have led zoos to focus on providing more naturalistic and stimulating environments for their animals (Coe, 1989). Scientific investigation into the effects of these enriched environments is needed to evaluate improved animal welfare. This study will use behavioral and hormonal indicators of animal welfare to examine how zoo animals respond to being moved to an innovative enclosure.

\subsection{Post-occupancy evaluation}

Post-occupancy evaluation (POE) is a method of systematically assessing the success or failure inherent in the design of man-made environments for humans and animals (Maple \& Finlay, 1987). These studies are commonly used to investigate human settings and more recently have been applied to evaluate the housing of primates in a zoo setting (Hoff \& Maple, 1995; Ross et al, 2011). In general, POEs of primate environments focus on evaluating change of 
enclosure events and involve collecting behavioral data prior to the move, upon initial introduction to the new enclosure, and repeatedly in the new enclosure throughout the duration of the study (Chang et al, 1999). These POEs investigate how the new environment affects animal welfare and are helpful in assessing and improving current projects while providing direction and insight for future projects (Wich et al., 2009). Recently, some zoo studies have begun to include the collection of physiological parameters such as stress and reproductive hormonal measurements (Condon \& Wehnelt 2003; Clark et al. 2011) to study the effects of environmental enrichment on non-human primate animal welfare. Combining behavioral observations with quantitative data obtained from stress hormone measurements has the potential to provide a more complete framework for evaluating the overall well-being of animals before and after being moved to a new enclosure.

\subsection{Animal welfare}

An examination of the history of animal welfare and its designations in zoo animal research is useful in providing a framework from which to proceed in conducting a POE. "Animal welfare" is a term which is commonly used in zoological and other animal research without there being a clear or universal definition. The adoption of animal welfare as a scientific concept worthy of study originally grew out of ethical concerns regarding quality of life and treatment of animals (Fraser, 1997). The Animal Welfare Act of 1966 was the first law in the United States to include protection of captive animals and was later amended in 1985 to include provisions for the psychological well-being of non-human 
primates (Cowan, 2010). In the last fifteen years, there have been progressively more studies exploring the behavior of captive animals and a growth in scientific undertakings to identify the necessary elements for not only physiological, but also psychological well-being. Hill and Broom (2009) define animal welfare as the degree at which an animal is able to cope with its environment on a continuum varying from poor or low functioning to excellent or optimal functioning. The welfare of captive animals is thus largely dependent on an ability to cope with changing or variable environmental and social conditions.

Despite the recent increase in animal welfare research, there is a lack of a universally established methodology for assessing and measuring welfare. Fraser (2009) lists three major goals associated with efforts for improving animal welfare: "(1) Ensure good physical health and functioning of animals, (2) Minimize unpleasant "affective states" (pain, fear, etc.) and to allow animals normal pleasures, and (3) Allow animals to develop and live in ways that are natural for the species". These objectives can be summed up into three main approaches used by scientists when evaluating welfare (Seijan et al., 2011). The first is a functional approach that can be objectively measured by monitoring physiological functioning through biological measurement. The second, which involves the evaluation of psychological well-being is a subjective approach and is much more difficult to gauge scientifically because animal emotions or how an animal "feels" can be tough to observe and measure. The third is a naturalistic approach that involves comparison between behavior of wild and captive populations in attempting to provide captive animals the necessary elements for 
living in a natural way. Scientific assessments of these approaches involve the identification of species-specific traits and life histories that frame the level at which animals are able to adapt and/or cope in their environment.

The use of POE for evaluation of animal welfare is most compatible with a functional and naturalistic approach (Seijan et al., 2011; Condon \& Wehnelt, 2003; Maple \& Finlay, 1987). The former allows for quantification of biological parameters, which can be valuable in answering questions regarding the level at which an animal is functioning or coping in a new environment. The latter can provide a solid framework for answering questions regarding whether a change of exhibit event will provide a more naturalistic environment and result in more natural behaviors.

\subsection{Stress and cortisol in correlation to animal welfare}

An examination of stress and the body's response to stress is an integral part of evaluating the health and well-being of captive animals. The ability to define and quantify stress presents a valid means of evaluating animal welfare (Moberg, 1987). Like animal welfare, stress is often used ambiguously and as a result, can be difficult to define. In their review of the use of 'stress' in the current literature, the Committee on Recognition and Alleviation of Distress in Laboratory Animals (2008) define it in broad terms as that which disrupts the physical homeostasis or normal psychological functioning of an animal. In the face of an actual or presumed threat by a stressor, the body's adaptive response causes an organism to undergo behavioral or physiological changes to reinstate internal stability. McEwen and Wingfield (2010) argue for the use of allostasis as a term 
to supplement the concept of homeostasis to distinguish between stability of vital systems and how these systems are maintained in balance.

\subsubsection{Allostasis}

The concept of allostasis originated in biomedicine (McEwen \& Wingfield, 2003) and has more recently been applied to animal behavior and endocrinology research. Allostasis, literally translates to "maintaining stability through change" (Goymann \& Wingfield, 2004) and describes the biological processes, which sustain or restore homeostasis through the neuroendocrine activities that help an animal cope with modified or new environments and situations (McEwen and Wingfield, 2010). The intensification of physiological costs and burdens that accumulate during allostasis are referred to allostatic load (Creel et al., 2012; Goymann \& Wingfield, 2004). If an animal reaches a point where it cannot deal with the allostatic load, there is a high potential for biologically harmful pathologies and reduced animal welfare. McEwen and Wingfield (2003) describe two different types of allostatic overload. The first, Type 1 occurs when energy demands exceed the energy available for utilization by the body. This negative energy balance can result in a loss in body mass as energy stores such as fat are mobilized to deal with the high allostatic load (McEwen \& Wingfield, 2010). The second, Type 2 allostatic overload is related to situations where energy is not a limiting factor, in fact it is often characterized by an over consumption and storage of energy. This can be due to metabolic imbalances, namely a prediabetic state; or occur in the form of food intake related to stress including selection of a high fat diet (McEwen \& Wingfield, 2010). Allostatic load and 
instances of allostatic overload can be monitored in part by measurement of glucocorticoids released by the hypothalamic-pituitary adrenal (HPA) axis. Application of McEwen and Wingfield's allostasis model is a useful tool for systematic evaluation of stress and its potential effects on animal welfare during a change of enclosure study.

\subsubsection{Physiology of stress}

A multitude of biological parameters are involved in the body's response to stress including metabolic and immunological changes, actions of the autonomic nervous system, and the cascading effects of the hypothalamic pituitary adrenal (HPA) axis (Lupien, 2007). The latter is considered the key player in the hormonal stress response of non-human primates (Dedovic et al., 2009). Activation of the HPA axis begins in the hypothalamus with the release of corticotrophin releasing hormone $(\mathrm{CRH})$. Along with arginine vasopressin (AVP), $\mathrm{CRH}$ initiates the immediate secretion and release of adrenocorticotrophic releasing hormone $(\mathrm{ACTH})$ into the bloodstream (Herman, 2003). As a tropic hormone, ACTH then stimulates the adrenal cortex causing the secretion of glucocorticoids namely, cortisol, which is the end product of the HPA axis.

Cortisol is the major glucocorticoid of non-human primates and has a wide range of effects on body tissues due to the large number of receptors for cortisol on body cells (Buckingham, 2006). In general, cortisol causes the body to temporarily cease costly, nonessential bodily functions while assembling the energy needed to respond to current stressor(s). The physiological effects of cortisol production on the body systems include an increased rate of 
gluconeogenesis by the liver, changes in protein metabolism, and an inhibition of growth, reproduction and immunity (van der Ohe \& Servheen, 2002). The shortterm release of cortisol is important in its role of eliciting a physiological response, which helps an animal cope with the stressor and through "allostasis" return the body to a balanced state. However, long-term production of cortisol can have detrimental effects on animal welfare. As the body is continually mobilizing the energy necessary to deal with the existing perturbations there is a snowball effect, which over time can result in Type 1 allostatic overload.

An important distinction can be made between stress and distress. The latter generally develops over a prolonged period of time or is related to high intensity stressors and describes a biologically negative state in which an animal fails to adapt to present stressors and reaches a state of allostatic overload (Moberg, 1985). Stress and a stress response are not intrinsically bad in regards to animal welfare, however distress is; it poses serious negative health effects to animals. Progression to a state of distress ensues whenever normal biological functioning is no longer possible and mechanisms for coping are depleted. This can occur following both acute and chronic stress, which reveals that magnitude as well as duration is important in evaluating the ability to adapt to stressors (Moberg, 1985). In assessing changes in an animal's ability to cope with changes to its environment, this study will examine both short and long term changes in cortisol production. The actual event of being moved to the new exhibit could manifest as an acute stressor with the potential to cause distress when the animals are anesthetized and transferred to their new holding area. On the other 
hand, an evaluation of chronic stress requires long term measurement of cortisol and a comparison of values before and after the change of enclosure event.

\subsubsection{Non-invasive sampling}

When collecting samples for measurement of cortisol from captive animals it is important that care is taken to not illicit a stress response during the collection process. Non-invasive sampling methods using saliva and urine allow for cortisol measurement without the use of stressful procedures that confound results, such as capture and restraint associated with blood serum or plasma collection. The major limitation of these methods is that they are only capable of reflecting short-term changes in cortisol production, and thus require repeated sampling (Fig. 1.1). Following exposure to stressors, salivary cortisol levels peak within 20-30 minutes (Kirshbaum \& Hellhammer, 1989) and urine reflects cortisol levels within hours. The use of hair for determination of steroid hormones, specifically cortisol, offers a non-invasive alternative capable of measuring longterm cortisol production (Koren et al., 2002). Hair carries a history of cortisol exposure over weeks and months (Sheriff et al, 2011). Hair assay validations have been carried out using samples obtained from laboratory animals (Davenport et al., 2006), domestic cats and dogs (Accorsi et al., 2008), and wildlife (Koren et al., 2002). The necessary validation of these hair assays has not yet been conducted for zoo animals. This validation is one of the aims of this study. 


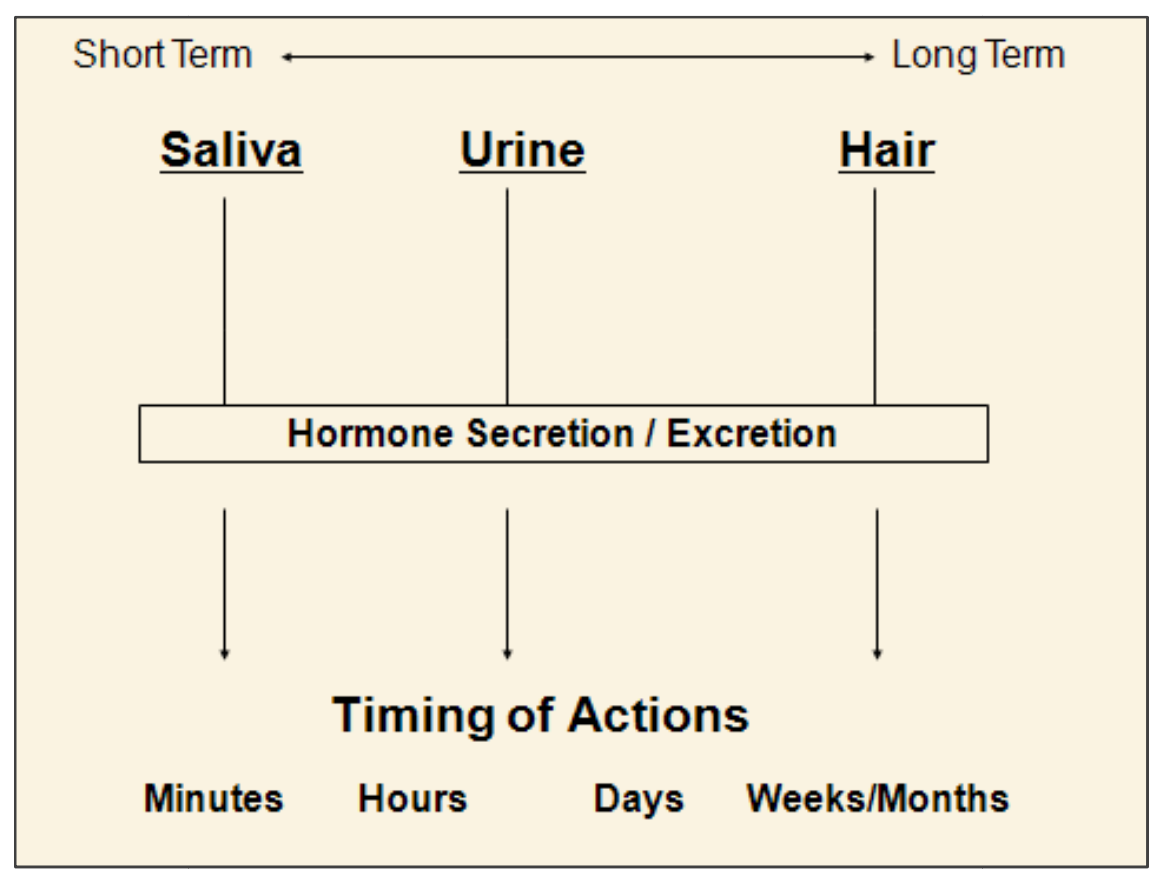

Figure 1.1 Time associated with hormone secretion/excretion and action as adapted from Whitten, Brockman \& Stavisky (1998).

\subsection{Orangutan life history traits}

The orangutan is a large-bodied arboreal ape whose wild populations exist exclusively in Southeast Asia (Fig. 1.2). They are generally divided into two distinct species of the genus Pongo, which are endemic to the islands of Borneo (Pongo pygmaeus pygmaeus) and Sumatra (Pongo pygmaeus abelii). The Sumatran orangutan populations are restricted to the northern most regions of the island, whereas the Bornean orangutan is found in Central, West, and East Kalimantan, Sarawak, and Sabah (Warren, 2001). 


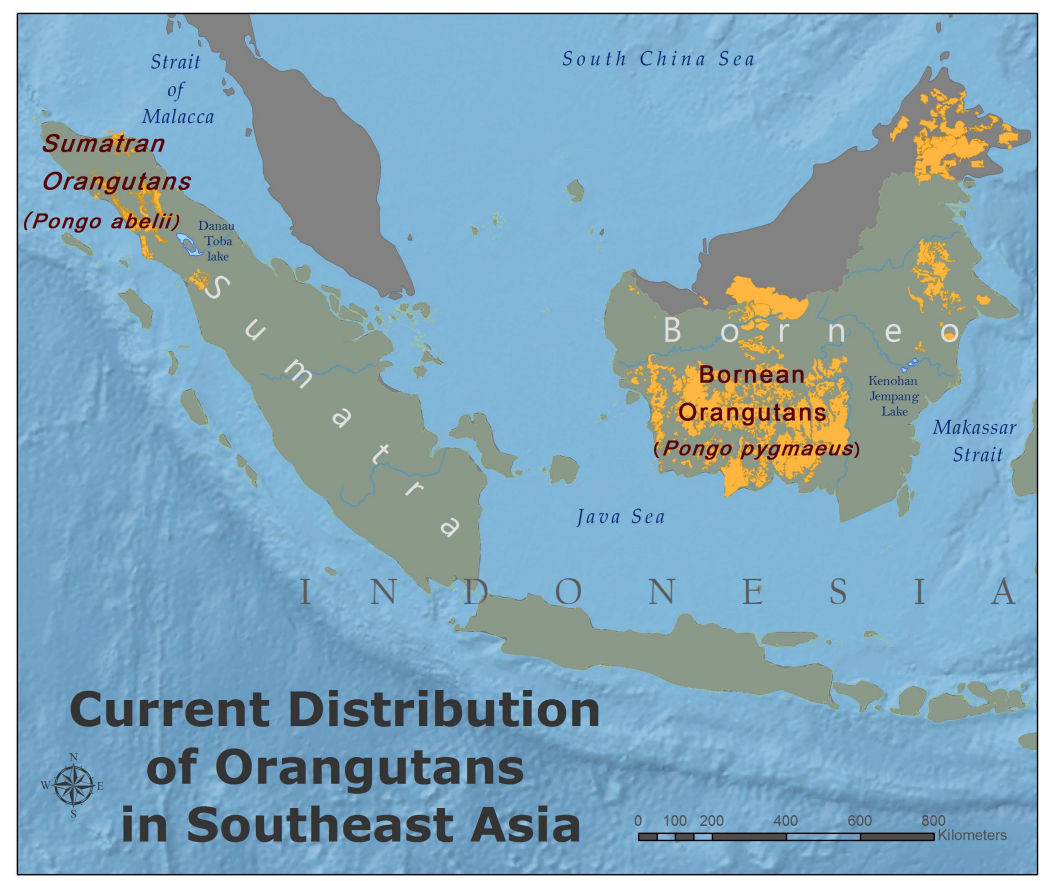

Figure 1.2 Map of orangutan distribution in Southeast Asia Created by Leigha Tingey, Data source IUCN Red List 2012

Orangutans exhibit a high degree of sexual dimorphism; adult males weigh in over twice the size of their female counterparts. Orangutan males undergo a distinctive bimodal development with two distinctive adult morphs: unflanged and flanged, which vary physically and in their reproductive strategies (Harrison and Chivers, 2006). The flanged male is characterized by a large laryngeal sac, distinct cheek pads (Fig. 2.1) all of which will develop in response to social conditions, namely the lack of a resident adult male (Rijksen, 1978).

Unusual when compared to other diurnal anthropoid primates, orangutans are characterized as being primarily solitary animals in the wild, with the exception of long term groupings of females with their off-spring (Rijksen, 1978; Rodman, 1979; Sugardjito et al., 1987). Instances of sociality in orangutan have 
been correlated with times of food abundance and sexual consortship (Galdikas, 1978). Orangutans are primarily frugivorous which often requires that they disperse and move large distances in response to food availability (Wich et al., 2008).

\subsubsection{Conservation Status}

Populations of both species, whose ranges historically extended throughout much of Southeast Asia and Mainland Asia (Wich et al., 2008), are currently in decline and at risk for extinction, primarily the Sumatran orangutan. Using nest density and satellite images from 2002 researchers estimate 6,600 individuals remain in Sumatra (Singleton et. al. 2009). The International Union for Conservation of Nature (IUCN) classifies the Bornean orangutan as endangered and the Sumatran orangutan as critically endangered (Singleton et al., 2008).

Specific life history traits including a long inter-birth interval of approximately 7-9.3 years (Wich et al., 2004); subsistence at low population densities and the occupation of large home ranges makes then uniquely vulnerable to environmental degradation. The foremost threat on both islands is deforestation, which has resulted in large-scale habitat loss and fragmentation of forests. This loss of habitat initially comes from extensive commercial logging, both legal and illegal. More recently the threat has been amplified with the conversion of these lowland logged areas into oil palm (Elaeis guineenisis) plantations. The latter is driven by the demand for oil palm in the global market as a highly profitable cash crop. Between $1950-2000$ Indonesia lost $40 \%$ of forests resulting in the reduction of ground cover from approximately 162 million 
hectares to 96 million (Dellatore, 2007). Given this, the successful management of captive orangutans is important. Zoos serve as educate the public regarding conservation issues, while zoo animals provide useful information concerning a species overall flexibility of life history traits (Wich, 2009) and contribute to international breeding programs (Condon \& Wehnelt, 2003).

\subsection{Indicators of animal welfare in orangutans}

Seijan et al. (2011) delineates different classes for evaluation of farm animal welfare, including behavioral, physical and physiological parameters. These categories lend themselves well to application in zoological research and objectives for improving animal welfare. Assessment methods of zoo animal welfare often focus on reducing abnormal and repetitive behaviors known as stereotypies. Many zoo animals exhibit stereotypic behaviors, which in addition to being repetitive are fairly consistent in duration without serving a clear purpose (Swaisgood \& Shepherdson, 2005). These aberrant behaviors can be used as indicators for risk of reduced animal welfare.

Captive orangutans however, do not engage in stereotypic behaviors (Wright, 1995; Condon \& Wehnelt, 2003) and thus it can be challenging when evaluating specific needs for improving animal welfare. There is currently a lack of reliable and established behavioral indicators of welfare for zoo housed orangutans. High levels of inactivity, including reduced foraging, locomotion, and play have all been cited as possible behavioral signs of reduced welfare in orangutans (Birke, 2002). Frequent use of objects to cover head or body to avoid 
visitor contact has also been linked with compromised welfare (Jones, 2003). Some physical signs of reduced welfare in orangutans include an increase in weight (from inactivity cited above), reduction in grooming habits resulting in a matted and dirty coat, and development of skin and hair problems (Pizzutto et al., 2008). Physiological indicators of welfare in orangutans include changes in biological response to environment and can result in an increase in cortisol production. It is clear that efforts to improve the overall welfare of captive animals should focus on providing an environment with sufficient stimulation and variation (Birke, 2002).

\subsection{Environmental Enrichment}

Environmental enrichment is a useful tool for improving the welfare of captive animals. It can be defined in broad terms as husbandry standards and practices whose objectives are to improve the care of captive animals and offer optimum physiological and psychological well-being through identification and provision of environmental stimulus (Swaisgood \& Shepherdson, 2005).

Providing increased opportunities for animals to make behavioral choices (BenAri, 2001), creating an environment which encourages active exploratory behaviors (Mench, 1998), and increasing the complexity involved in obtaining food are all specific aims of environmental enrichment. The primary goals of undertaking an environmental enrichment program are to improve an animal's overall ability to cope with its environment by reducing or eliminating instances of distress (Mellen \& MacPhee, 2001). Environmental enrichment and POE have overlapping goals; both endeavor to provide animals with more "naturalistic" 
environments. Incorporating the aims of environmental enrichment when conducting a POE will assist in evaluating the new enclosure design and answering question related to improvement of animal welfare.

\subsection{Specific Objectives}

The overall goal of this study was to conduct a comprehensive postoccupancy evaluation to investigate how the move to a new enclosure would affect the animal welfare of zoo housed orangutans. The design and construction of the innovative Red Ape Reserve at the Oregon Zoo in 2010 provided the opportunity to look at changes in orangutan behavior and cortisol production during three phases 1 ) before the move, baseline; 2) immediately following the move, habituation and 3) progressively in the exhibit, postoccupancy. To date, no studies have adopted a scientific approach which includes collection of behavioral and hormonal data for assessment of a change of enclosure event for zoo housed orangutans.

\subsubsection{Objective 1}

One specific objective of this study was to investigate whether the increase in overall available area in the new exhibit and greater diversity of locations, including an outdoor exhibit area would have a positive effect on reducing behaviors linked to decreased animal welfare in zoo housed orangutans. I set out to collect and evaluate a suite of behaviors during all study phases to assess individual changes in each animal's ability to successfully cope with its environment. Based on my review of environmental enrichment studies focused on zoo housed orangutans, I chose two primary indicators of welfare 
assessment for captive orangutans: 1) level of inactivity, and 2) vertical space use. In addition, I sought to evaluate animal choice by comparing overall diversity of behaviors (e.g. choice of location, activities, and locomotion) that animals were engaged in for both the old and new exhibits.

I hypothesized that behaviors associated with reduced well-being would be less frequent in the new exhibit because of design efforts to encourage exploratory behaviors in a "naturalistic environment". I projected these changes would provide more behavioral choices and expand the overall repertoire of observable behaviors. With the increase in total space and addition of vertical space in the new enclosure, I predicted that there would be a rise in activity levels including increased locomotion at higher elevations.

\subsubsection{Objective 2}

The second objective of this study was to examine the physiological aspects of animal welfare for orangutans in terms of stress response and production of cortisol during all study phases. I chose to use multiple sample matrices (saliva, urine and hair) to analyze cortisol levels by collecting baseline samples in the old exhibit, habituation samples immediately following the move, and post-occupancy samples after one month in the new exhibit.

I hypothesized that the event of being moved to the new exhibit would be a stressor sufficient to result in an acute rise in cortisol levels. I postulated that this allostatic response to the environmental changes would decrease over the course of the habituation phase as the animals adapted to their new surroundings. I predicted that over time cortisol levels would decrease below 
those seen during baseline and distress would be minimized during the postoccupancy phase. These endocrinological changes would be the result of the structural modifications and increased complexity in the new exhibit, which would allow the animals to live in a more natural habitat while engaging in speciesspecific behaviors. 


\section{Chapter 2}

\section{METHODS AND PROCEDURES:}

\subsection{Study subjects and exhibit features}

\subsubsection{Orangutans at Oregon zoo}

Study subjects were three Sumatran orangutans, one adult male and two adult females (Table 2.1) housed at the Oregon Zoo. The male in this study, Kutai developed his secondary sexual characteristics including large cheek pads, a large throat sac, and overall increase in body size at the onset of the study and is thus considered a flanged male (Fig. 2.1). He is the grandson of the dominant female, Inji and was brought to the Oregon Zoo as a potential reproductive mate for Batik, the subordinate female. Batik became ill and died near the end of the first phase of the study and therefore will not be included in the pre and post behavioral data analysis. However, her hormonal data was processed to assess cortisol levels before, at the onset and during the final days of her illness (Section 3.2.3).

Table 2.1

Individual orangutans housed at the Oregon Zoo

Animal Sex Rank Date of Birth Place of Birth Arrival at the

Oregon Zoo

\begin{tabular}{|c|c|c|c|c|c|}
\hline Batik & $\mathrm{F}$ & $\begin{array}{l}\text { Subordinate Adult } \\
\text { Female }\end{array}$ & $\begin{array}{l}8 / 19 / 87 \\
\text { d. } 7 / 8 / 10\end{array}$ & Brookfield Zoo, IL & 1996 \\
\hline Inji & $\mathrm{F}$ & $\begin{array}{l}\text { Dominant Adult } \\
\text { Female }\end{array}$ & $\begin{array}{l}1960 \\
\text { (estimated) }\end{array}$ & wild born & 1961 \\
\hline Kutai & M & Adult Male & $12 / 16 / 93$ & $\begin{array}{l}\text { Sedgwick County } \\
\text { Zoo, KS }\end{array}$ & 2001 \\
\hline
\end{tabular}




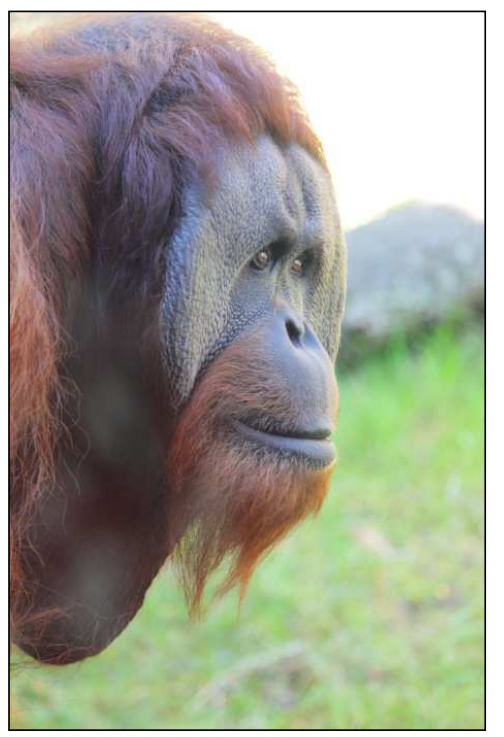

Figure 2.1 Photograph of adult flanged male, Kutai at the Oregon Zoo

\subsubsection{Old enclosure details}

The original orangutan exhibit, built in 1959 offered the animals an entirely indoor space with a total area of $1616 \mathrm{ft}^{2}$. The old enclosure had a maximum height of 32 ' and minimum height of 22'. Furnishings included two climbing structures made of both horizontal and vertical logs, a metal pole allowing movement between structures, a tire swing, metal basket and mesh hammock (Fig. 2.2). An assortment of enrichment items were added to the exhibit daily including cardboard, paper, straw, fabric, and branches with or without leaves. The exhibit featured a single large window for zoo visitors to view animals (Fig. 2.3). 


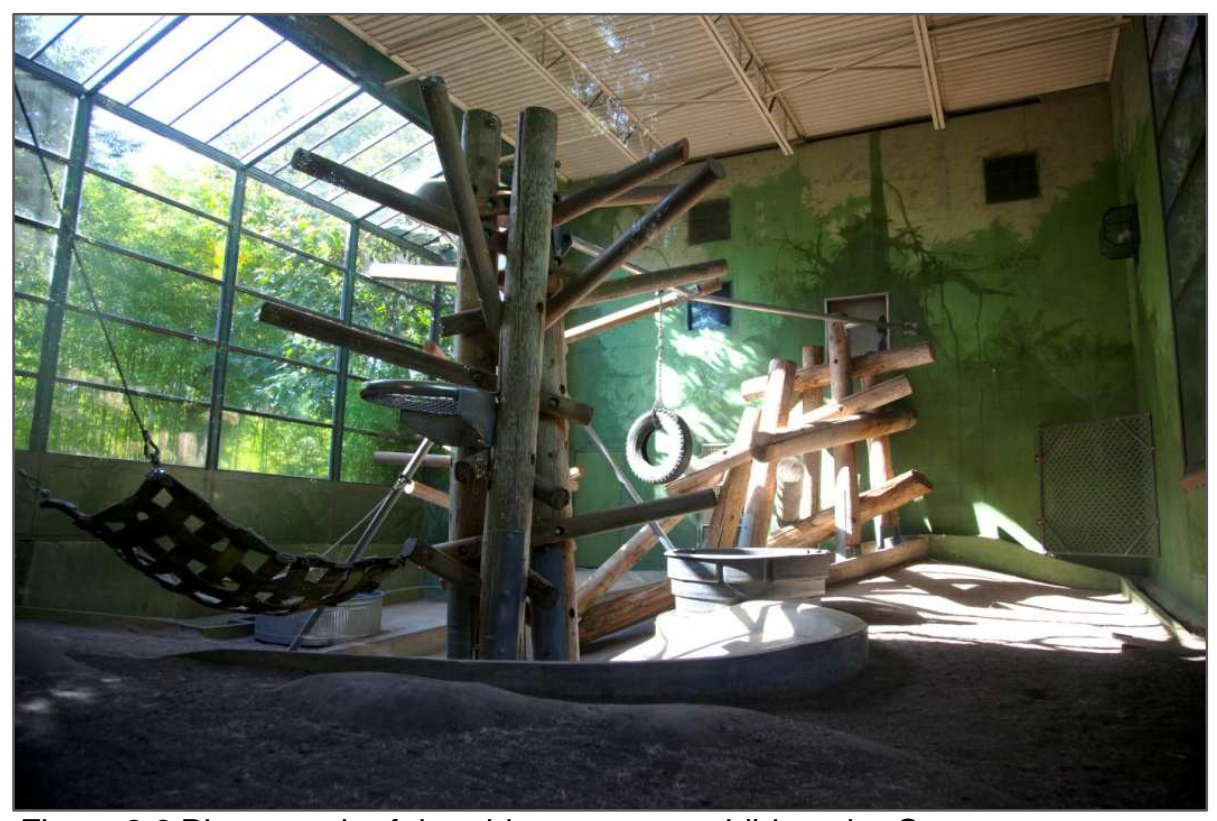

Figure 2.2 Photograph of the old orangutan exhibit at the Oregon zoo taken from single visitor viewing window.

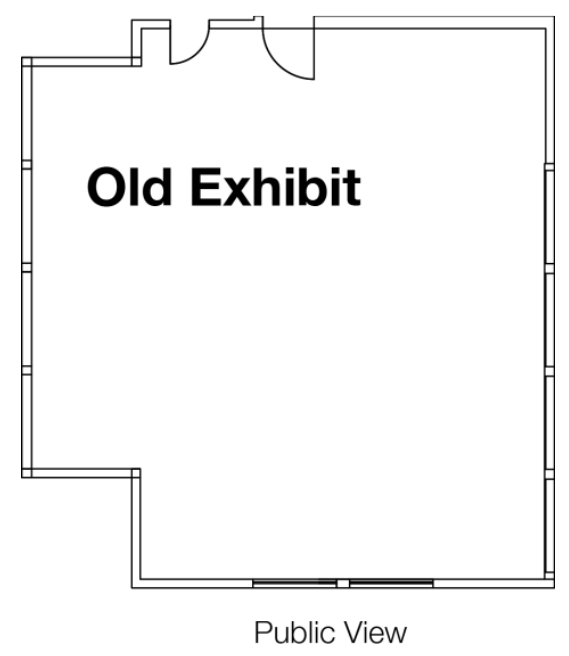

Figure 2.3 Old exhibit design parameters depicting single public view window

\subsubsection{New enclosure details}

The new exhibit, Red Ape Reserve was built in 2010, includes $820 \mathrm{ft} 2$ of indoor space and 5,400 ft2 of open air space for the animals to explore an outside environment. The new indoor exhibit has a maximum height of 29' and a 
minimum height of $16^{\prime} 8$ ". The new outdoor exhibit area has a maximum and minimum height of 20' $10^{\prime \prime}$ and 13' 9", respectively. This enclosure was designed to maximize the use of vertical space and incorporates a mesh ceiling and perimeter, sway poles, horizontal and vertical logs, and ropes allowing the animals more opportunities for species-specific locomotion by brachiation, a form of arboreal locomotion (Fig. 2.4).

The outdoor exhibit was divided into three zones to evaluate the use of outside space for each individual (Fig. 2.5). All zones of the outside are shared with two of the Oregon zoo's white-cheeked gibbons. Outside area zone 1 features a hollow gunite enrichment tree, which resembles a strangler fig and offers hiding places for the zookeepers to place food and other enrichment items. As in the previous exhibit various enrichment items are added daily to the indoor enclosure area. In contrast to the old exhibit, the outdoor enclosure of the new exhibit features a variety of live plant species. This live vegetation provides a more naturalistic environment and allows greater opportunity for the animals to engage in foraging behaviors (Appendix 1). The new exhibit offers one large window for animal viewing in their indoor location and several windows for viewing at various outside locations (Fig. 2.5). The mesh enclosed outside area is visible at three indoor and four outdoor viewing windows, as well as nine small porthole windows in the log tunnel. In addition, it was possible for visitors to view animals through the mesh perimeter at outside locations other than the public view windows. 


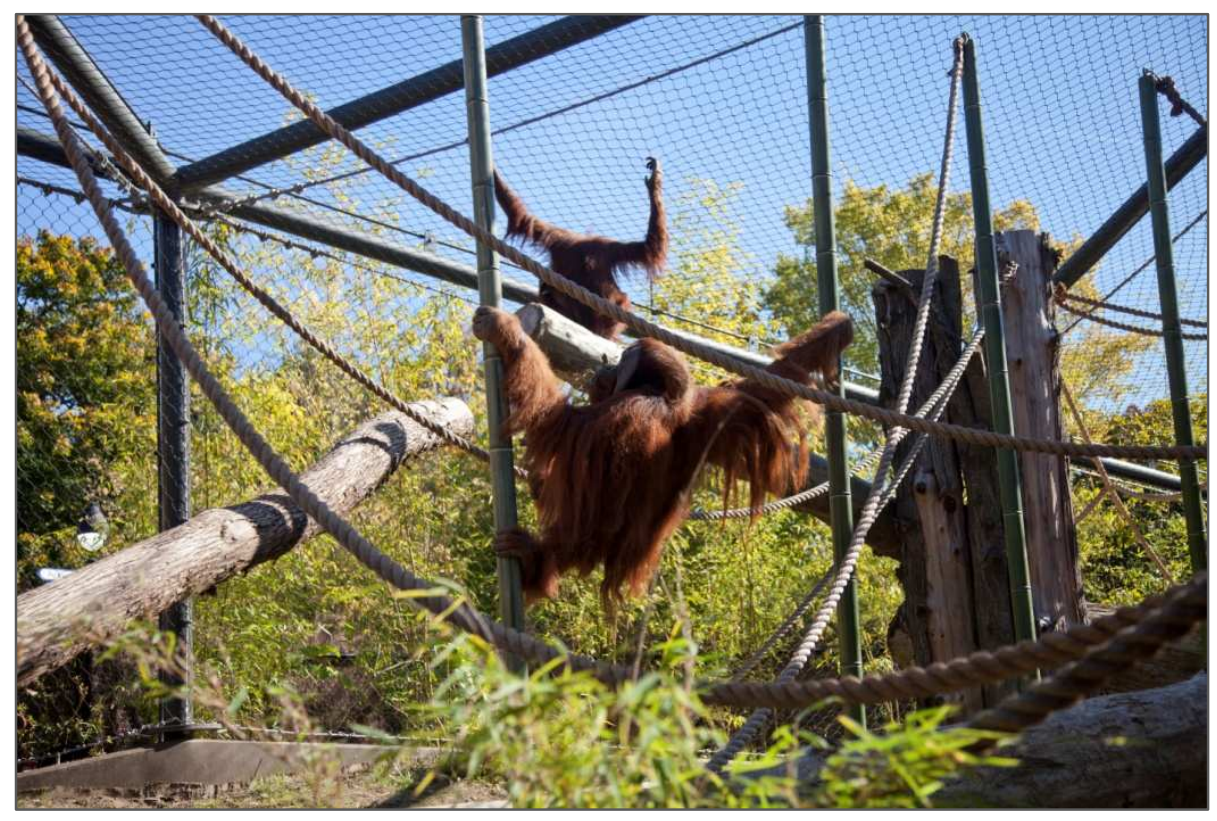

Figure 2.4 Photograph of new Red Ape Reserve exhibit at the Oregon Zoo showing exhibit structures (including: mesh perimeter, horizontal and vertical logs, rope, and sway poles) with animals in outside zone 1

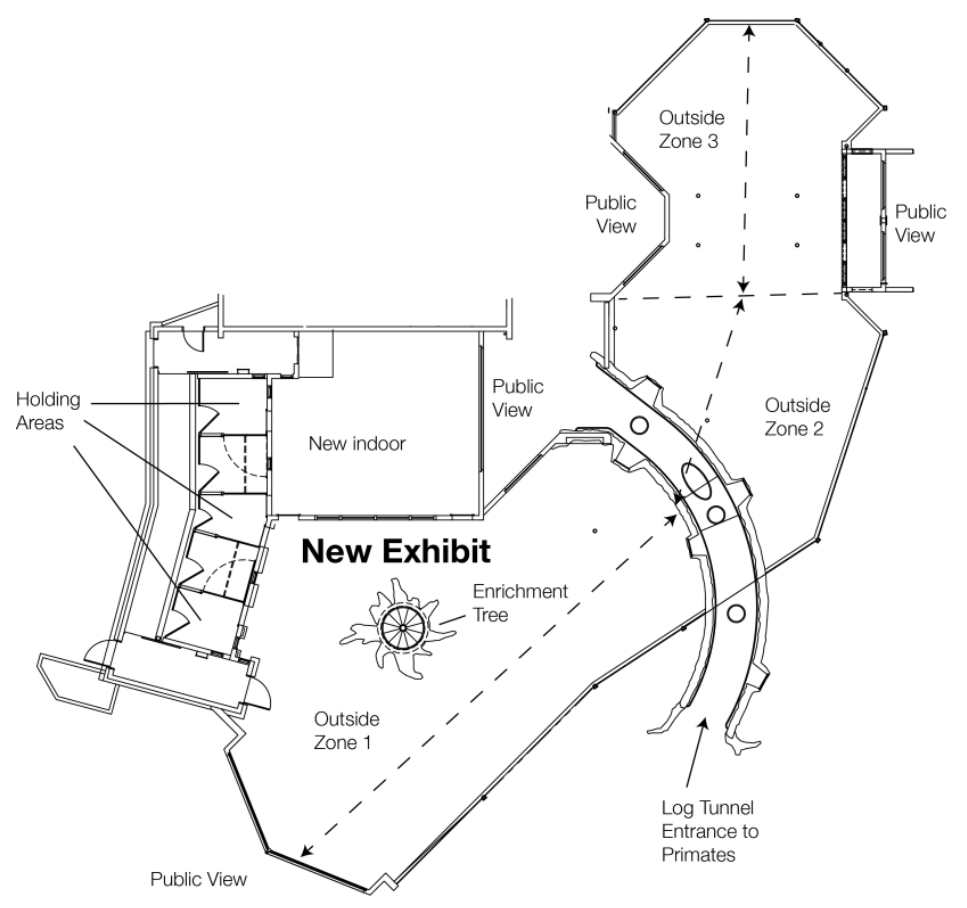

Figure 2.5 New exhibit design parameters showing public viewing areas and outside exhibit area zones. 


\subsubsection{Husbandry}

In both the old and new exhibits, animals were fed daily between 7:30-

8:30 am and then again between 1:30-3 pm. Inji was given $400 \mathrm{~g}$ of fruit and $160 \mathrm{~g}$ of chow, whereas Kutai was given $700 \mathrm{~g}$ of fruit and $500 \mathrm{~g}$ of chow. In addition, they shared $2200 \mathrm{~g}$ of vegetables and $2200 \mathrm{~g}$ of greens between the two of them. Food was given in the holding area, and scattered in the indoor exhibit area. In the new red ape reserve exhibit food was also placed in the outdoor exhibit areas and in the enrichment tree outside in zone 1 . The zookeepers did more scattering of food in the new exhibit than in the old exhibit.

In both enclosures the animals were put on exhibit at approximately 9 am following feeding in the holding area. While on exhibit, the holding doors were closed and access to holding was not available. At approximately 1:30 pm, the holding doors were opened and the animals were allowed access to the holding area for their afternoon feeding.

In the new exhibit access to the outside varied depending on time of year. In the summer the orangutans had access to the outdoor exhibit areas from 9 am-7 pm. In the winter access was shortened to the hours of $11 \mathrm{am}-5 \mathrm{pm}$. During the colder months access to the outside exhibit areas was suspended if temperatures dropped below $32^{\circ} \mathrm{F}$ or if there was any freezing of climbing structures. 


\subsection{Behavioral Data}

This study took place in three phases, including: 1) pre-move or baseline data; 2) habitation data collected immediately following the move to the new exhibit; and 3) post-move data collection beginning one month after the move. Instantaneous scan sampling at 1 min intervals was used to collect all behavioral data throughout the study. This behavioral sampling method has been found to have a high degree of inter and intra-observer reliability (Altman, 1974) and suited this study well, as over the four year collection period there were numerous observers collecting data. Information regarding each animal's location, elevation, proximity to others, locomotion, and engagement in activities with enrichment objects were recorded using an ethogram established by Oregon Zoo staff Karen Lewis and Sharon Glaeser (Appendix 2). With the move of the animals to the new enclosure, the original ethogram was expanded in 2010 by summer intern Kevin Lee to include new locations, as well as recording whether the animal was indoors or outdoors. All other parameters of the ethogram remained the same following the move to the new exhibit.

Behavioral category frequencies were totaled for each individual and then divided by total number of one-minute observation intervals to give an average proportion for each behavior. Observable interval was defined as the total time in which behaviors were present and did not include out of sight or missing data. Out of sight was defined as an animal being out of the observer's view, thus no behaviors could not be collected. Missing data were defined as any behavior uncollected by an observer during the duration of the observation period. During 
post data collection, the gathering of incomplete data was precluded; any minute(s) where observable behaviors were missed and data were not collected were omitted and not included in the final data set. The baseline and to a lesser degree, habituation data were collected with less rigor for avoiding incomplete data. These differences are reflected in the proportion of total minutes collected for each behavioral data category.

\subsubsection{Baseline data Collection}

Pre-move observations (baseline data) were collected during three different sequential time periods (Table 2.2). The majority of behavioral data were collected in 2007 by zoo staff and volunteers. All observations of animals in the old exhibit were made from a single visitor-viewing window (Figs. $2.2 \& 2.3$ ).

Table 2.2

Pre-move observation data collection details

\begin{tabular}{lll}
$\begin{array}{l}\text { Collection } \\
\text { Months }\end{array}$ & $\begin{array}{l}\text { Collection } \\
\text { Days }\end{array}$ & $\begin{array}{l}\text { Collection } \\
\text { Hours }\end{array}$ \\
\hline May- July 2007 & Mon-Sun & $9: 30 \mathrm{am}-5: 30 \mathrm{pm}$ \\
June- August 2008 & Mon- Fri & 9 am - 2:30pm \\
January- April 2010 & Mon-Fri & $9: 30 \mathrm{am}-2 \mathrm{pm}$ \\
\hline
\end{tabular}

\subsubsection{Habituation Data Collection}

The orangutans were anesthetized and moved to the new exhibit August 2, 2010. Animals were kept in the new holding area without access to the new exhibit for two days following the move. Habituation data were collected August 4-September 3, 2010 beginning the day the animals were given access to the 
new exhibit and concluded when the exhibit opened for public viewing. Data for both animals were collected together from 8 am-4 pm Sunday through Friday.

During this time the animals did not have any interaction with the public.

Exhibit viewing windows were covered and access was only granted to zookeepers and those conducting behavioral observations. Upon initial introduction to the new exhibit the holding doors remained open during all hours the animals were on exhibit. The animals were gradually introduced to different aspects the new exhibit over the habituation period (Table 2.3).These data were kept separate from all other post-move data due to the atypical conditions, namely increased access to holding and lack of enrichment items.

Table 2.3

Introductions to the new exhibit

\begin{tabular}{lc}
\hline Introduction & Date \\
\hline Access to inside exhibit, no outside access & $8 / 4 / 10$ \\
Access to outside, one door only & $8 / 11 / 10$ \\
No Access to holding 9am-2pm and access to outside, both doors & $8 / 16 / 10$ \\
Shared exhibit access with gibbons & $8 / 17 / 10$ \\
Enrichment objects added to exhibit & $8 / 23 / 10$ \\
\hline
\end{tabular}

\subsubsection{Post-Occupancy Data Collection}

Post-occupancy data were all collected in the new exhibit following the habituation phase. The post-move phase extended from September 2010 to the end of March 2011. Behavioral data were collected together for both Inji and Kutai Monday through Friday between the hours of 9 am-4 pm. Weekend 
observations were avoided due to the large number of zoo visitors and problems with animal visibility. Observations were made from a number of visitor viewing areas and one non-visitor outside viewing area on the log tunnel above the entrance to primates (Fig.2.3). No single viewing area allowed the observer to see the orangutans at all indoor and outdoor locations. Viewing area was chosen by the observer to maximize visibility of animals for collection of complete and accurate data.

\section{3 Hormone Data}

Saliva and urine sample collection by zookeepers began at the Oregon Zoo in January 2010 while the animals were still in their old exhibit. Sample collection during the habituation phase immediately following the move to the new exhibit was not possible. During this time, Kutai refused food offered by the zookeepers and as a result sample collection was temporarily suspended. Staff turnover at the zoo delayed the start of post-sample collection, which began in January 2011. In addition, during both phases of collection several samples were collected and stored without recording the time of collection. Like many other species, orangutan cortisol levels have been found to exhibit a diurnal rhythm with values highest in the morning and decreasing gradually throughout the day (Elder \& Menzel, 2001). Because of this, all samples collected without time of day were discarded and not included in sample analysis. A cortisol challenge test was not feasible with these animals, as the aim of the study was to remain as noninvasive as possible. 


\section{3.1 Urine sample collection and validation}

Urine samples were collected opportunistically using disposable plastic pipettes to transfer urine from small imperfections in the holding area floor to $2 \mathrm{ml}$ micro centrifuge tubes. Date and time of collection was recorded on each tube and samples were stored at $-20^{\circ} \mathrm{C}$ immediately follow ing sample transfer. Urine sample collection generally corresponded with the zookeeper's daily feeding routine. All am samples were collected between 7:45 am and 9 am and all pm samples were collected from 1:30 pm to $2: 30 \mathrm{pm}$. This type of collection is optimal, because it does not introduce new conditions which could potentially be stressful to the animals. Samples were easier to acquire from Inji, the dominant female, due to prior training for collection of urine samples by the zookeepers. This is reflected in the total number of samples available for analysis from each animal (Table 3.5).

All urine samples were analyzed for cortisol using Roche Cobas e411 automated clinical platform. To test for linearity, serial dilutions (1:2-1:128) were assayed on the Roche machine in duplicate (Fig. 2.6) and there was no evidence of matrix interference. On day of assay the Roche Cobas e411 was calibrated and quality controls were processed for cortisol prior to sample analysis. The inter-assay CV for the controls was $7.1 \%$ and the sensitivity lower limit was 0.36 $\mathrm{ng} / \mathrm{ml}$. All samples were thawed to room temperature, programmed for detection of cortisol on the machine and any remaining volume was returned to storage at $20^{\circ} \mathrm{C}$. 


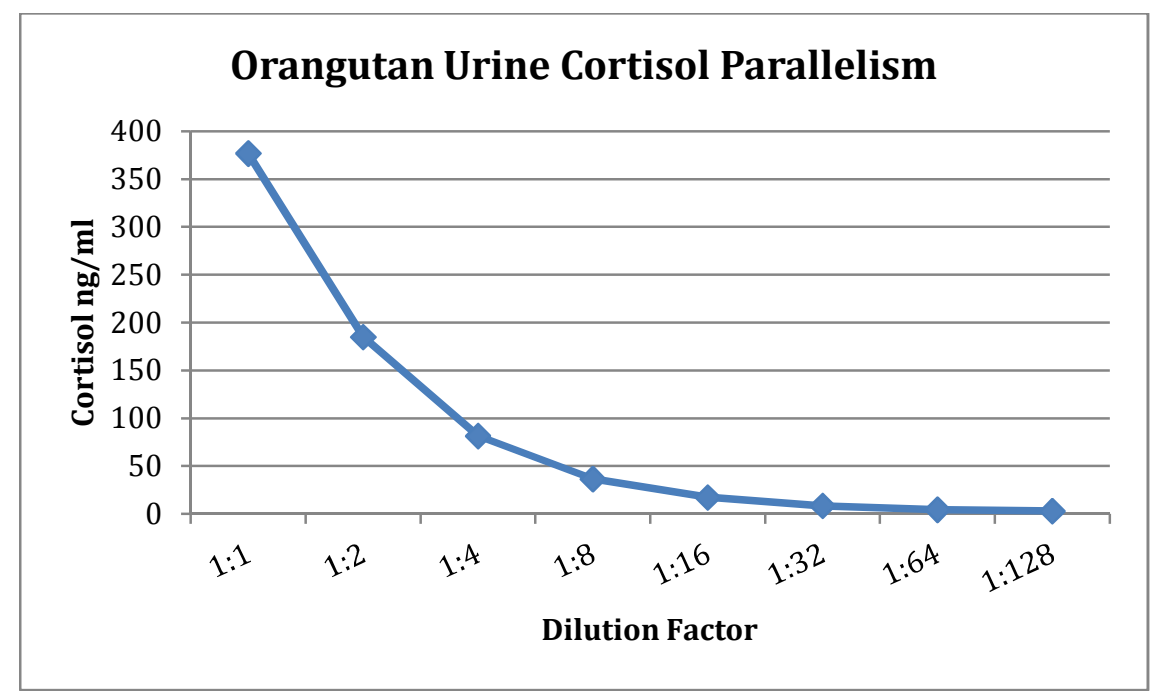

Figure 2.6 Serial dilutions of orangutan urine samples depicting linearity

\subsubsection{Saliva sample collection and validation}

Saliva collection involved zookeepers giving each animal a small

disposable paper Dixie@ cup filled with yogurt. Each animal licked the majority of the yogurt out of the cup with their tongue and returned the empty cup to the zookeepers. This cup was then transferred to a conical $15 \mathrm{ml}$ centrifuge tube labeled with date and time. All samples were frozen at $-20^{\circ} \mathrm{C}$ immediately following sample collection. At the beginning of the study, several saliva collection methods were tested in addition to the one described above, including the use of cotton swabs and dental rolls dipped in juice. The yogurt saliva method was chosen over all others in large part because it was already a part of the daily feeding routine. It proved to be the least invasive technique and most readily accepted by the animals.

In preparation for saliva assay, all samples were thawed completely and centrifuged at 3,000 rpm $(1500 \mathrm{X} \mathrm{g})$ for 15 minutes. Following centrifugation samples were immediately placed on ice. Using metal forceps, the disposable 
paper cup was removed from each $15 \mathrm{ml}$ centrifuge tube. Any saliva present in the conical bottom of the tube following centrifugation was then transferred using a $1 \mathrm{ml}$ pipette to a $2 \mathrm{ml}$ micro centrifuge tube. Care was taken to avoid the transfer of any sediment present in the bottom of the tube. Following transfer to microcentrifuge tubes, all samples were stored at $-20^{\circ} \mathrm{C}$ until assay.

Samples were discarded if there was no saliva present following centrifugation or if volumes were below $25 \mu$ l. Samples suspected of being diluted during sample collection and processing were also rejected. There was no way to determine a dilution factor for amount of yogurt remaining in the Dixie@ cup, instead a volume distribution for all samples was determined (Fig. 2.7). More than $70 \%$ of samples were between $25-150 \mu$, with a median volume of $50 \mu$ l. This was used as the acceptable range and all other samples were rejected due to insufficient volume or excessive volume indicating sample dilution.

Approximately $12 \%$ of these samples were $>150 \mu$ l, while $16 \%$ were $<25 \mu$ l.

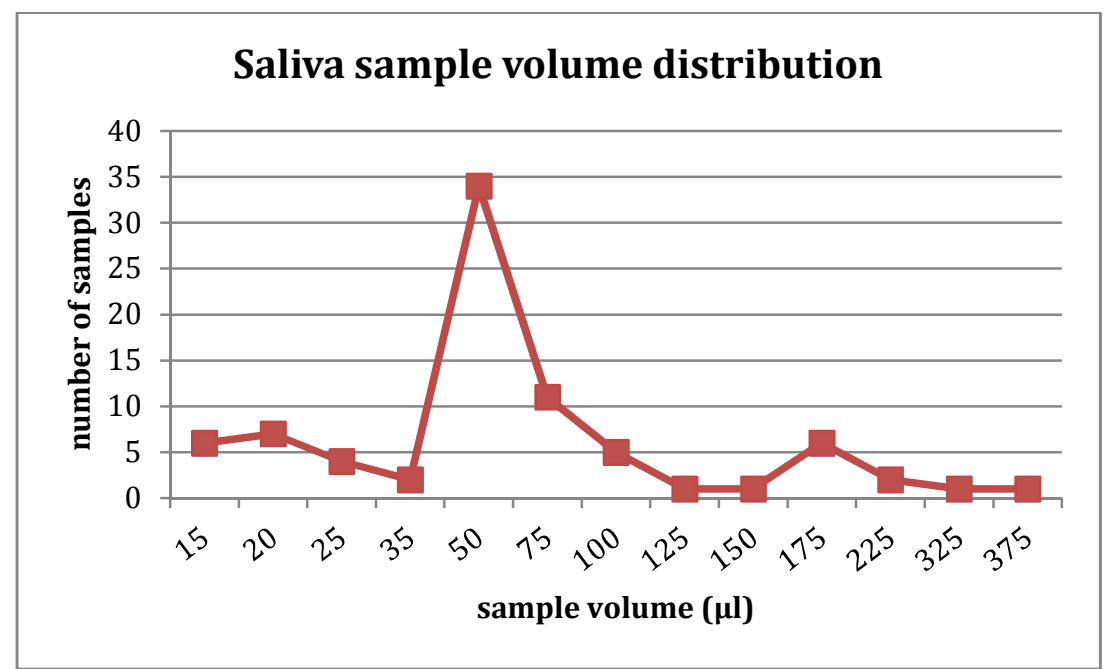

Figure 2.7 Distribution of saliva sample volumes 
For saliva assay, samples were brought to room temperature, and centrifuged at 3,000 rpm (1500 X g) for 15 minutes. Salivary cortisol was analyzed using a Salimetrics high sensitivity salivary cortisol enzyme immunoassay kit (EIA), which included monoclonal cortisol antiserum, horseradish peroxidase conjugated label and cortisol standards. To test for linearity of orangutan saliva in the Salimetrics EIA kit, repeated dilutions (1:21:128) were assayed in duplicate (Fig. 2.8). The intra-assay and the inter-assay CVs were $8.7 \%$ and $9.1 \%$, respectively. The sensitivity lower limit was 0.03 $\mathrm{ng} / \mathrm{ml}$. All samples were run in duplicate when volume was sufficient. Care was taken to avoid particulate matter, which can falsely elevate results when adding samples to plate wells.

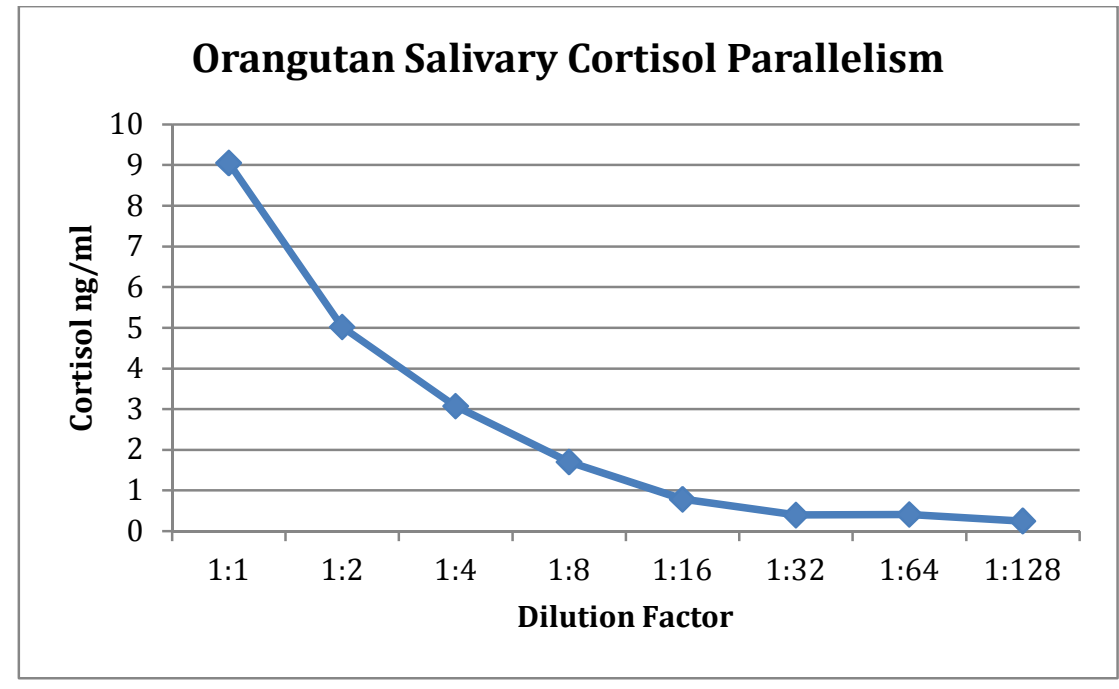

Figure 2.8 Serial dilutions of orangutan saliva depicting linearity

\subsubsection{Hair sample collection}

Hair samples were collected beginning April 2010 and concluded April 2012. Collection of hair sample collection proved most challenging for 
zookeepers. Orangutan hair is very wiry and does not easily shed. The use of scissors was not an option for collection from Inji due to potential stress associated with fear of a sharp object. A single pre-move sample was collected from Inji while anesthetized for a routine physical. Zookeepers were not able to collect a post-move hair sample from Inji for comparison of cortisol levels before and after the move.

Several samples were collected from Kutai and Batik using a razor comb. The use of the comb was ultimately discontinued due to dull blades, the inability to collect an adequate amount of hair, and collection problems associated with zoo staff turnover. One of Batik's hair samples was collected on June 6, 2010 by shaving hair off her arm during surgery to remove an infected gallbladder and enlarged right kidney. One of Kutai's hair samples was also collected by shaving at the site of hair removal on June $24^{\text {th }}, 2010$ while anesthetized for his routine physical examination.

Methods for orangutan hair extraction and detection were adapted from Koren et al. (2002). The hair was first washed using isopropanol, dried and then minced to $<2 \mathrm{~mm}$ using either clean scissors or an 8-razor blade chopping apparatus as designed by Dr. Francis Pau for all hair cortisol projects undertaken in the Endocrine Service and Technology Laboratory at Oregon National Primate Research Center. Orangutan hair was then weighed out to $100 \mathrm{mg}$ and extracted in glass tubes with $5 \mathrm{ml}$ methanol shaking overnight. Following overnight extraction, samples were centrifuged, and decanted into a second set of glass tubes to collect the extract minus the hair. Tubes were evaporated to dryness 
under an air-stream suction hood at $37-50^{\circ} \mathrm{C}$. Dry residue was then reconstituted with $0.6 \mathrm{ml}$ of phosphate-buffered saline (PBS) $0.05 \mathrm{M}, \mathrm{pH}$ 7.5. Following extraction all samples were run in Salimetrics high sensitivity salivary cortisol enzyme immunoassay kit (EIA). The inter-assay and intra-assay coefficients of variation were $7.6 \%$ and $8.1 \%$, respectively. Both values were calculated using the readings for duplicate control samples and confirm the reliability of the hair cortisol determination methods. For $100 \mathrm{mg}$ of hair, the assay sensitivity lower limit was $0.03 \mathrm{ng} / \mathrm{ml}$, with $77 \%$ percent hot recovery of cortisol from the extraction procedures.

\subsection{Statistical Analysis}

\subsubsection{Diversity Index}

The Shannon-Weaver biodiversity index was used to compare the diversity of orangutan location, locomotion and activity from the old to the new exhibit as per Shepherdson et al. (1993). Frequently used by ecologists, this index was initially developed by Shannon \& Weaver (1949) to measure plant and animal species diversity for a community or area. The formula for calculating the Shannon-Weaver index is as follows:

$$
H=\sum P_{i} \log \left(\frac{1}{P_{i}}\right)
$$

$P_{i}=$ proportion of observed interval that the animal was engaged in $\mathrm{i}_{\mathrm{th}}$ behavior . A higher $\mathrm{H}$ value indicates a greater degree of diversity between behaviors. This index value is based in part on an equal distribution of time amongst behaviors and in part on the total number of behaviors (Shepherdson et al., 1993). 
Comparing the index values for behaviors in both exhibits can reveal whether animals engaged in a more diverse repertoire of behaviors under the two conditions.

\subsubsection{Mann-Whitney U test}

The Mann-Whitney is a non-parametric two-sample rank-sum test. It is useful in determining if a difference exists between two data sets that are not normally distributed. For this study, a Mann-Whitney $U$ test was performed in Minitab 16 to statistically test differences between hormone values for saliva and urine samples. Data collected in the old exhibit $\left(n_{1}\right)$ and the new exhibit $\left(n_{2}\right)$ represented the two random sample sets. Samples were combined and each value was assigned a rank. The $U$ statistic is calculated as follows:

$$
U=n_{1}{ }^{*} n_{2}+\left[n_{1}\left(n_{1}+1\right) / 2\right]-T
$$

T represents the sum of ranks for the first sample set $\left(n_{1}\right)$. All tests were run as two-tailed with a $95 \%$ confidence interval. 


\section{Chapter 3}

\section{RESULTS}

\subsection{Behavioral results}

Results for each category of behavior were compared for baseline, habitation and post-occupancy phases (Table 3.1 and 3.2).

Table 3.1

Behavioral data categories and observable intervals totals (proportion of total minutes) for Inji

\begin{tabular}{lccc}
\hline & Baseline & Habituation & Post-occupancy \\
\hline Location & $87 \%$ & $97 \%$ & $96 \%$ \\
Elevation & $88 \%$ & $66 \%$ & $96 \%$ \\
Proximity & $87 \%$ & $69 \%$ & $96 \%$ \\
Activity & $89 \%$ & $64 \%$ & $96 \%$ \\
Object & $89 \%$ & $96 \%$ & $96 \%$ \\
Locomotion & $89 \%$ & $96 \%$ & $96 \%$ \\
\hline
\end{tabular}

Table 3.2

Behavioral data categories and observable intervals totals (proportion of total minutes) for Kutai

\begin{tabular}{lccc}
\hline & Baseline & Habituation & Post-occupancy \\
\hline Location & $82 \%$ & $98 \%$ & $97 \%$ \\
Elevation & $83 \%$ & $62 \%$ & $97 \%$ \\
Proximity & $82 \%$ & $71 \%$ & $97 \%$ \\
Activity & $84 \%$ & $62 \%$ & $97 \%$ \\
Object & $84 \%$ & $99 \%$ & $97 \%$ \\
Locomotion & $84 \%$ & $99 \%$ & $97 \%$ \\
\hline
\end{tabular}




\subsubsection{Orangutan elevation}

In the wild Sumatran orangutans are almost entirely arboreal, (Rijksen, 1978; van Schaik, 1999) spending their time in elevations well off the ground. Therefore, elevation data were collected to assess the use of vertical space by each individual animal. Exhibit elevation was divided into three categories in relation to the animal's distance from the ground (Appendix 2). An elevation of 1 was used if the animal was in contact with the ground, elevation 2 if the animal was $<2 \mathrm{~m}$ off the ground, and elevation 3 was used to denote placement $>2 \mathrm{~m}$ from the ground.

Comparison of elevations used by Inji in the old and new exhibit (Fig. 3.1) revealed a decrease in use of ground level coupled with a small increase in the highest elevations from baseline to post-occupancy. Inji used elevations $<2 \mathrm{~m}$ off the ground much more frequently in the new exhibit as shown by a $13 \%$ increase in the use of these mid-level locations. The habituation data revealed the most substantial changes in vertical space use by Inji when compared to the baseline data. During the habituation phase, there was a greater decline in use of ground level (from $96.8 \%$ of the time in the old exhibit to $67.8 \%$ ) and a large increase in time spent at the highest elevations (from 3.8\% to 30.6\%). This was indicative of a period of pronounced exploration of places at higher elevations in her new environment immediately following the move. 


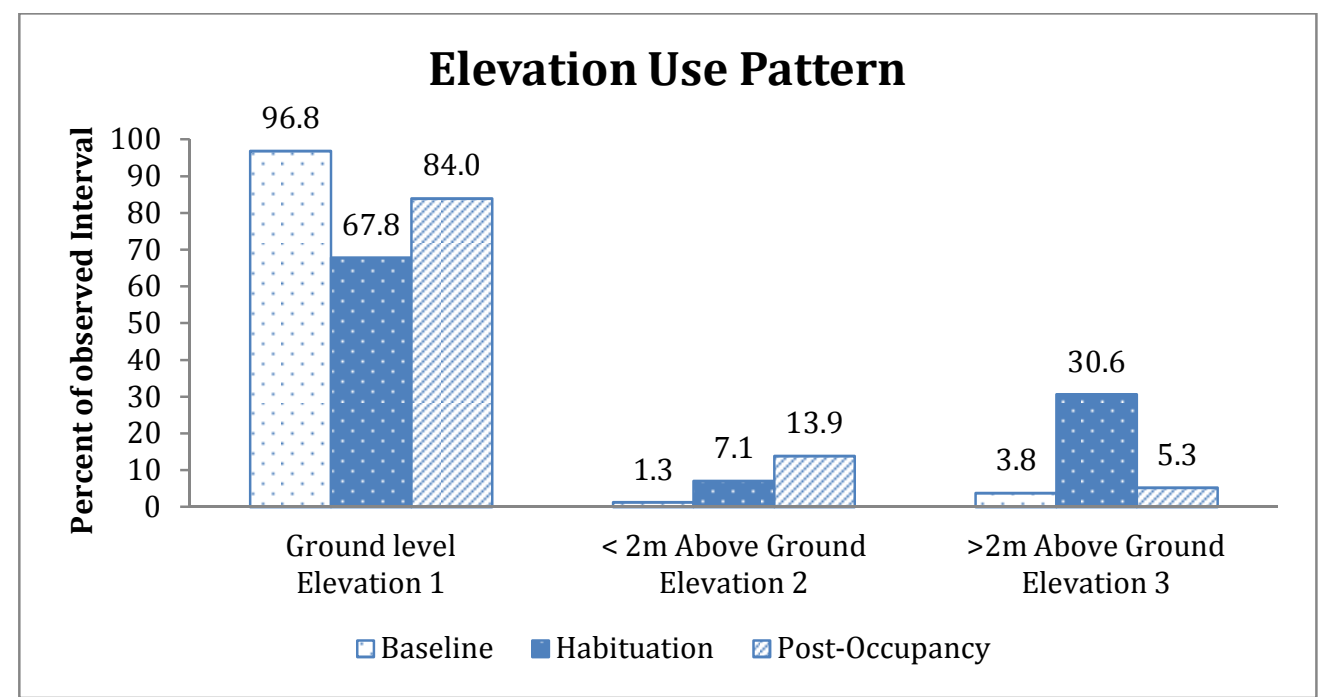

Figure 3.1. Inji's percentage of elevations observed during the three phases of the study

In contrast to Inji, there was a greater use of vertical space by Kutai following the move to the new enclosure (see Figure 3.2). The most striking difference was a large reduction in ground level use (from $90 \%$ of the time in the old exhibit to $47.3 \%$ in the new exhibit). This corresponded with an increase in use of places at higher elevations in the new exhibit. Kutai also exhibited a period of greater exploration of places at higher elevations during the habituation phase, specifically elevation 3. Unlike Inji, whose use of elevation 3, rose during habituation and then declined during post-occupancy back down to levels similar to those seen during baseline, Kutai continued to utilize elevation 3 locations (with use $53.3 \%$ of the time during habituation and $35.5 \%$ during postoccupancy). Long term changes in elevation use from the old exhibit to the new exhibit following the habituation phase were observed for Kutai. These included a $17 \%$ increase in the use of mid-level elevations $<2 \mathrm{~m}$ off the ground and a $26 \%$ increase in the use of higher elevations $>2 \mathrm{~m}$ off the ground. 


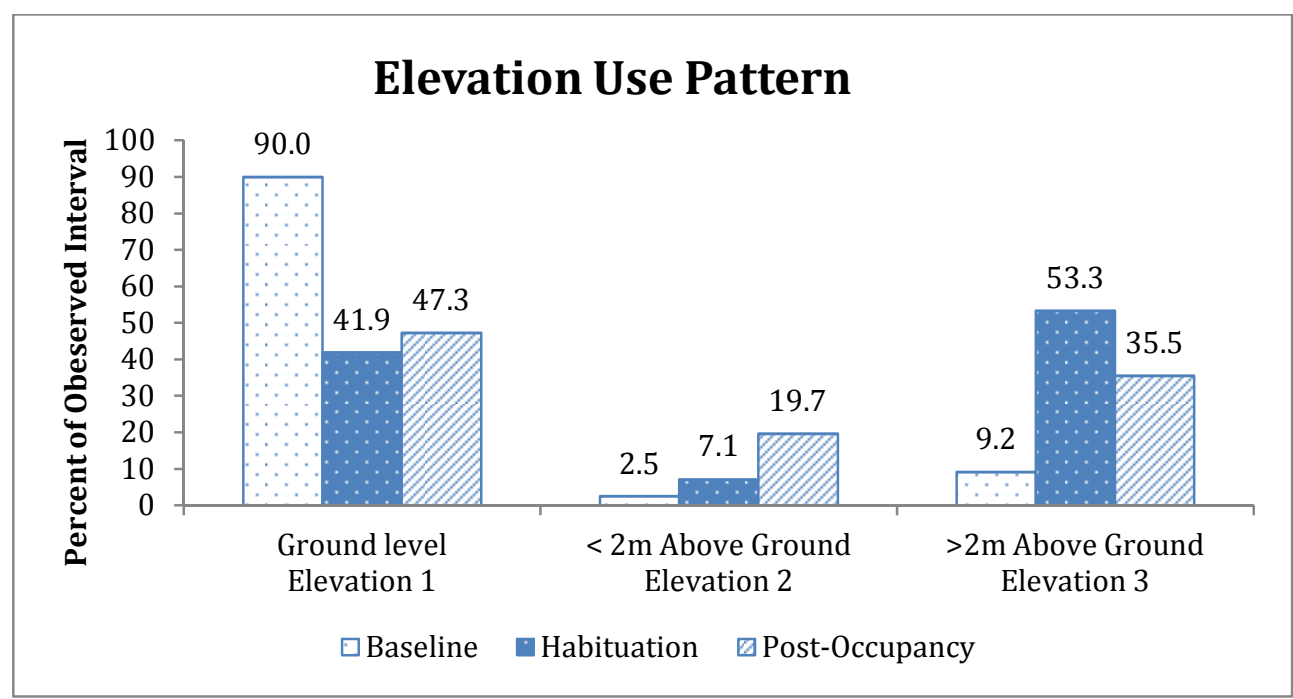

Figure 3.2. Kutai's percentage of elevations observed during the three phases of the study

\subsubsection{Proximity to others}

Orangutans are far more solitary than any other great apes species (Warren et. al, 2001). In the wild, adults generally have limited social interactions with the exception of sexual consortship and aggregation in times of food abundance (Galdikas, 1978). In particular, orangutans on Sumatra are thought to be more gregarious than those on Borneo due to differences in habitat and higher food abundance on Sumatra, which results in greater densities of orangutans in close proximity (Delgado \& van Schaik, 2000; MacKinnon, 1974). However, in captivity where it is not necessary to search for food resources, their social behaviors can be markedly different and Perkins (1992) argues for the formation of stronger social bonds in captivity. Distance between animals was compared as one component relevant to evaluating changes in social behavior during the post-occupancy phase. Proximity for Inji and Kutai from the old exhibit to the new exhibit revealed a $46 \%$ and $49 \%$ increase in use of space $>20 \mathrm{~m}$ from 
another animal, respectively (Figs. 3.3 and 3.4). These observations reveal that both animals spent their time farther away from another animal in the new exhibit. There was not a notable difference between the habituation and post occupancy phase for either animal.

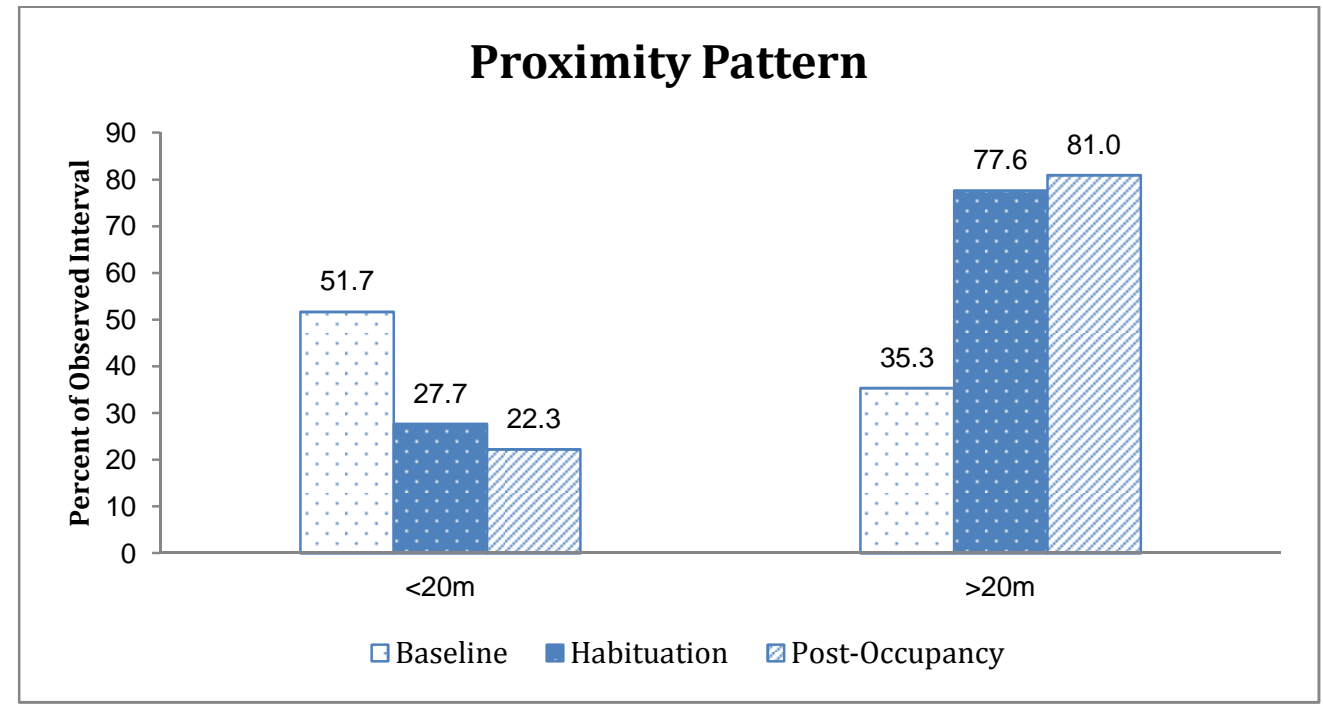

Figure 3.3 Inji's percentage of proximity observations during the three phases of the study

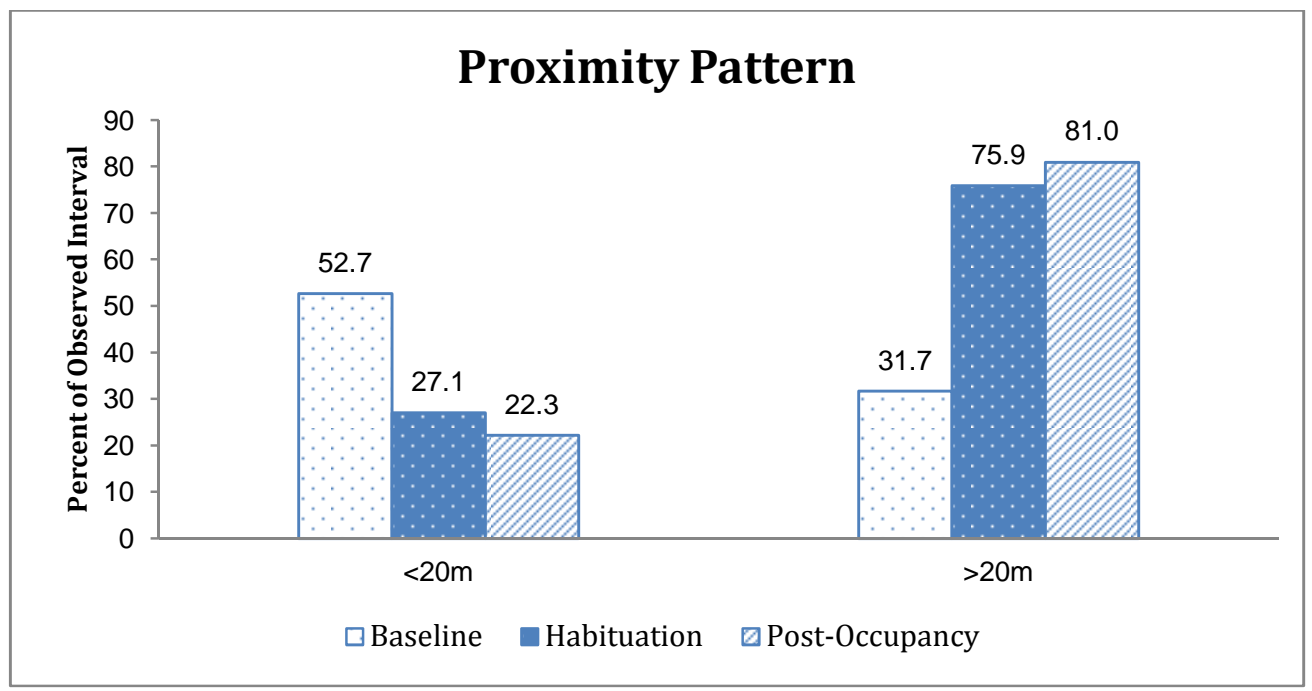

Figure 3.4 Kutai's percentage of proximity observations during the three phases of the study 


\subsubsection{Orangutan location}

It was not possible to do a direct comparison for all locations from the old to the new exhibit because the ethogram changed to reflect additional locations in the new Red Ape Reserve. I chose to focus on comparing exhibit structure and window use patterns between the two exhibits. For the habituation and postoccupancy phases, I looked at outside use by both animals. In addition, I analyzed changes in diversity of locations occupied using the Shannon diversity index.

The diversity value $\mathrm{H}$, for the Shannon index increased from a mean value of 3.33 during baseline observations to 6.96 during post-occupancy for locations used by Inji. For Kutai, the $\mathrm{H}$ value rose from a mean of 4.37 during baseline to 8.12 during post-occupancy. The rise in $\mathrm{H}$ values reveals that there was an increase in diversity of locations used in the new exhibit. This indicates that animals were less prone to remain in a single location and utilized a greater variety of exhibit spaces.

\subsubsection{Orangutan structure use}

To determine how the orangutans used the different structures present in the old and new exhibit, specific structure use was compared for both exhibits (Figs. 3.5 and 3.8). Nest and hammock were available to the animals in both exhibits which allowed for direct comparison of their use during both time periods. One of the wire nests from the old exhibit was relocated to the new exhibit and placed at the back of the exhibit just below a window which allowed visible access to the holding area. The nest in the old exhibit had an elevation of 
3 ( $>2 \mathrm{~m}$ above ground), whereas in the new exhibit the nest was scored as elevation 1 because it was equivalent to ground level. The old exhibit ethogram used 'structure' as a generic location, which included all structures that were not nest 3, or hammock. The majority of structures in the old exhibit were horizontal and vertical logs, with the addition of a tire swing and horizontal pole suspended across two log structures. In the new exhibit the ethogram was revised to collect whether the animal was on a horizontal or vertical log. The percentage of horizontal and vertical log use in the new exhibit during habituation and postoccupancy are presented individually (Figs. 3.6 and 3.9).

A comparison of overall structure use during all three phases was used to determine if the animals used structures more frequently following the move to the new exhibit (Figs. 3.7 and 3.10). Inji was found to use exhibit structures at a much greater frequency in the new exhibit than in the old exhibit (from $4.2 \%$ use of all structures during baseline to $29 \%$ during post-occupancy). This large increase in structure use can be attributed to an overall greater number of structures and availability of novel constructions in the new exhibit. These numbers indicate that a structurally enriched environment can lead to more diverse behaviors. In the new exhibit Inji showed a preference for logs (10.9\%), nest $(10.3 \%)$ and rope (6.8\%) when compared to all other structures available (Fig. 3.8).

Inji's overall use of structures during habituation was similar to what was observed for post-occupancy; however she was found to use different types of structures between the two phases. She showed a preference for horizontal logs 
in the new exhibit, especially during habituation (16.4\%) when compared to postoccupancy (7.6\%). Her use of vertical logs increased from 1.8\% during habituation to $3.4 \%$ for post-occupancy. Also of note, was a $4.9 \%$ use of the enrichment tree during habituation compared to $0.5 \%$ use during postoccupancy. This artificial tree was designed to provide a more stimulating environment offering opportunities for climbing as well as searching for food items placed by the zookeepers. This increased use of the enrichment tree corresponds well with her use of high elevations also seen during the habituation phase.

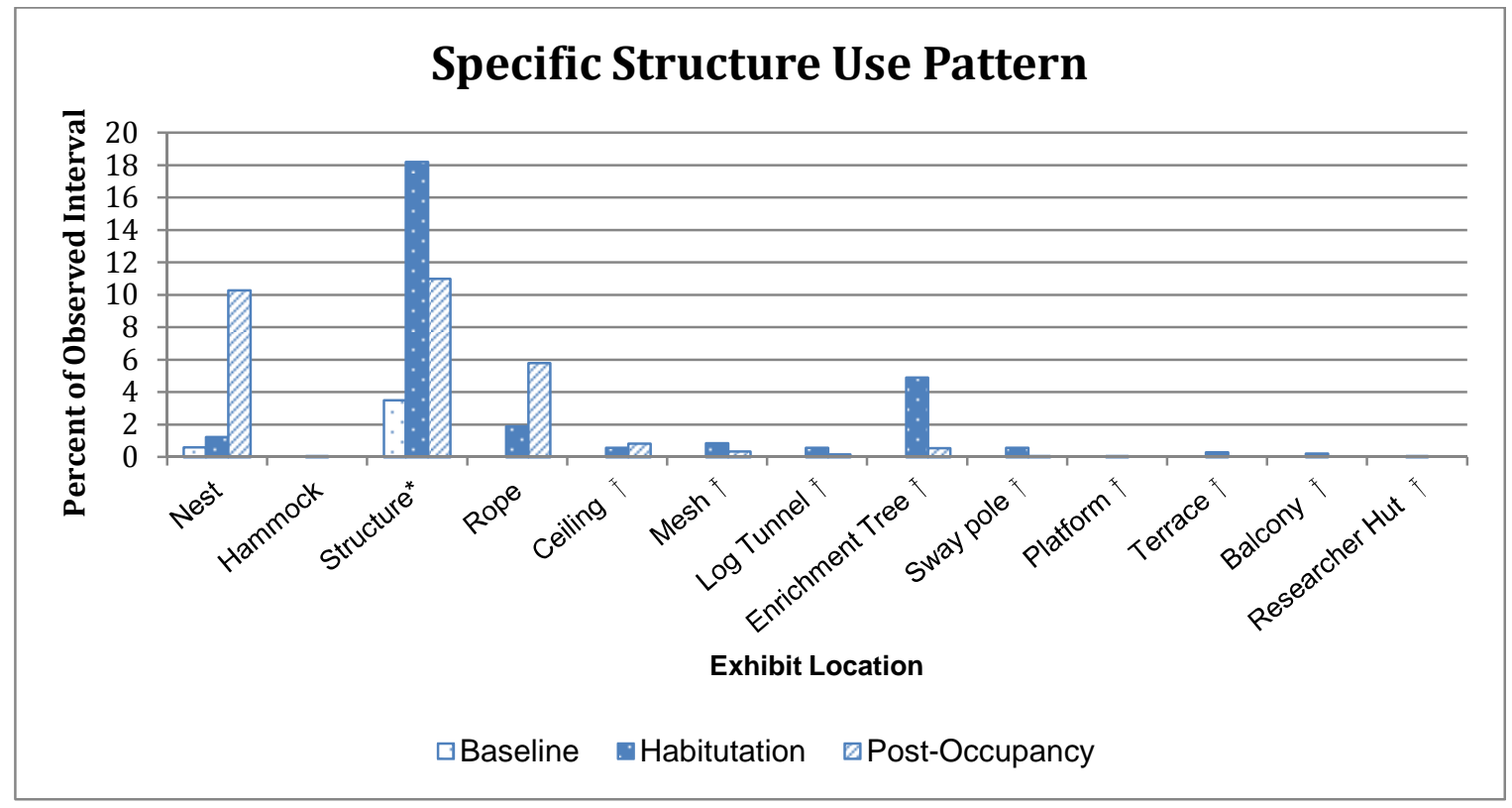

Figure 3.5 Inji's percentage of specific structure use observed during all three study phases *Structure for habituation and post-occupancy include both horizontal and vertical logs as displayed below (Fig. 3.6)

$\mp$ Locations exclusively in the outside exhibit 


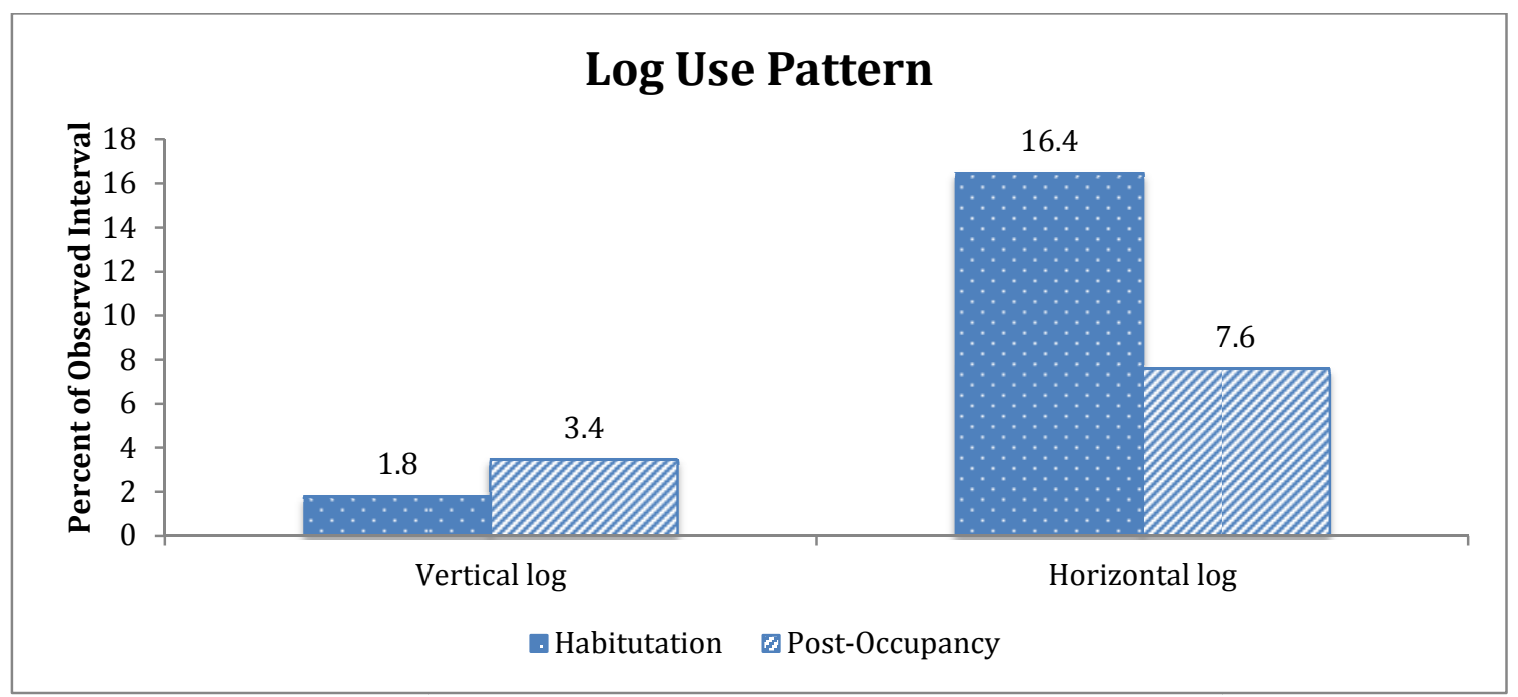

Figure 3.6 Inji's observed use of vertical and horizontal log during habituation and post-occupancy phases

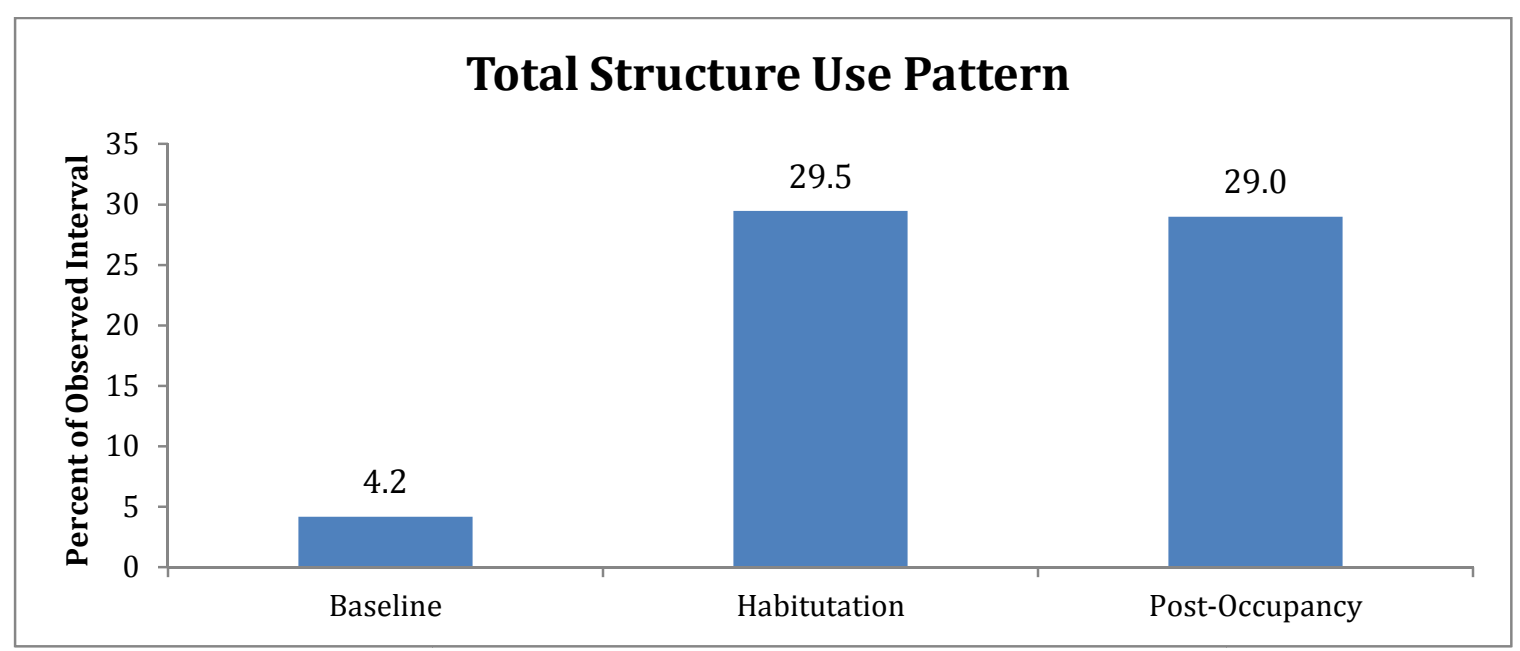

Figure 3.7 Inji's percentage of total structure use observed during all three study phases

Like his exhibit mate, Kutai used structures more regularly in the new exhibit than in the old exhibit $(7.2 \%$ throughout baseline to $42.2 \%$ during postoccupancy). He showed a less diverse use of the new exhibit structures when compared to Inji. The novel structures he was observed using included rope and ceiling (both 2.8\%) and mesh (3.8\%). Ropes were located in both the inside and outside areas, whereas ceiling and mesh were found only in the outside exhibit 
area. The outside area was enclosed by a mesh wall and ceiling, which the animals could utilize for locomotion. Kutai also showed a strong preference for horizontal log structures in the new exhibit with use highest during habituation (37.3\%), compared to post-occupancy (11.8\%). He used structures most frequently during the habituation period $(51.8 \%)$, which correlates with his use of high elevations $>20 \mathrm{~m}$ off the ground. The majority of his structure use during this time was exhibit logs which are located at higher elevations.

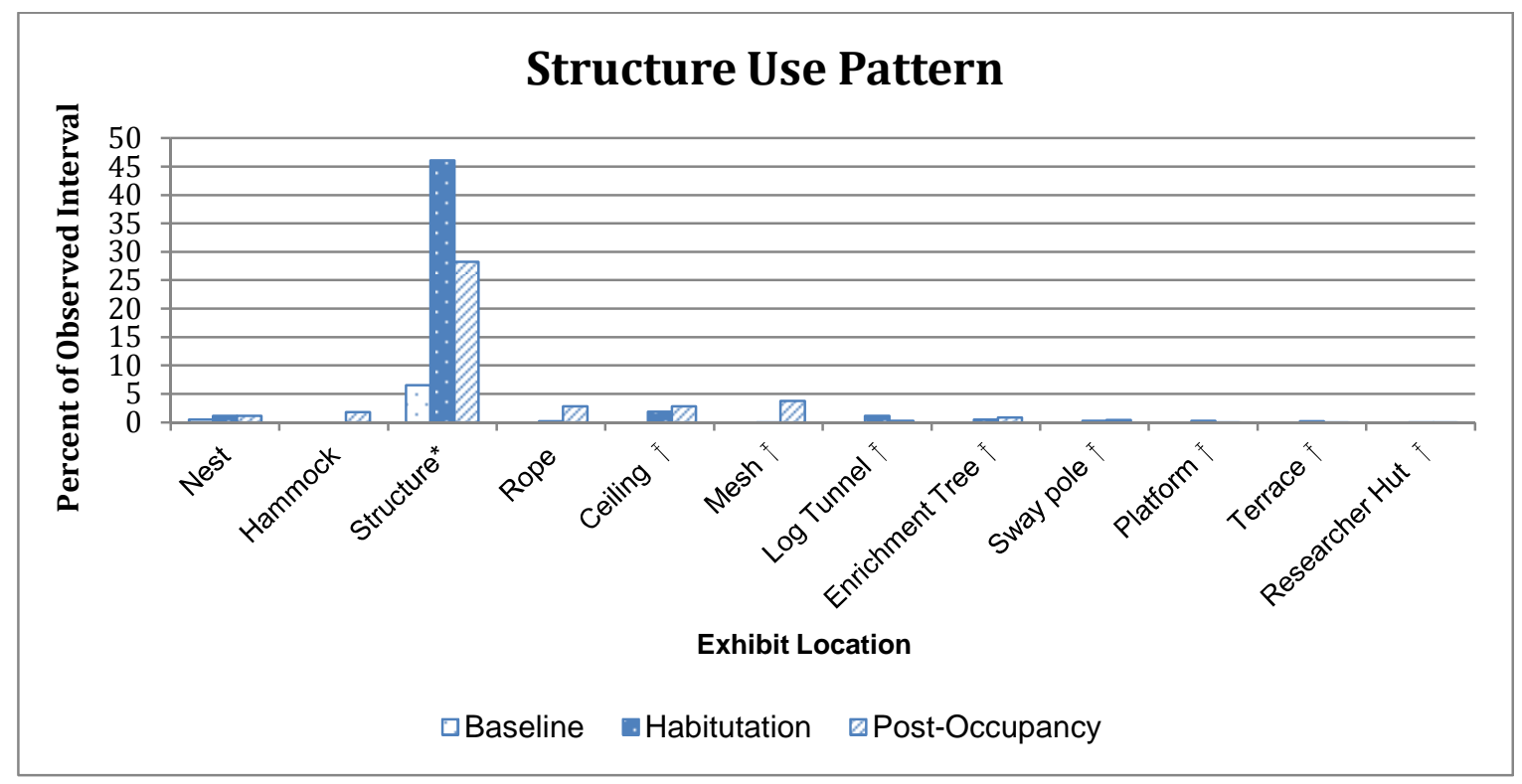

Figure 3.8 Kutai's percentage of specific structure use observed during all three study phases *Structure for habituation and post-occupancy include both horizontal and vertical logs as seen below (Fig. 3.9) ¡Locations exclusively in the outside exhibit Note: For Kutai, Balcony was excluded; no values were recorded for this location 


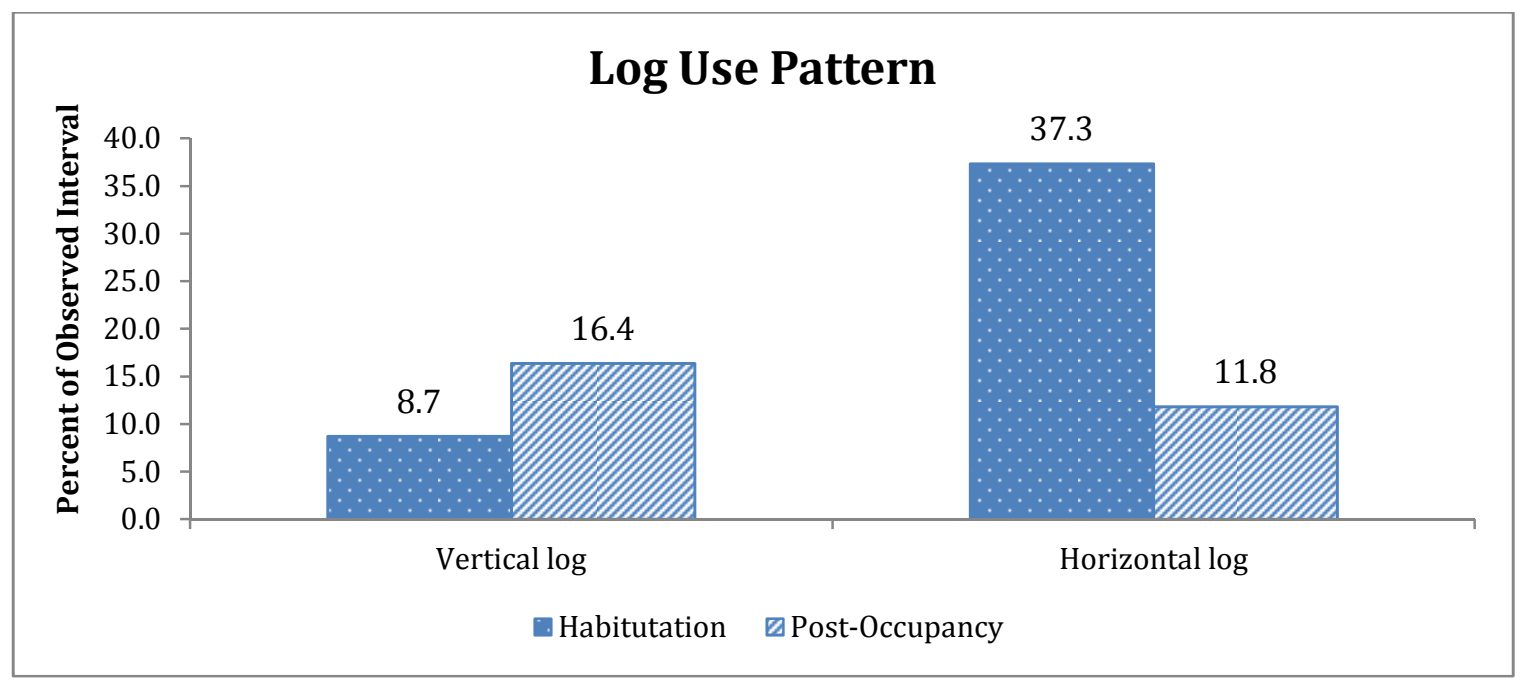

Figure 3.9 Kutai's observed use of vertical and horizontal log during habituation and post-occupancy phases.

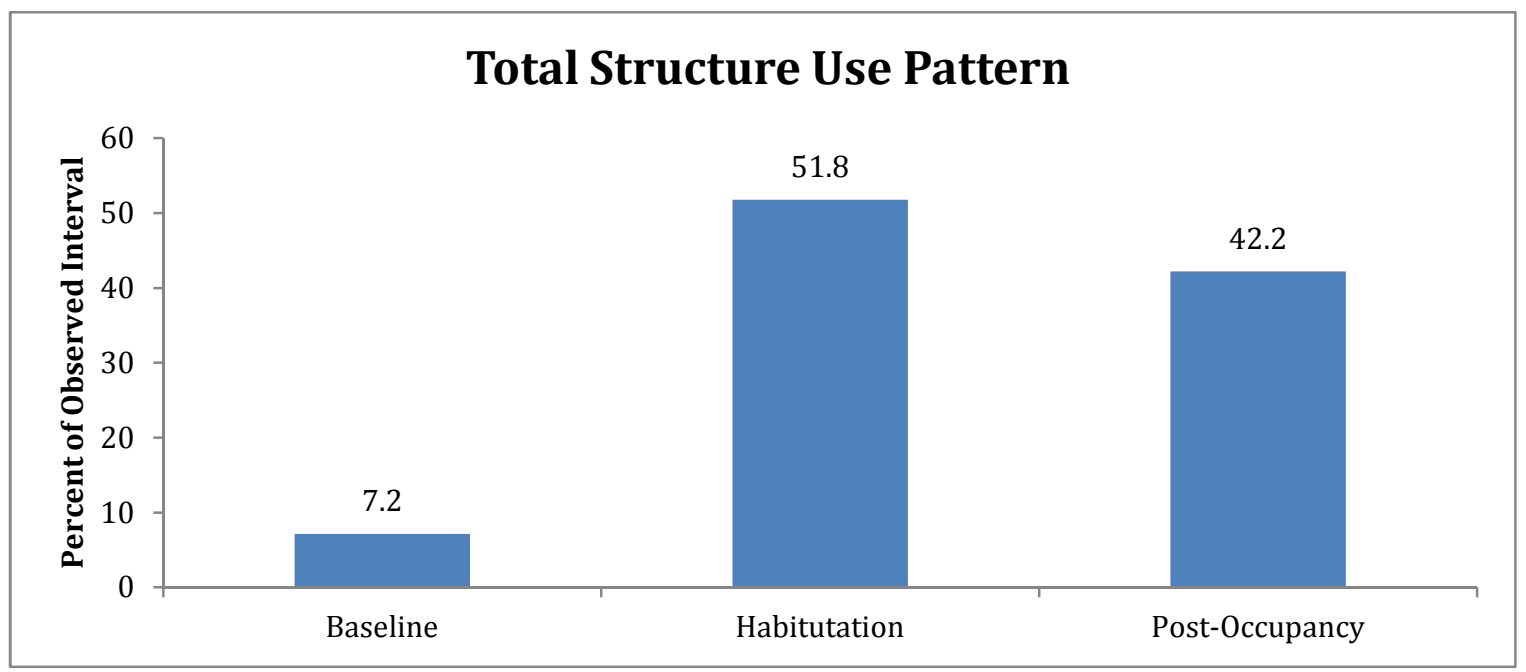

Figure 3.10 Kutai's percentage of total structure use observed during all three study phases

\subsubsection{Orangutan Use of Exhibit Windows}

In the old exhibit there was a single window for visitors to interact with the animals (Fig. 2.3). In the new Red Ape Reserve exhibit there are several options for animal viewing at various indoor and outdoor locations (Fig. 2.5). All of the windows which allowed visitor interaction with the orangutans were categorized as 'public windows'. 
The new exhibit also features a wall of windows, which separates the indoor and outdoor exhibit areas. The ethogram was expanded for data collection in the new exhibit to differentiate whether an animal was at a public interaction window or at the window wall. Location at the window wall could be on either side of the glass with the animal situated inside looking outside or located outside looking into the indoor area.

To determine whether there were any differences in interaction with the public between the two exhibits, public window use in the new exhibit was compared to percentages in the old exhibit (Figs 3.11 and 3.12). Inji had higher window use levels in the old exhibit than her grandson Kutai; she spent 14.2\% more time positioned at the single public view exhibit window. Following the move to the new enclosure Inji was found to spend less time at a public interaction window (from $25.5 \%$ during baseline to $12.9 \%$ throughout postoccupancy). The fact that there were no visitors to interact with during the habituation phase may explain why public window use during that time was less than during post-occupancy for both animals. Inji and Kutai spent very little of their time at the window wall during the habituation and post-occupancy phases. There were no major differences in public window use percentages for Kutai from the old to new exhibit (11.3\% during baseline and $11 \%$ during post-occupancy). 


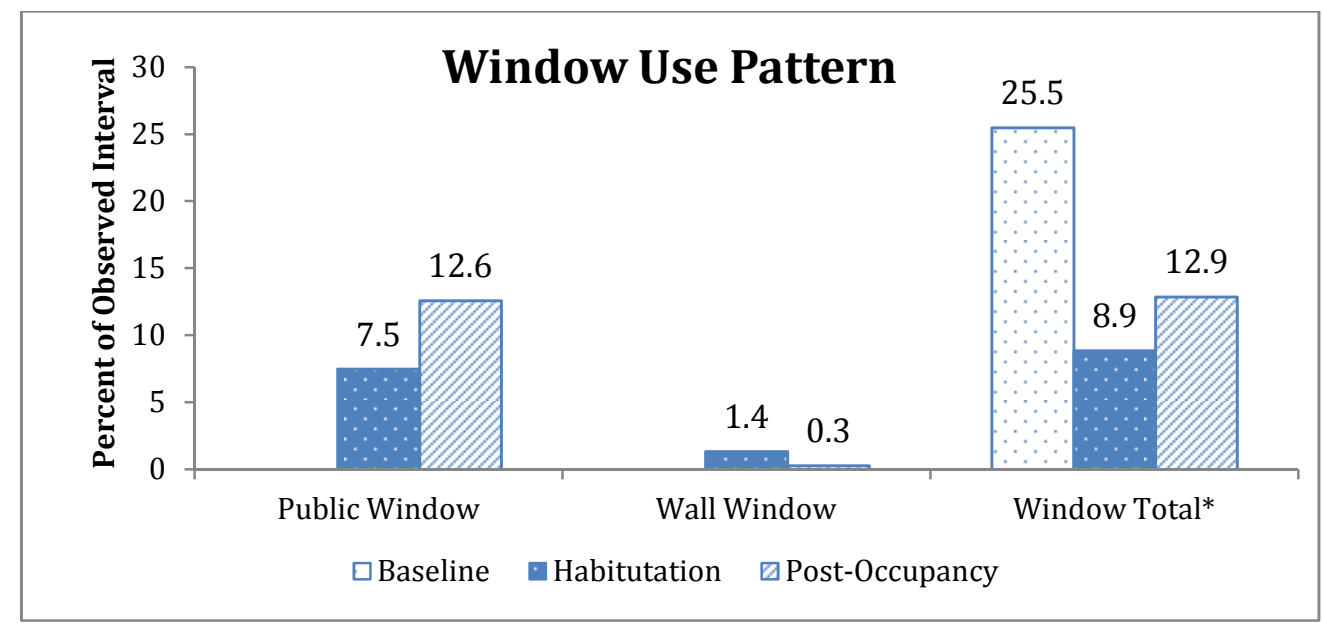

Figure 3.11 Inji's percentage of window use observed during the three study phases

* For post-occupancy and habituation phases, 'window total' is the sum of public and wall window percentages.

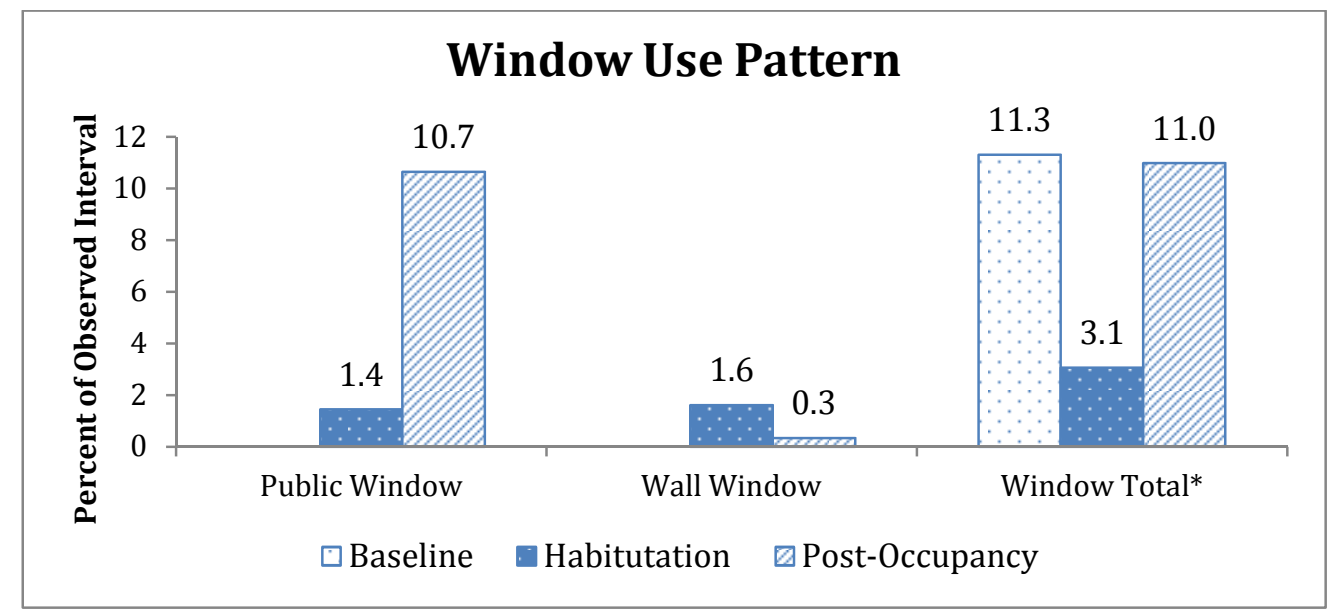

Figure 3.12 Kutai's percentage of window use observed during the three study phases

* For post-occupancy and habituation phases, 'window total' is the sum of public and wall window percentages.

\subsubsection{Outdoor Exhibit Use}

Access to a mesh enclosed outdoor space in the new exhibit allowed the animals to explore outside, an opportunity that was not available in the old exhibit. A comparison was made between the habituation and post-occupany phases for each animal (Figs $3.13 \& 3.14$ ). Inji was found to explore the outside exhibit considerably more during the initial month in her new surroundings. She 
exhibited a pronounced decline in use of the outside exhibit in the months following the move to the new exhibit (from $23.9 \%$ during habituation to $8.5 \%$ throughout post-occupany). This change in use of the outside exhibit areas could be a factor of season and temperature as discussed later. During both phases Inji spent the majority of her time outside in zone 1.

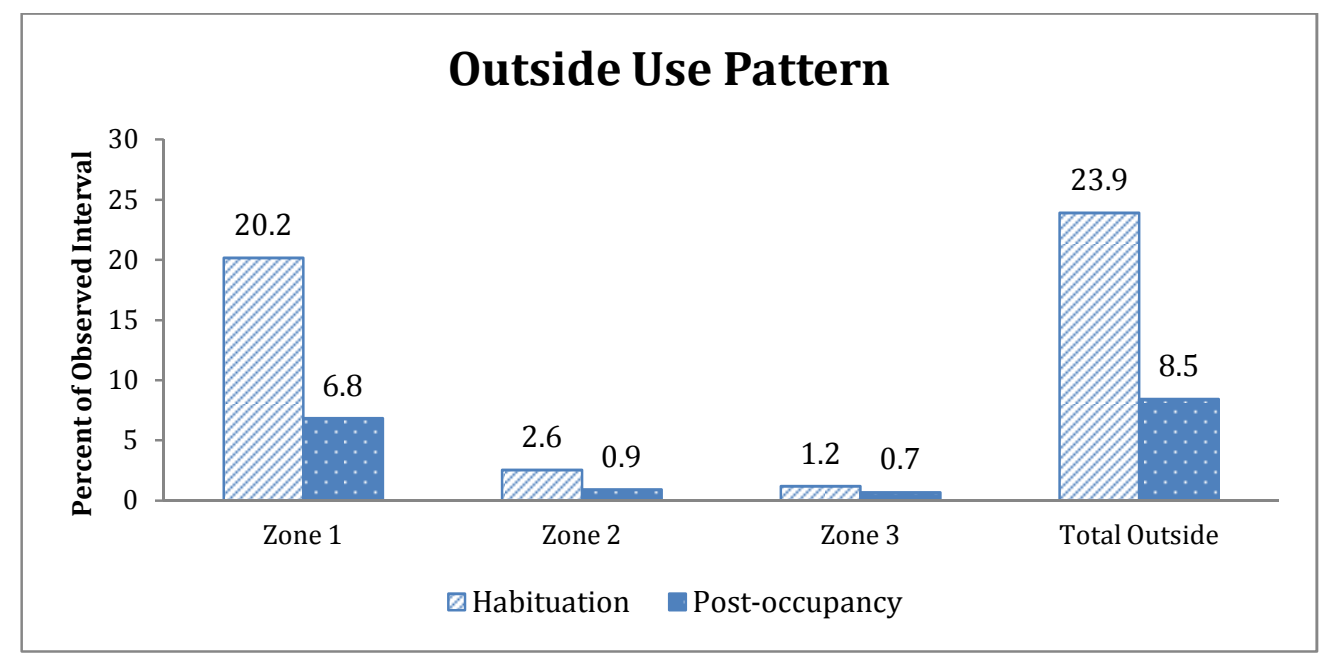

Figure 3.13 Inji's percentage of outside use during the habituation and post-occupancy phases

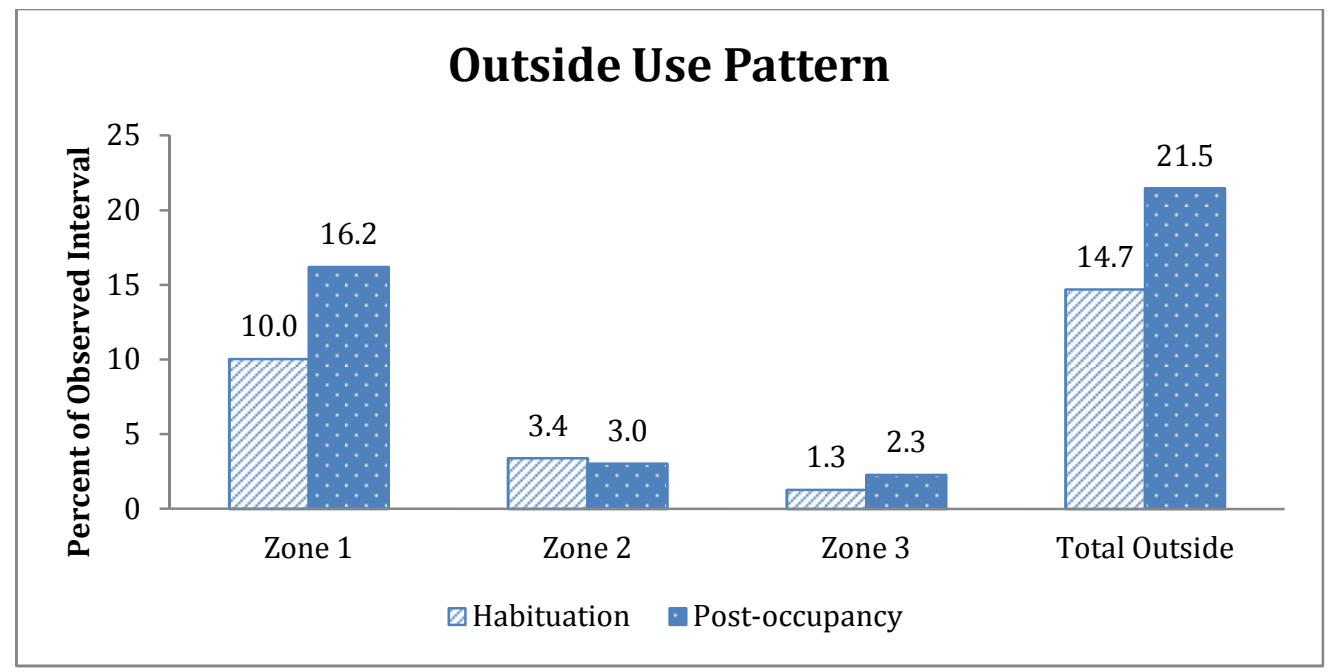

Figure 3.14 Kutai's percentage of outside use during the habituation and post-occupancy phases 
Kutai was found to use the outside exhibit to a greater extent after he became acclimated to his new surroundings (from 14.7\% during habituation to $21.5 \%$ during post-occupancy). This was the opposite of what was observed for Inji whose time spent outside declined from the habituation to post-occupancy. Although he also showed an inclination for zone 1, Kutai was found to explore zone 2 and zone 3 more during both phases of observation collection in the new exhibit.

\subsubsection{Orangutan locomotion}

The Shannon Diversity index was applied to the locomotion data collected in the original and new exhibit to determine whether there was a difference in diversity of locomotive behaviors between the two enclosures. The diversity Index $\mathrm{H}$, measured for Inji during baseline observations was 1.30. During postoccupancy there was a very slight increase with a mean value of 1.42 . Similar results were recorded for Kutai, whose baseline mean value was 1.40 and then rose faintly to 1.44 . These values reveal that there was not a significant change in diversity of movement by the animals between the two exhibits.

Orangutans in captivity are provided with food daily and live in a far less complex environment than their wild counterparts that spend a significant portion of their day actively acquiring food in Southeast Asian forests (Galdikas, 1978; Rodman, 1979). Consequently, captive orangutans have a reduced repertoire of daily behaviors and much lower overall activity levels than those observed in the wild. However, Maple and Stine (1982) report an increase in diversity of behaviors observed with the occurrence of new behaviors as well when 
orangutans were moved to a naturalistic exhibit with a greater degree of complexity. One goal of this study was to examine changes in activity level and determine whether the new exhibit's design would have a positive effect on animal welfare by increasing levels of activity. It was predicted that the additional space and enrichment in the new exhibit would result in a decrease in overall inactivity levels for both Inji and Kutai.

For general locomotion patterns observed in the old and new exhibits, time spent sitting was presented independent of active and inactive behaviors. Sitting was not measured as an active locomotion, however it was not considered strictly inactive either. Sitting was scored when an animal was alert without anything supporting its weight, whereas inactive was scored when an animal was leaning, lounging or resting and in general inattentive to its surroundings.

A comparison of Inji's general locomotion patterns (Fig. 3.15) revealed an $8.3 \%$ increase in active locomotive behaviors, an $11 \%$ increase in sitting and a $17 \%$ decrease in inactivity from baseline to post-occupancy. An assessment of Inji's active locomotion patterns (Fig. 3.16) showed an increase in three specific behaviors from the old to new exhibit including: knucklewalk (3.7\% during baseline to $7.7 \%$ during post-occupancy), climbing (1.4\% during baseline to $3.2 \%$ during post-occupancy) and hold-walking (0.4 during baseline to $1.6 \%$ during post-occupancy). The increase in active locomotion was most pronounced during the habituation phase. During the first month in the new exhibit, Inji was actively moving a greater frequency $(27.7 \%$ of the time) than seen during baseline $(8.1 \%)$ and post-occupancy (16.4\%). During this time she was also observed engaging 
in a greater variety of locomotive behaviors (knucklewalk, quadramanous, climbing, hold-walking and hang-standing) than seen during the other phases of the study. This overall increase in active locomotive behaviors during the first month in the new exhibit corresponds well with the use of higher elevations (Fig 3.1) and increased use of structures (Fig 3.7) further supporting that Inji actively explored her new environment immediately following the move.

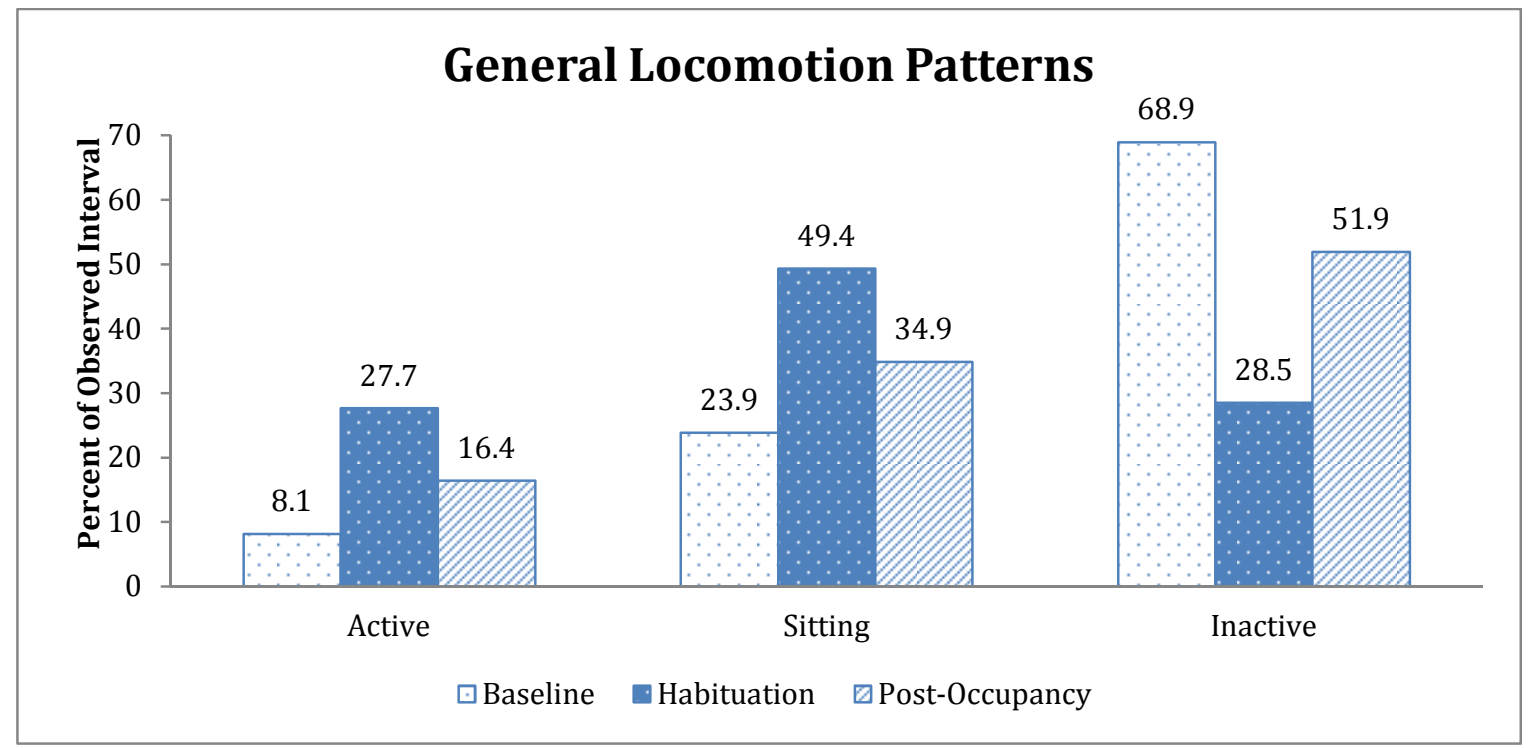

Figure 3.15 Inji's percentage of general locomotions observed for all study phases 


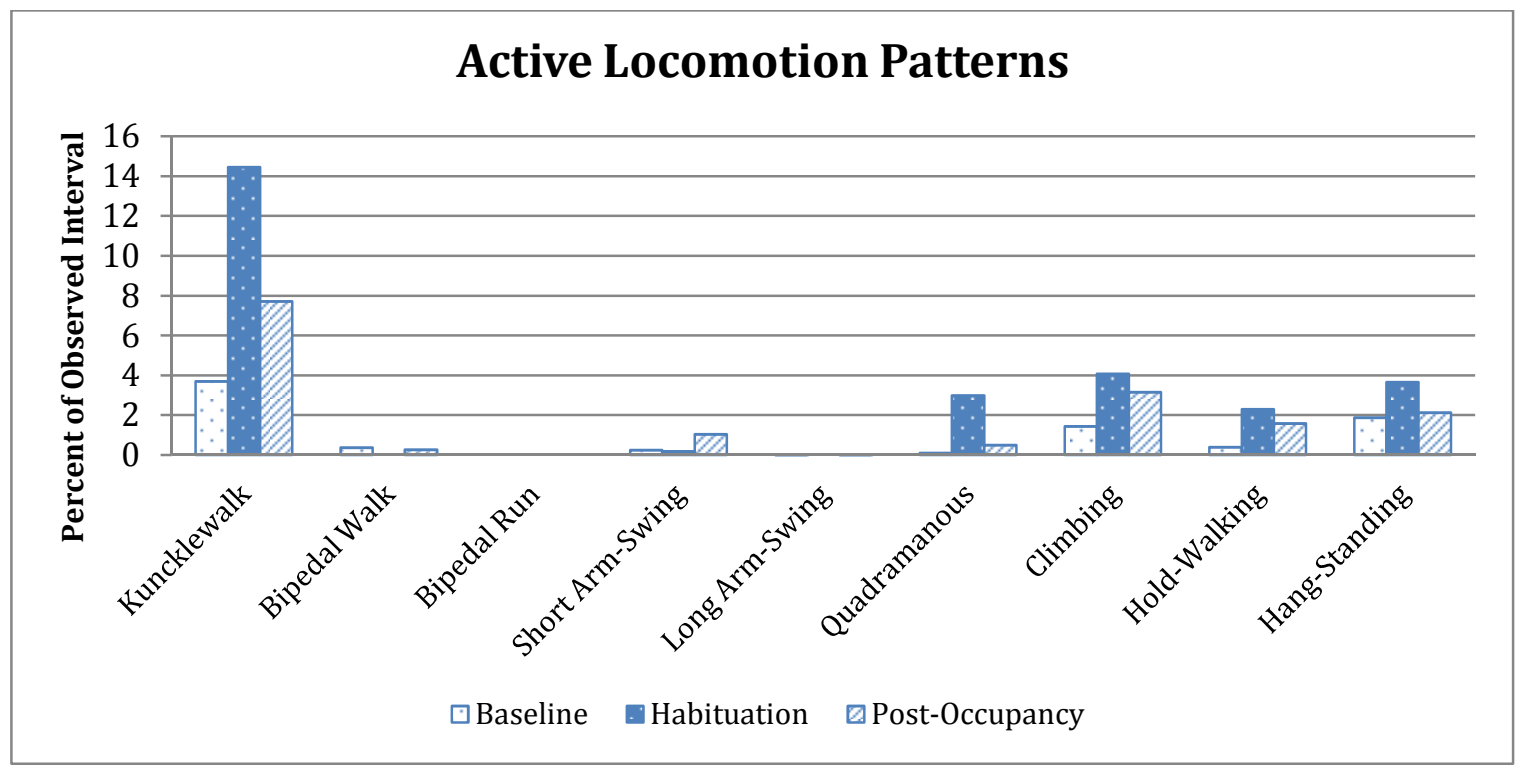

Figure 3.16 Inji's percentage of active locomotions observed during all study phases

An analysis of Kutai's general locomotion patterns from the old to postoccupancy in the new exhibit (Fig. 3.17) revealed a 15.3\% increase in active locomotive behaviors, a $3.6 \%$ decrease in sitting and a $9.9 \%$ decrease in inactivity levels. A comparison of his specific active locomotions (Fig. 3.18) showed an increase in climbing (1\% during baseline to $10 \%$ during postoccupancy) and knucklewalking (3\% during baseline and 11\% during postoccupancy) behaviors with the change to the new enclosure. Unlike Inji, whose frequency of active locomotion increased initially in the new exhibit but dropped over time, Kutai spent more time engaged in active locomotive behaviors during post-occupancy (26\%), than habituation (23.1\%) and baseline (10.7\%). During habituation he spent a considerably smaller amount of observed time inactive coupled with a greater percentage of time sitting. This decrease in inactivity levels and increase in time spent sitting was also seen for Inji during the first month in the new exhibit. 


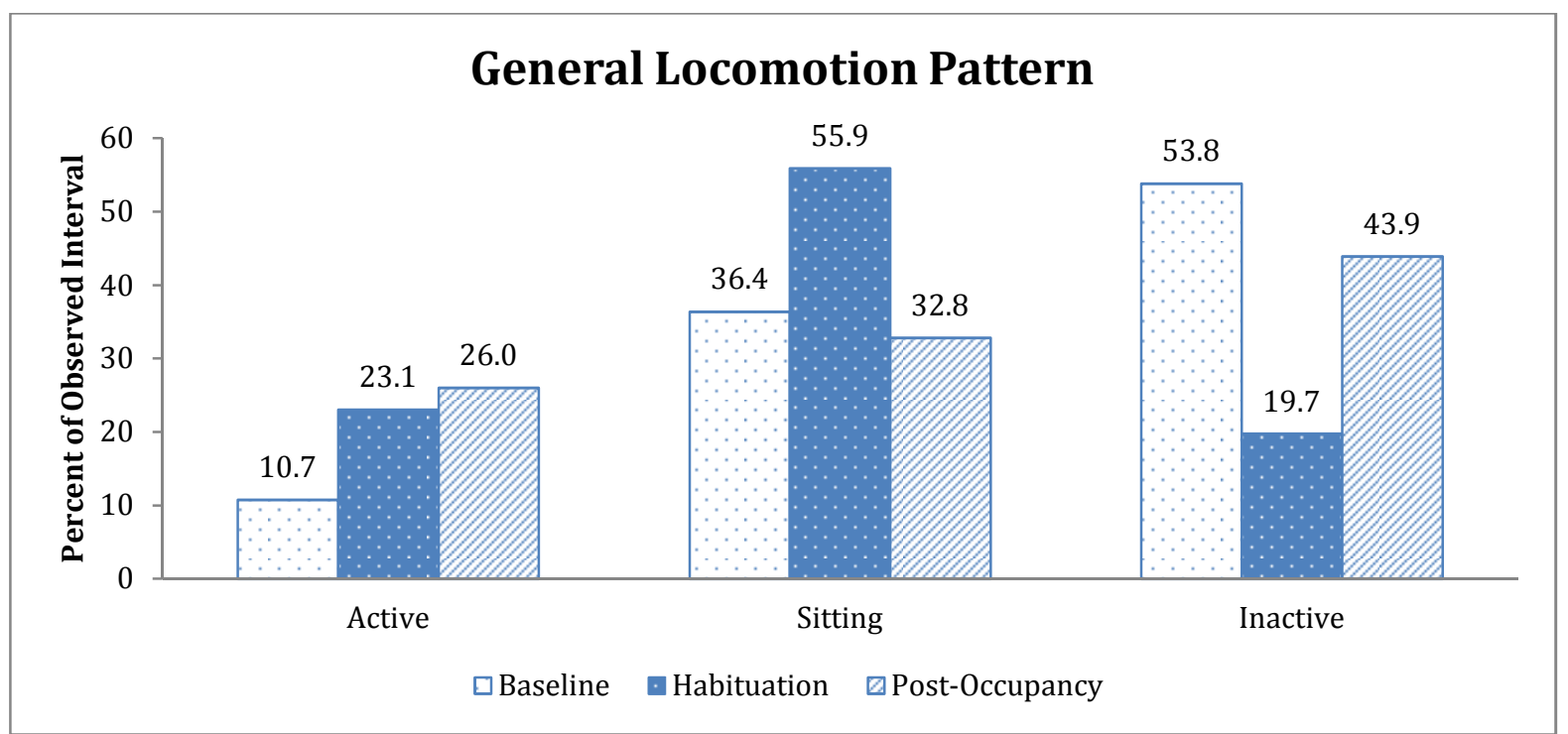

Figure 3.17 Kutai's percentage of locomotion observed during all phases of the study

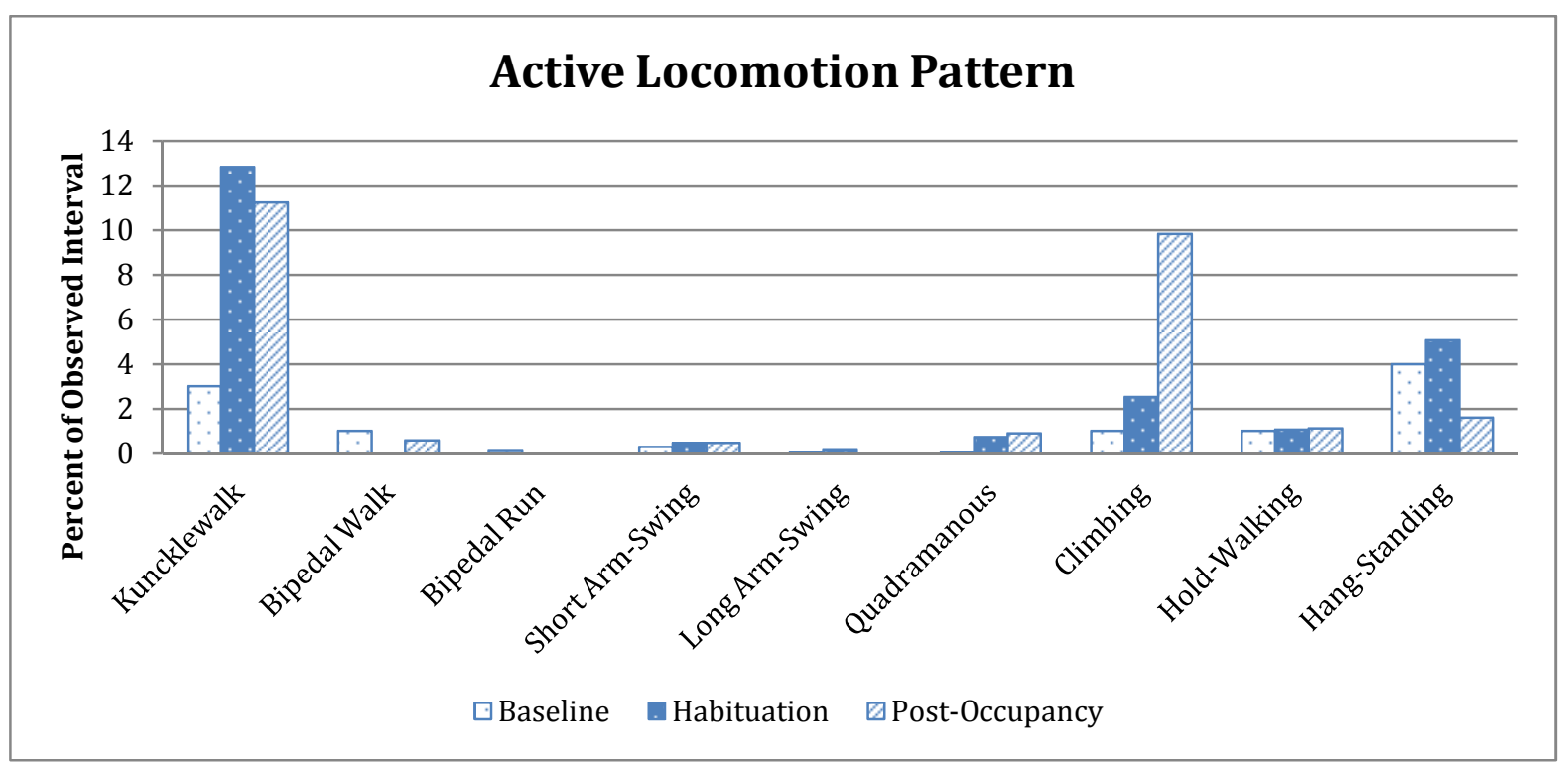

Figure 3.18 Kutai's percentage of active locomotion observed during all phases of the study

\subsubsection{Orangutan activity with enrichment objects}

For every activity performed by the orangutans, there was always an enrichment object which corresponded to the activity. For example, if an animal was engaged in the activity 'under' there was a corresponding object, such as 'fabric' or 'cardboard'. Activity was collected as a behavior that was independent 
of locomotion. For example, an animal could be performing an activity such as 'eating' the object 'browse', as well as engaging in a locomotive action, for instance 'climbing'. As a result, it was difficult to calculate a definitive activity budget, which included both locomotion and activity as a definitive active behavior.

The habituation period was characterized as abnormal for collection of activity and object use since the majority of this time period lacked the usual addition of enrichment materials to the exhibit (Table 2.3). Although the animals were introduced to the new exhibit on August 4, 2010, enrichment items were not presented to the animals in their new environment until August 23, 2010. As a result, habituation data was excluded from analysis of activity and enrichment object use patterns in the old and new exhibit.

The Shannon Diversity index was applied to the activity observation data to determine if there was a greater diversity of activities related to enrichment items in the new enclosure. There was a small increase in the diversity index value $\mathrm{H}$ from the old to new exhibit for Inji (3.7 during baseline to 4.33 during post-occupancy). Conversely, for Kutai there was a slight decrease of the $\mathrm{H}$ value following the move to the new exhibit (4.64 during baseline to 3.15 during post-occupancy). These small changes in $\mathrm{H}$ values for each animal indicate that there was not a significant change in the range of activities each animal engaged in from the old to the new exhibit.

Activity patterns were also compared between the two exhibits by looking at changes in observed activities from baseline to post-occupancy (Figs. 3.19 
and 3.21). For Inji, there was a slight increase in eating (3\%), manipulating (2\%) and under, or use of an object to cover head and/or body (1\%) from the old to new exhibit. More apparent was a decrease in contact with an object $(21 \%)$ and to a lesser degree holding of an object (4\%) following the move to the new enclosure.

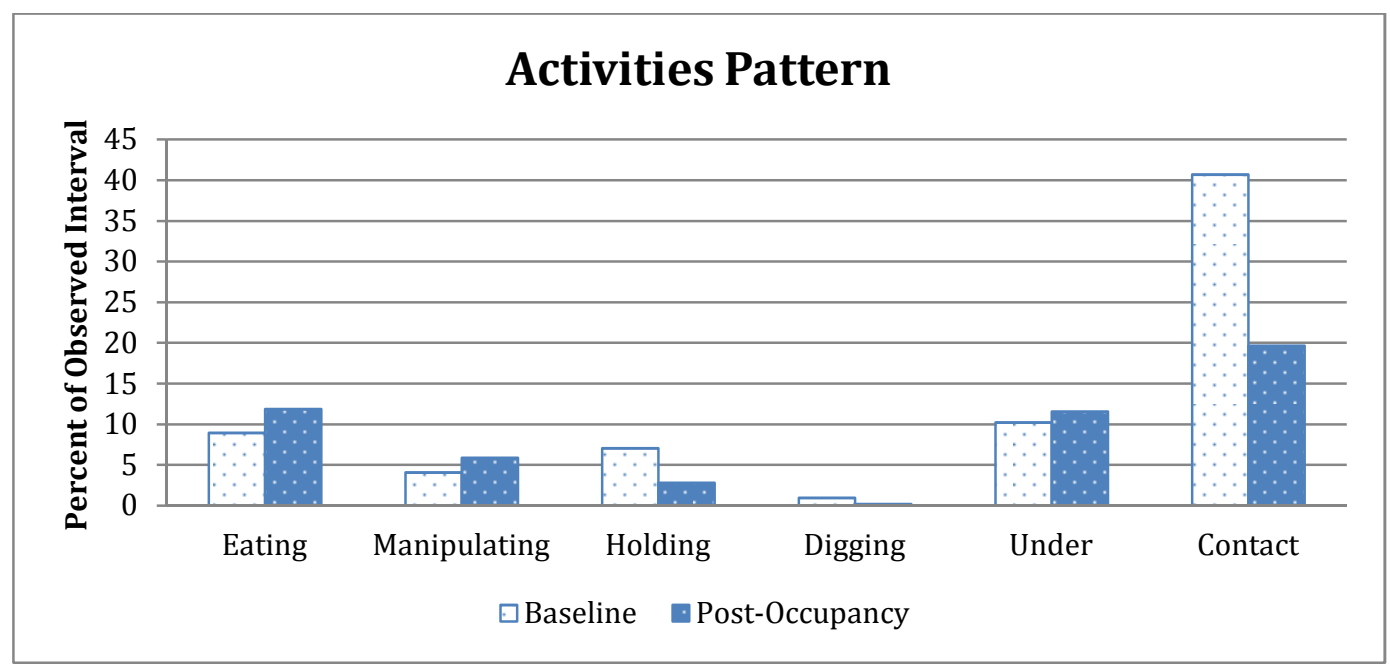

Figure 3.19 Inji's percentage of activities observed during all phases of the study

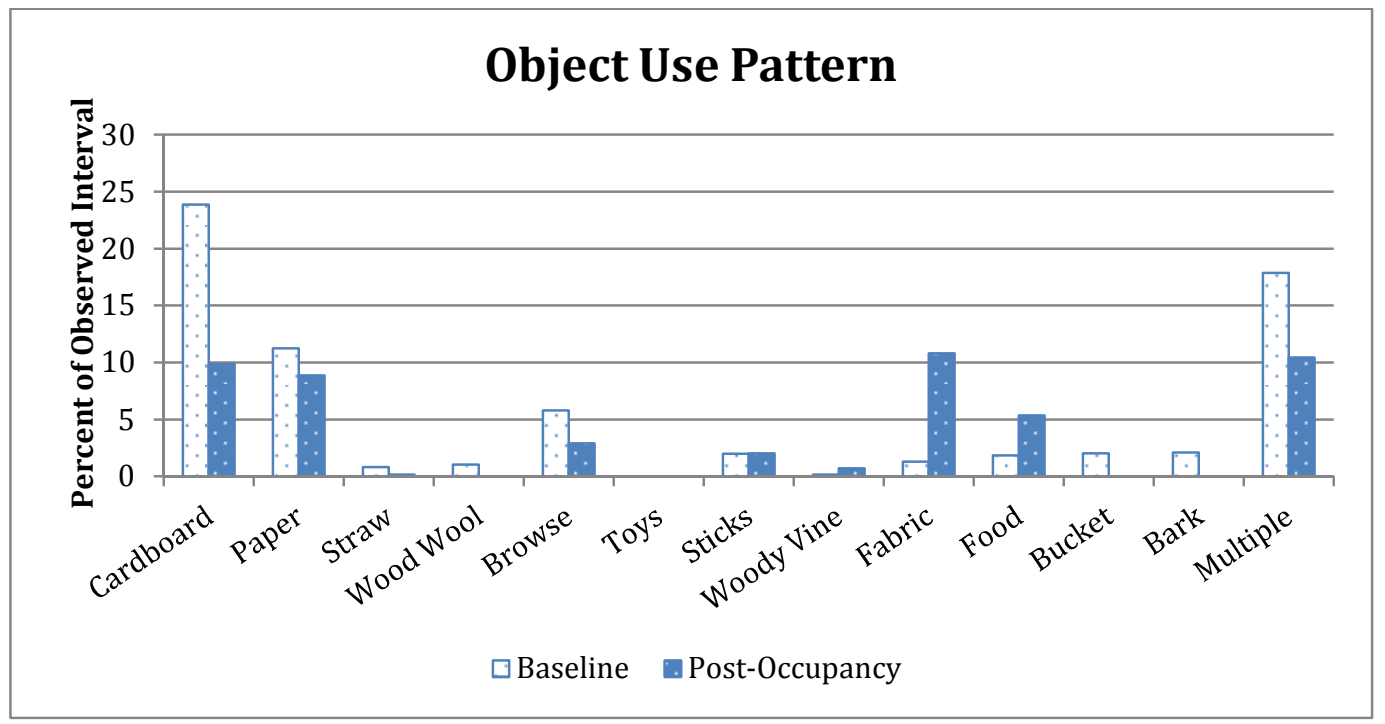

Figure 3.20 Inji's percentage of object use observed during all phases of the study 
Object use patterns were also evaluated to determine if there were changes between the old and new exhibits (Figs. 3.20 and 3.22). If animals were engaged in an activity that involved multiple objects, object use was coded as 'multiple'. Inji increased her use of food (from 1.9\% baseline to $5.4 \%$ during postoccupancy) and fabric (from 1.3\% during baseline to $10.9 \%$ throughout postoccupancy). Use of all other objects used by Inji decreased from baseline to post-occupancy.

A comparison of activity patterns for Kutai from the old to the new exhibit revealed a decrease in all activities. This reduction in activities with enrichment objects should be viewed in light of the increases in locomotive behaviors. That is to say that an overall decrease in activity with enrichment objects does not equate an overall decrease in activity level. Kutai's use of enrichment objects also decreased for all items except the use of fabric and food. His increase in the use of food was most noteworthy with a $5 \%$ rise (from $2.1 \%$ during baseline to 7.4 during post-occupancy). 


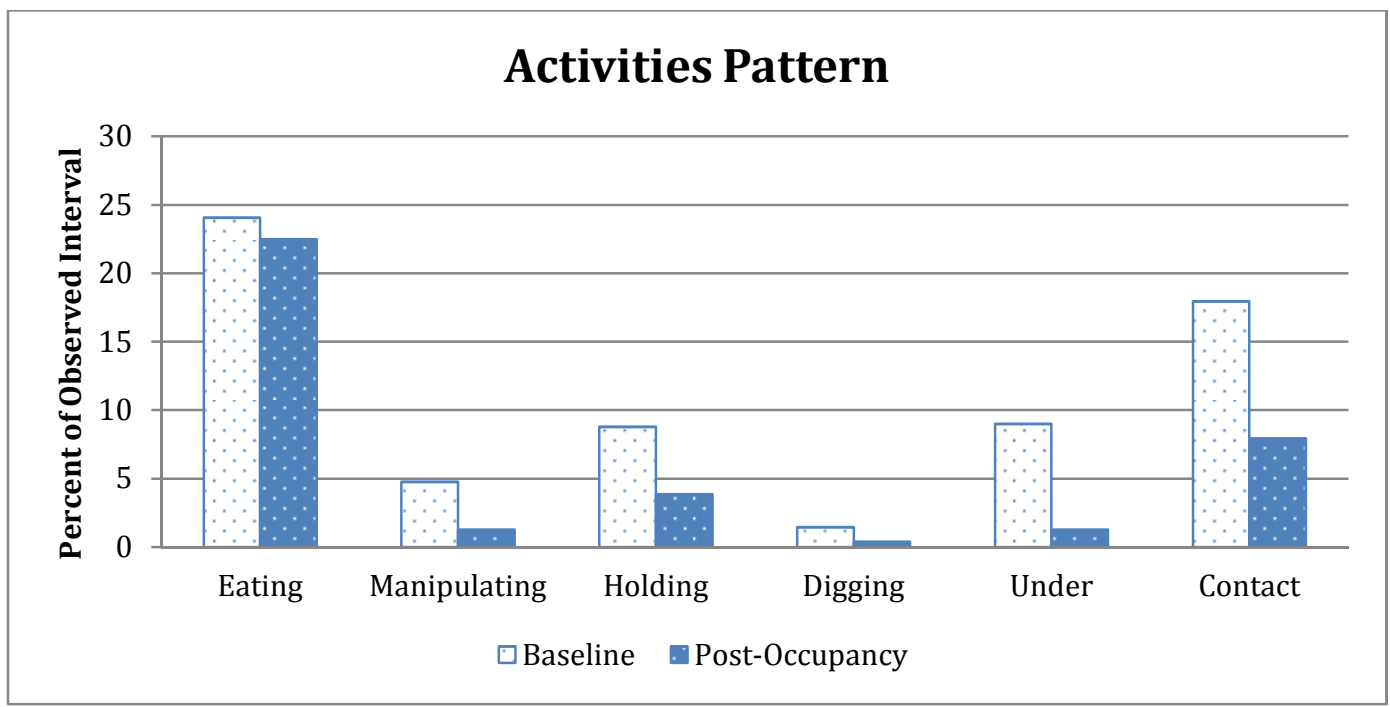

Figure 3.21 Kutai's percentage of activities observed during all phases of the study

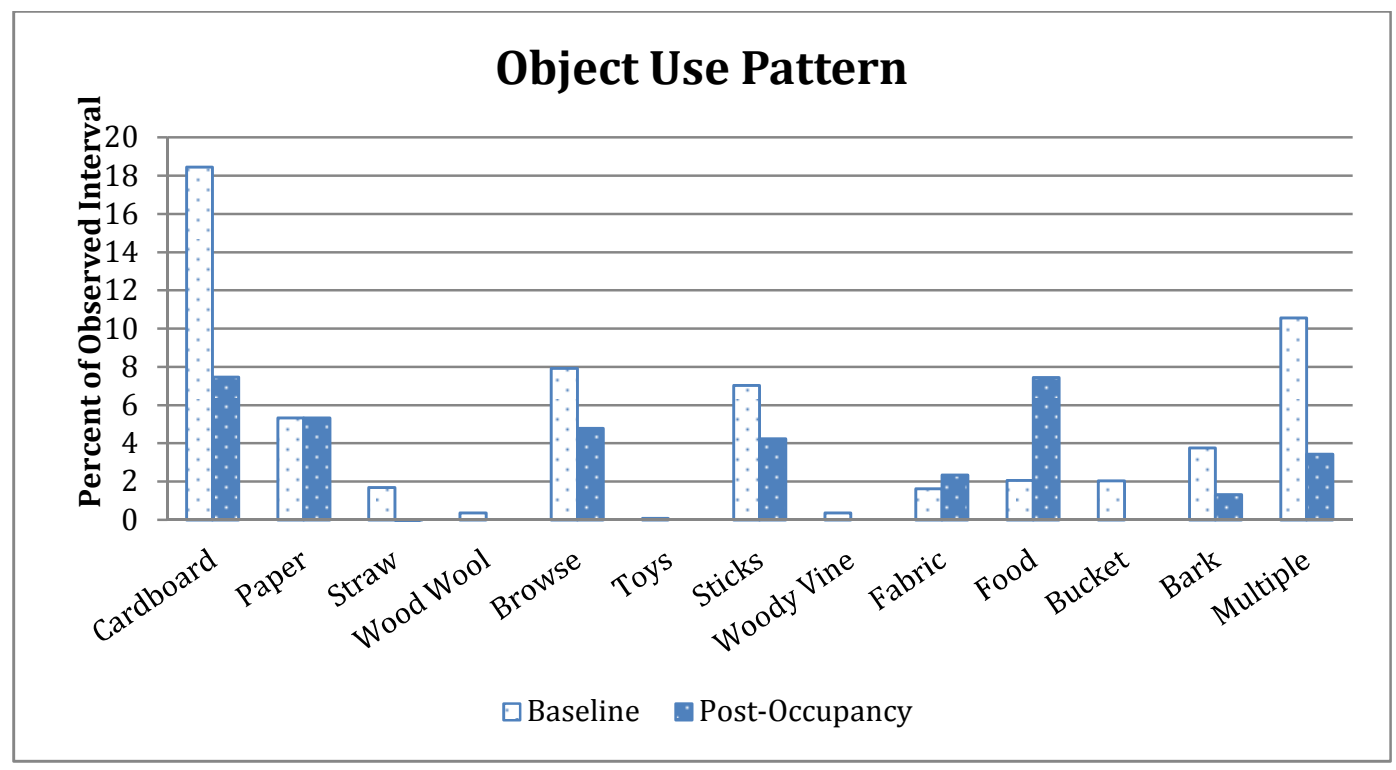

Figure 3.22 Kutai's percentage of object use observed during all phases of the study

\subsection{Hormonal Results}

Hormonal data were statisically compared between baseline and postoccupancy phases using the Mann-Whitney $U$ test. The habituation phase was not included in hormone analysis due to lack of sample collection during this time. All hormone samples were processed in the Endocrine Technology and 
Services lab at the Oregon National Primate Research Center in Beaverton, Oregon.

\subsubsection{Saliva sample analysis}

All saliva samples analyzed for cortisol were collected in the morning. A diurnal comparison of salivary cortisol levels was not possible due to the lack of afternoon samples. Of the total saliva samples collected for Inji (Table 3.3), 20 baseline and 14 post-occupancy samples were analyzed for cortisol (Table 3.4, Fig. 3.23). There was not a significant difference in Inji's salivary cortisol concentrations $(P=0.07)$ between the two study phases. This suggests that physiological parameters related to stress remained relatively the same before and after Inji's move to the new exhibit.

\begin{tabular}{lcc}
$\begin{array}{l}\text { Table } 3.3 \\
\text { Inji salivary cortisol sample totals }\end{array}$ & \\
\hline & Baseline & Post-occupancy \\
\hline Total collected & 22 & 25 \\
Discarded $>150 \mu l$ & 2 & 6 \\
Discarded $<25 \mu \mathrm{l}$ & 0 & 4 \\
Assay Total & $\mathbf{2 0}$ & $\mathbf{1 4}$ \\
\hline
\end{tabular}

Table 3.4

Inji mean values of salivary cortisol $(\mathrm{ng} / \mathrm{ml})$ before and after the move to the new exhibit

\begin{tabular}{llll}
\hline Study Phase & Time & $\begin{array}{l}\text { Cortisol } \\
(\mathrm{ng} / \mathrm{ml})\end{array}$ & St.Dev. \\
\hline Baseline & am & 0.395 & 1.46 \\
Post-occupancy & & 0.478 & 1.24 \\
\hline
\end{tabular}




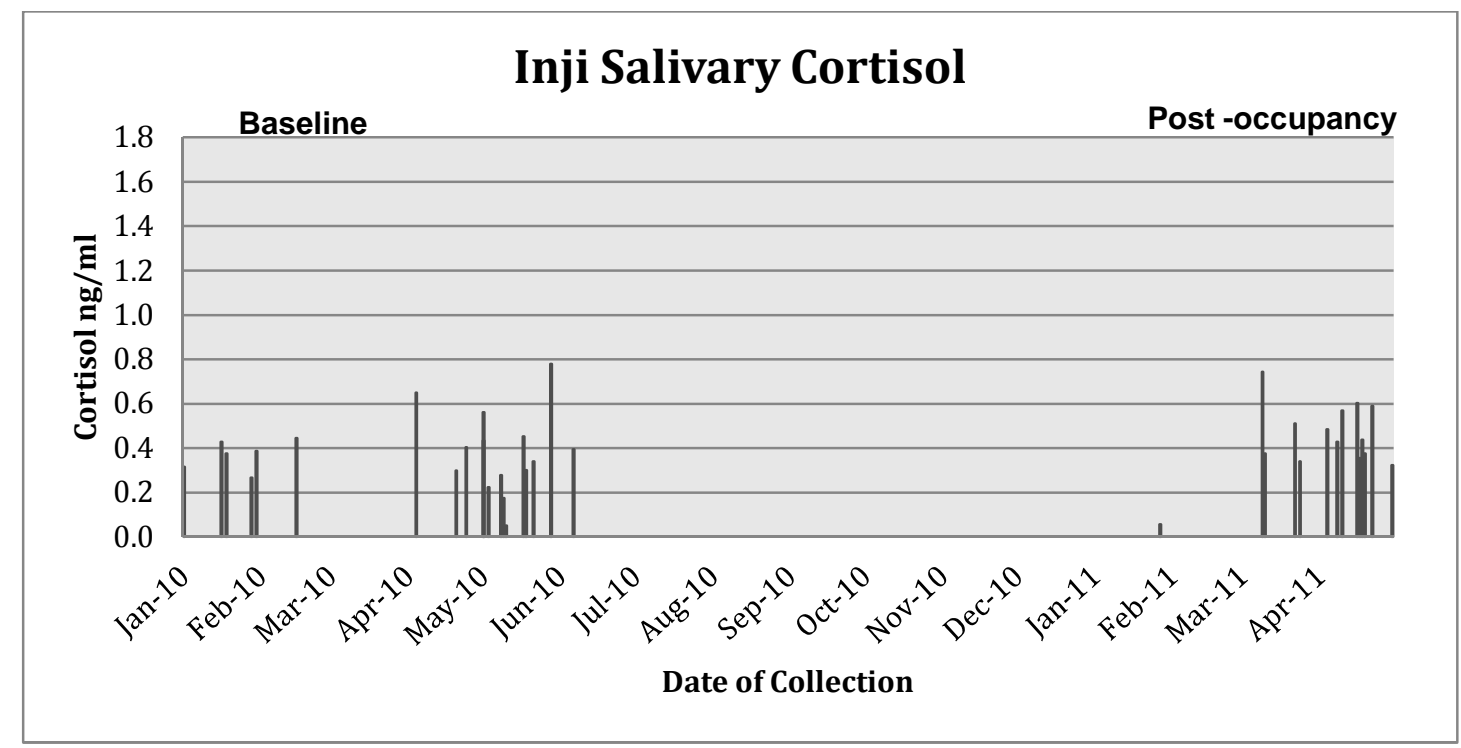

Figure 3.23 Salivary cortisol values for Inji's morning samples compared across baseline and post-occupancy

For Kutai, a total of 13 baseline and 11 post-occupancy samples were analyzed for cortisol (Table 3.6, Fig. 3.24) following the loss of samples that did not fall within the necessary volume range (Table 3.5). There was a significant difference $(P=0.04)$ in salivary cortisol concentrations across the different study periods for Kutai, with an overall decrease in cortisol production following the move to the new exhibit. This may inidicate an increase in animal welfare, however due to the small sample size these results should be taken as preliminary findings needing corroboration with additional sample collection. Because there is no data for the habituation phase it cannot be determined whether the move itself ilicted a short-term period of distress for either animal. 
Table 3.5

Kutai salivary cortisol sample totals

\begin{tabular}{lll}
\hline & Baseline & Post-occupancy \\
\hline Total collected & 14 & 19 \\
Discarded $>150 \mu \mathrm{l}$ & 0 & 2 \\
Discarded $<25 \mu \mathrm{l}$ & 1 & 6 \\
Assay Total & $\mathbf{1 3}$ & $\mathbf{1 1}$ \\
\hline
\end{tabular}

Table 3.6

Kutai mean values of salivary cortisol $(\mathrm{ng} / \mathrm{ml})$ before and after the move to the new exhibit

\begin{tabular}{lll}
\hline Study Phase & $\begin{array}{l}\text { Cortisol } \\
(\mathrm{ng} / \mathrm{mg})\end{array}$ & St.Dev. \\
\hline Baseline & 0.770 & 3.42 \\
Post-occupancy & 0.540 & 1.81 \\
\hline
\end{tabular}

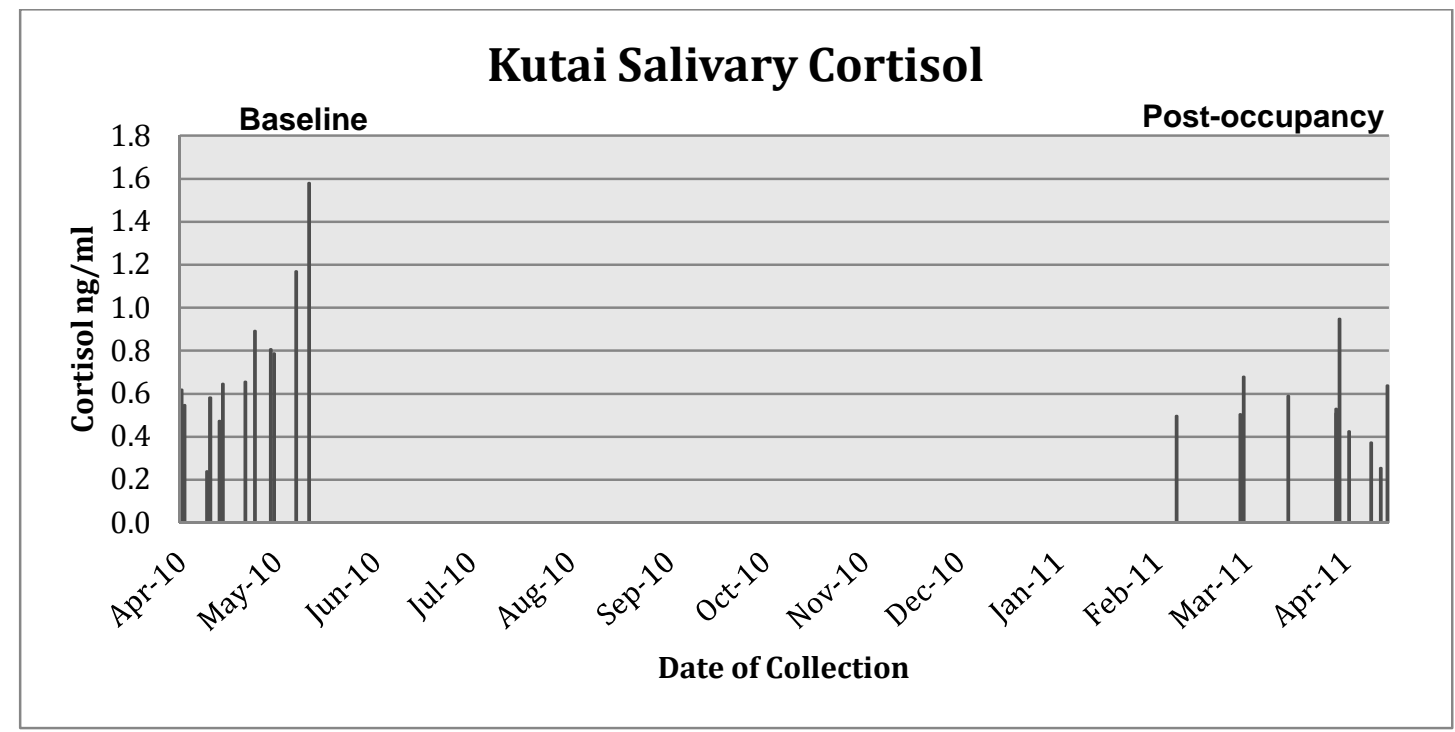

Figure 3.24 Salivary cortisol values for Kutai 's morning samples compared across baseline and post-occupancy 


\subsubsection{Urine sample analysis}

The number of urine samples collected between the two study phases varied dramatically. A total of 24 baseline and 13 post-occupancy samples were compared (Table 3.7, Fig. 3.25) for Inji and found not to differ significantly $(P=0.07)$. However, to examine the diurnal pattern of cortisol characterisitic of non-human primates, Inji's morning and afternoon baseline samples were also compared (Table 3.7, Fig. 3.26). Morning and afternoon cortisol levels differed significantly $(P=<0.001)$, confirming what had previously been reported for orangutans (Elder \& Menzel, 2001).

\begin{tabular}{|c|c|c|c|c|}
\hline Study Phase & Time & Totals & $\begin{array}{c}\text { Cortisol } \\
\text { (ng/ml) }\end{array}$ & St. Dev. \\
\hline \multirow[t]{2}{*}{ Baseline } & $\mathrm{am}$ & 24 & 217.8 & 68.3 \\
\hline & $\mathrm{pm}$ & 15 & 91.2 & 76 \\
\hline Post-occupancy & $\mathrm{am}$ & 13 & 178 & 80 \\
\hline
\end{tabular}




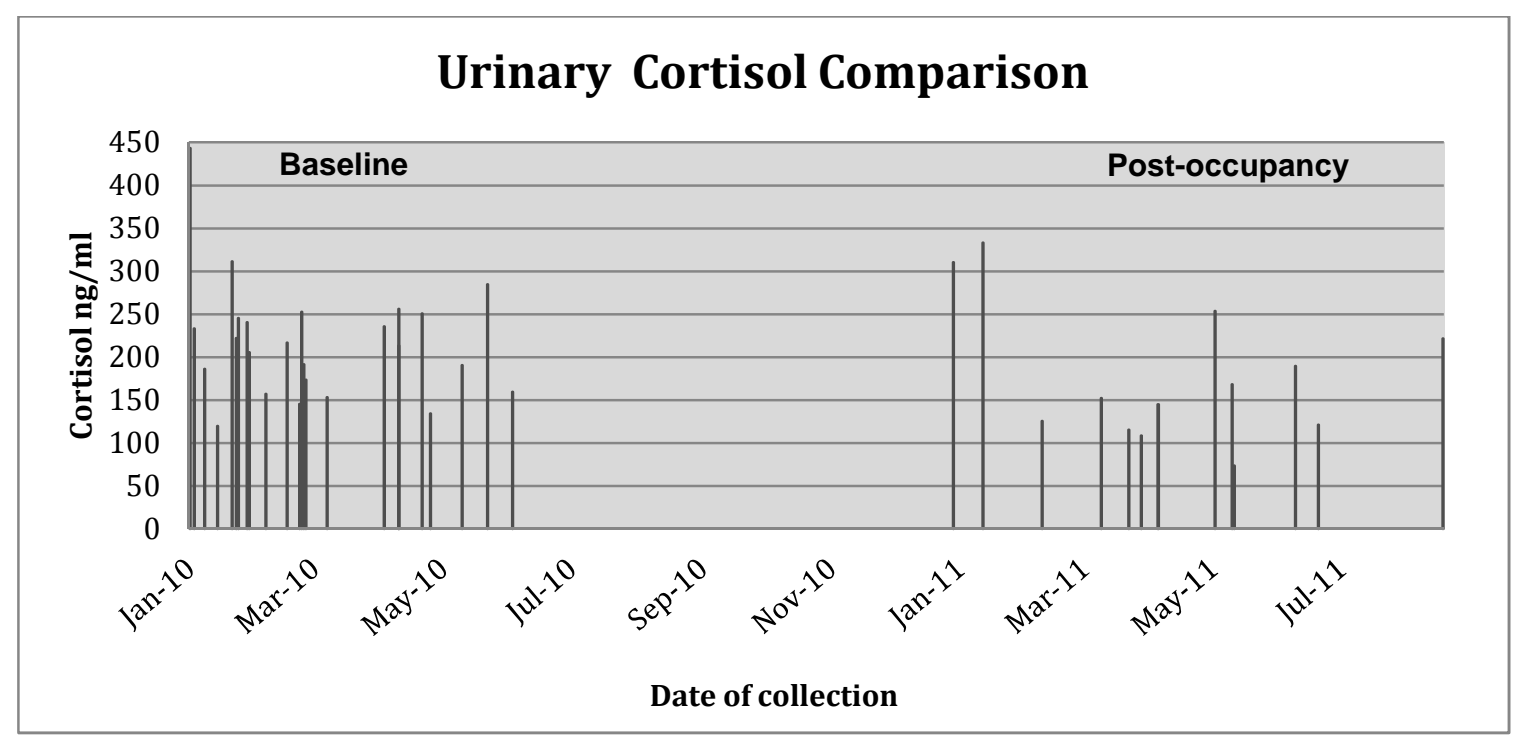

Figure 3.25 Urinary cortisol values for Inji's morning samples compared across baseline and post-occupancy

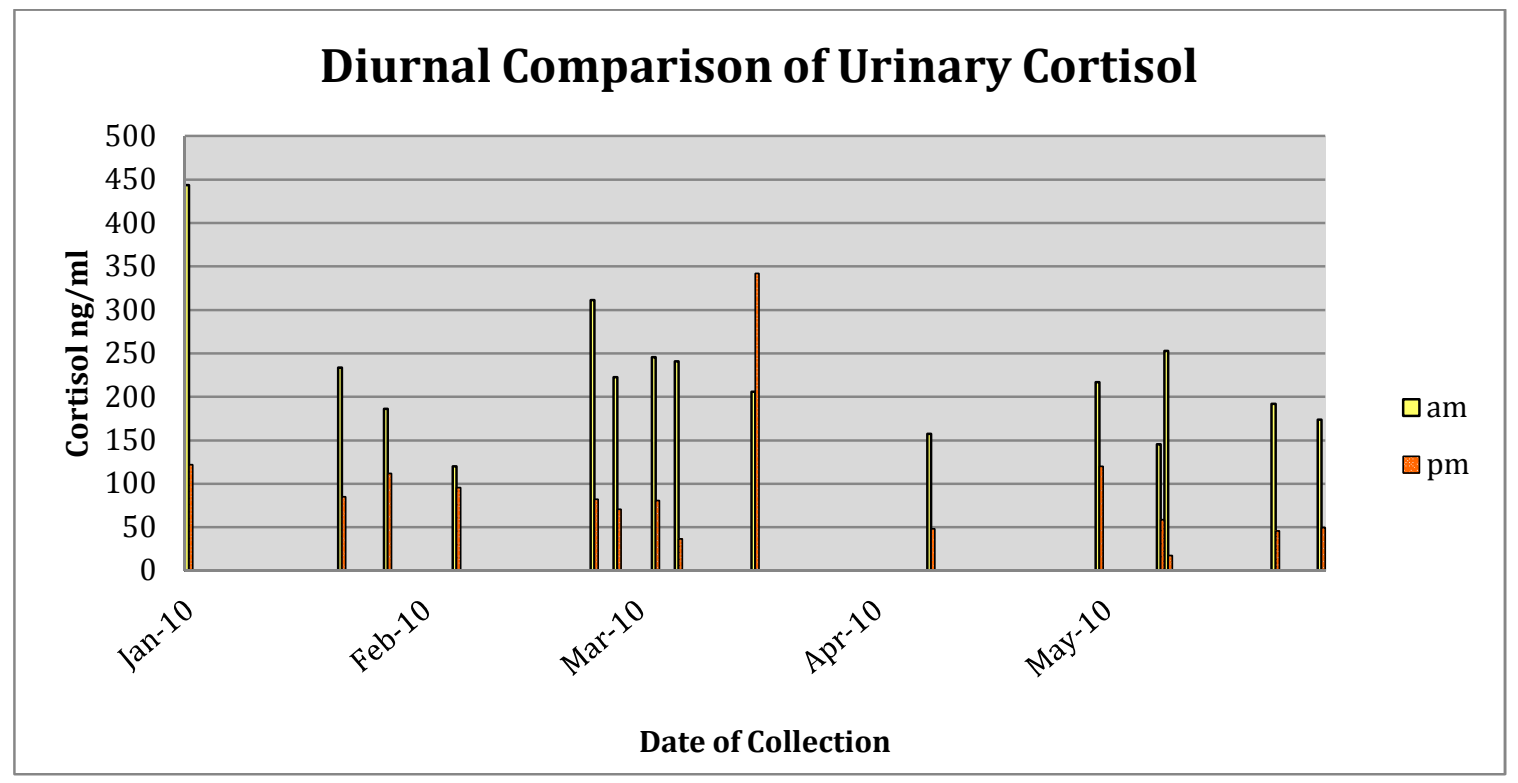

Figure 3.26 Morning and afternoon urinary cortisol values for Inji's samples collected during baseline

A comparison of Kutai's 4 baseline and 7 post-occupancy urine samples (Table 3.8) were not significantly different $(P=0.10)$. With a sample size this small 
and having large gaps between collections it is difficult to draw any conclusion or to compare with the salivary cortisol findings.

Table 3.8

Kutai urine sample totals and mean values of urinary cortisol $(\mathrm{ng} / \mathrm{ml})$ before and after the move to the new exhibit

\begin{tabular}{lcccc}
\hline Study Phase & Time & Totals & $\begin{array}{c}\text { Cortisol } \\
\text { (ng/ml) }\end{array}$ & St. Dev. \\
\hline Baseline & am & 4 & 115.9 & 79.5 \\
& pm & 1 & 234.4 & N/A \\
Post-occupancy & am & 7 & 236.8 & 76 \\
\hline
\end{tabular}

\subsubsection{Hair sample analysis}

The difficulties associated with hair sample collection, including fear of scissors, infrequent anesthetization, and overall coarse nature of orangutan hair resulted in an inability to compare Inji's hair cortisol levels before and after the move to the new exhibit. The mean cortisol value of Inji's single baseline hair sample, run in triplicate, was $0.008 \mathrm{ng} / \mathrm{mg}$. For Kutai the mean cortisol value of two baseline and one post-occupancy samples run in duplicate were 0.0155 $\mathrm{ng} / \mathrm{ml}$ and $0.016 \mathrm{ng} / \mathrm{mg}$, respectively (Table 3.9). These findings indicate that there was not a long term change in hair cortisol levels for Kutai from the beginning to the end of the study.

Table 3.9 Kutai's hair samples collected and analyzed for cortisol

\begin{tabular}{lll}
\hline & Date & Cortisol $(\mathrm{ng} / \mathrm{mg})$ \\
\hline Pre & $4 / 10$ pool $^{*}$ & 0.012 \\
& $6 / 24 / 10$ & 0.019 \\
Post & $4 / 27 / 12$ & 0.016
\end{tabular}

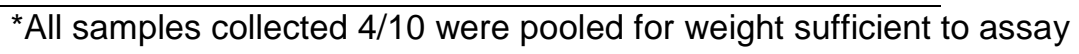


Batik's hair samples were processed to determine if there was a correlation between cortisol levels and the illness which required surgery and eventually led to her death. The analysis revealed a sharp increase in cortisol from early to late June (Fig. 3.19). Zookeepers first noticed Batik was sick with a loss of appetite at the beginning of June. On June 6th surgery was performed to remove her gallbladder and enlarged right kidney. On June 7th she received a blood transfusion from Kutai. During this time she was kept separate from Inji and Kutai while the zookeepers struggled to get her to eat. She refused both food and medication. Batik died on July 8, 2010, shortly after the collection of her hair sample in late June, which revealed hair cortisol levels nearly 50 times higher than seen in early June.

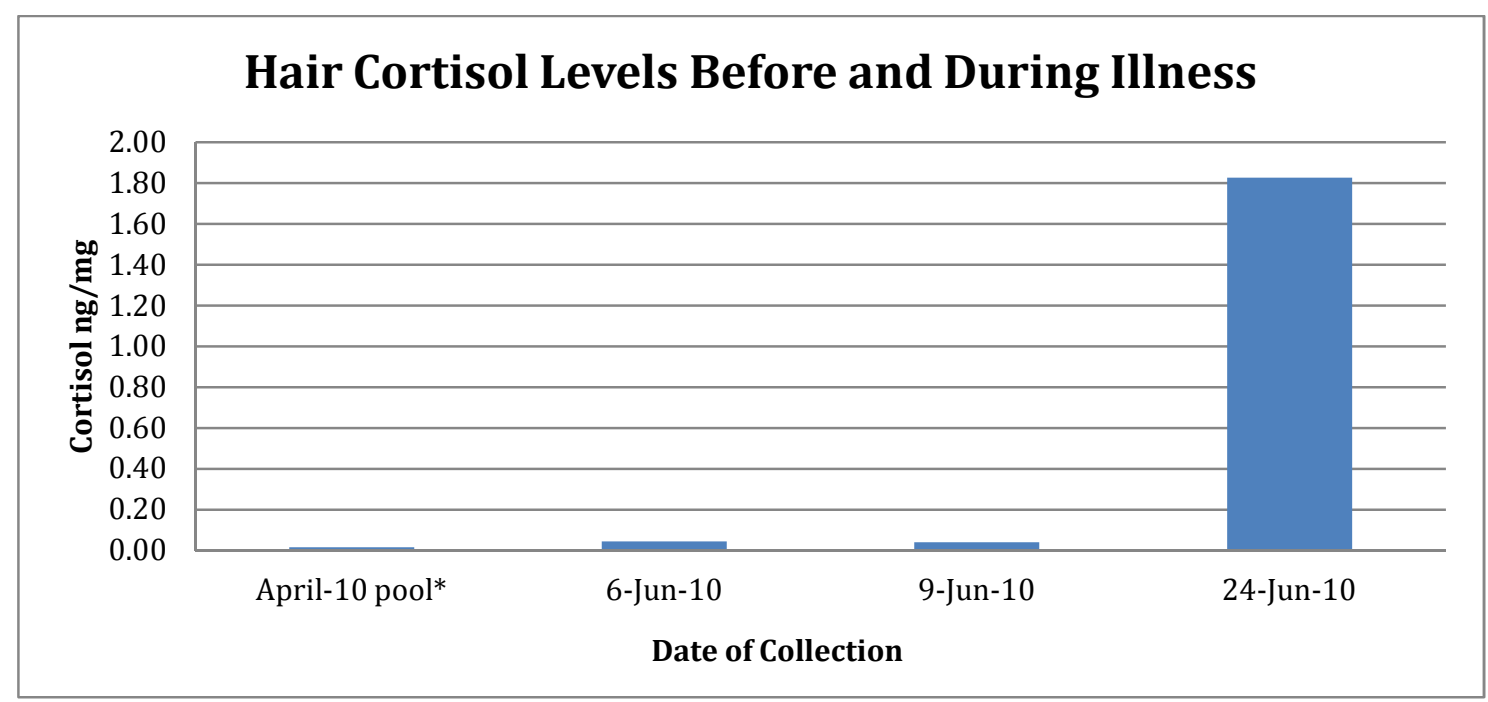

Figure 3.27 Batik's hair cortisol values collected during baseline prior to her death 


\section{Chapter 4}

\section{DISCUSSION:}

\subsection{Behavioral assessment}

This study indicates that the move to the new exhibit had a positive effect on eliciting more naturalistic behaviors in the orangutans at the Oregon Zoo. Overall inactivity levels decreased and both animals exhibited a surge in exploratory behaviors including a doubling in frequency of active locomotion, and an increase in the use of higher elevations, especially for Kutai in the new exhibit. High levels of inactivity have been associated with decreased welfare in captive orangutans (Condon \& Wehnelt, 2003), therefore a reduction in overall time spent inactive from the baseline to post-occupancy phases supports that the move was successful in terms of improving animal welfare. In addition, both animals' use of exhibit space was more diverse following the move to the new exhibit. This suggests that when given access to a more complex environment, orangutans in captivity will utilize a greater diversity of exhibit locations.

The improvement in use of vertical space also indicates that the move to the new exhibit provided a more natural environment. Herbert and Bard (2000) emphasize that as arboreal apes, it is especially important that orangutans are given opportunities for locomotion at higher elevations in captivity and that this will reduce physical signs of reduced welfare. An increase in active behaviors by providing more natural locomotion is also relevant in regards to implications for increased animal welfare. The notable large increase in climbing behaviors by 
Kutai and to a lesser degree by Inji following the move is therefore seen as an encouraging outcome in regards to improving their welfare.

Providing a stimulating and naturalistic environment to captive animals, permitting more choices to be made is central to efforts of improving animal welfare (Birke, 2002). The complexity and size of the new exhibit provided physical stimulation with numerous options for use of exhibit space. Structure use by both animals rose dramatically following the move to the new exhibit. Specifically, there was a noticeable use of ropes by Inji, which increased from habituation to post-occupancy. In contrast, she was found to use the enrichment tree more frequently during the habituation phase than post-occupancy. This naturalistic structure was designed to provide foraging opportunities with multiple locations for zookeepers to hide food. Specific information regarding the zookeeper's utilization of this tree for providing food for the orangutans was not available. However, it is encouraging that Inji was observed using this enrichment structure during her first month in the new exhibit. An evaluation of why her use of this structure decreased during post-occupancy should be undertaken, specifically whether preference for the enrichment tree is related to the presence or absence of food or changes in seasonal use of the outside structures as discussed below. Future observations should include notes regarding zookeeper's food enrichment schedule.

Habitat use data revealed that in the new exhibit both animals showed a strong preference when outside for zone 1 . There was infrequent use of outside zone 2 and very limited use of outside zone 3 . This pattern of use might be 
explained by the location of the doors. There are no doors that allow the animals to go from the inside directly to outside zones 2 and 3 . When moving from the inside to outside exhibit areas and vice versa, the animals must enter into zone 1. From there zone 2 must be accessed to arrive in and exit zone 3 . This data shows that both Inji and Kutai preferred outside areas, which allowed them to remain near an inside access door. Changes in this prefence could be monitored with continued collection of each animals outside use patterns as they continue to acclimate to the new exhibit.

It should be noted that the habituation data was collected during the month of August when daytime temperatures range between approximately $58^{\circ}-$ $80^{\circ} \mathrm{F}$, and average rainfall is approximately 0.66 inches. The post-occupancy data was collected September through March during which time temperature range is noticeably lower $38^{\circ}-75^{\circ} \mathrm{F}$, and can occa sionally drop below freezing during the colder winter months. In addition, rainfall is significantly higher with monthly precipitation totals ranging from $1.47-5.64$ inches based on data from 1981-2010 (NOAA, 2012).

This change in weather conditions between the two data collection periods might explain the large decrease in Inji's outside use and ultimately may not accurately reflect outside use in the new exhibit during post-occupancy. The collection of additional behavioral data in the new exhibit including collection during the same months as the majority of the baseline data (May-July), would allow for a more in-depth analysis by accounting for seasonal variation in behaviors. This data would make known specific seasonal patterns in use of the 
outside exhibit and could reveal that the orangutans make use of the outside exhibit at a greater frequency than this study suggests given that the postoccupancy data was collected during colder months. In contrast to Inji, Kutai's use of the outside did increase from habituation to post-occupancy. Additioanl data collection would control for changes in weather and reveal whether there are distinct differences between individual animals in their preference for utilizing the outside exhibit areas.

There was a clear increase in distance between animals from the baseline data to post-occupancy. This variation can be explained in part by the change from three animals in the old exhibit to two in the new exhibit. With more animals there is a greater chance that at least two of them will be in close proximity to each other. An additional factor is the increased size of the new exhibit which allows the orangutans to space themselves farther apart both horizontally and vertically. Increased exhibit size has been related to a decrease in aggressive behaviors for captive orangutans (Maple \& Finlay, 1987). Aggression between the two females, specifically Inji displacing Batik was regular occurrence during baseline; however there was only one instance of aggression, initiated by Kutai towards Inji in the new exhibit during habituation. In the wild adult orangutans are primarily solitary animals (Galdikas, 1978; Rodman, 1979), therefore exhibit changes that result in increased distance between animals could be considered successful in incorporating social behavior typical of natural habitats. However, it's difficult to form specific conclusions regarding how changes in proximity 
reflect changes in social behavior due to the confounding nature of variation in the number of animals present between phases of the study.

The orangutan and gibbon introduction, which occurred during the habituation phase, was considered extremely successful. The animals share all zones of the outside exhibit area and when the indoor to outside doors of the orangutan exhibit are open the gibbons can access the orangutan indoor exhibit. Both Inji and Kutai appeared to be unaffected by the presence of the two gibbons and not a single interaction between the two species was recorded.

The habituation phase data exhibited the most dramatic exploration of the novel environment. Inji was much more inclined to explore the new exhibit immediately following the move. Kutai was reluctant to leave holding for the first couple days, however his hesitation was short-lived and he soon joined Inji in exploring his new surroundings. Data indicated that inactivity levels were lowest for both animals during the initial month in the new exhibit. This period of investigation suggest that both animals not only adequately coped with the change of enclosure event, but that their new surroundings provided the type of stimulation associated with improved welfare.

The activities and object results, which would suggest a decrease in the majority of activities coded for, can be misleading for two reasons. One, "object use" did not relay information regarding what objects were made available for use by the animals, it was only a measure of objects that the animals actually interacted with. For example, the decrease in the use of cardboard as seen by both animals from the old to the new exhibit could be a function of whether the 
zookeepers made it available to the animals as often. Unfortunately, data recording of objects made available to the animals were not collected with regularity for the two study phases. This information should be collected for future studies not only to determine which were preferred, but also to establish if object use is directly correlated with object availability. Two, the collection of locomotion and activity with object data as independent variables can be problematic. Animals activities patterns do does not reflect any information regarding their use of active locomotive behaviors. The absence of an activity with object does not mean that the animal was inactive. Many of the activities collected for the orangutans were more likely to be associated with an animal being in a stationary position or sitting. For example, an animal engaging in an active locomotion such as climbing or quadramanous would be less likely to be perfoming and activity such as under or digging at the same time.

This study revealed that while overall activity level increased, activity patterns decreased, indicating that the rise in active locomotive behaviors and use of higher elevations meant that the animals spent less time on the ground engaged in a specific actitiy such as digging, holding or contact with an object. Data revealed that both animals had an increase in food as object use, this could be due to increased foraging opportunities provided with the live plants in the outside exhibit, an increase in food scattering in the exhibit by zookeepers or both. For Inji there was a slight increase in eating activies, whereas Kutai had a slight decrease in eating activites. However, the rise in use of food as objects would suggest that the new exhibit has provided a more natural way to live. For 
example, orangutans in the wild spend roughly $46 \%$ of time foraging (Rodman, 1979), and have been found to feed on upwards of 400 plant species (Birke, 2002).

Some studies have associated an animal's use of an object to cover head or body to be a sign of reduced welfare and is thought to be related to avoiding visitor contact (Condon \& Wehnelt, 2003; Birke, 2002; Jones, 2003). The decrease in 'under' as an activity engaged in by Kutai could be a result of the additional space available in the new exhibit which allowed ways to avoid contact with visitors, such as locomotion to higher places in both the inside and outside exhibit areas.

\subsection{Hormonal Assessment}

The absence of hormone data throughout the habituation phase made it difficult to determine if the actual event of being moved was a stressor that diminished over time as originally planned. Anecdotal evidence suggests that this was the case for Kutai. During his first few days in the new exhibit he refused food (conversations with zookeeper) and was hesitant to leave the indoor holding.

The small number of samples collected by the zookeepers was a constraint in statistically assessing overall changes in hormone levels across the study phases. Data collected for Inji showed that there was not a significant change in salivary or urinary cortisol levels between the baseline and postoccupancy. However, a comparison of Inji's morning and afternoon urinary cortisol samples collected during baseline revealed a diurnal rhythm 
characteristic of primates and other mammals with values highest in the morning and decreasing throughout the day. The absence of sufficient hair sample collection from Inji disallowed any long term comparisons of cortisol to be made. Both urine and saliva sample results indicate that since Inji did not experience any substantial change in cortisol secretion, hourly and daily stress levels remained the same from baseline to post-occupancy.

Kutai's salivary cortisol results suggest an increased biological response to stress upon post-occupancy with values significantly lower than baseline values in the pre-move habitat. However, with such a small number of samples it is difficult to draw robust conclusions from this data set. The collection of additional samples in the new exhibit could assess whether cortisol levels fluctuate by season or vary between age and sex. Perhaps more important, is the analysis of Kutai's urinary cortisol levels which did not corroborate the changes seen with the salivary cortisol. Additional salivary and urine samples are necessary to adequately assess Kutai's short-term biological response to the potential stresses associated with the change of enclosure event.

The lack of change between Kutai's baseline and post-occupancy hair cortisol levels reveals there were no long-term changes in his physiological response. His hair cortisol levels remained low throughout the study and were comparable to the Inji's baseline sample and Batik's initial sample collected in April 2010. Batik's illness at the end of the baseline phase provided an opportunity to measure the production of hair cortisol in orangutans in the presence of a known stressor. These results strongly showed that in response to 
stress, namely a terminal illness, orangutan hair cortisol levels dramatically increased and this rise could be detected within a month's time. This suggests that routinely tracking cortisol levels in hair could be an important tool for detecting or confirming serious illness in orangutans.

Some difficulties have been cited when directly correlating animal welfare with biological functioning. In his comprehensive survey of the interplay between glucocorticoids and stress, Sapolsky (2000) emphasizes the complexity of the biological response to stress and the diversity of internal actions. The response to stress is variable between individuals and different types of stressors have been found to bring about a different biological response in the same animal (Moberg, 1985).In addition, there have been reports of known stressors having no impact on cortisol levels (Moberg, 1987). The interplay between stress and cortisol levels is therefore an intricate issue and can be difficult to interpret.

Nevertheless, the use of adrenal corticosteroid measurement is still considered a useful tool, and is widely used as a measure for evaluating animal welfare (Whitten et al., 1998; Ange-van Heugten et al., 2009; Condon \& Wehnelt, 2003; Clark et al., 2011; Cross et al., 2004). When answering questions regarding whether 1) an experience or event is stressful, 2) has resulted in distress causing a change in biological function and 3) ultimately reduced an animal's ability to cope with its environment, it is important to not oversimplify. Distress implies reduced well-being, however an increase in cortisol does not automatically equate that an animal is experiencing distress. Short-term increased production of cortisol is a normal biological mechanism, which has 
evolved for coping with stressors. Moberg (1985 \& 1987) emphasizes the need to determine changes in biological functioning which lead to development of a prepathologic state, both of which are related to rate of recurrence and extent or the stressor

It is imperative that duration of stressors be factored into hormonal analysis (Sheriff et al., 2011). This study utilized three different types of biological samples to account for time of hormone secretion. Of all sample matrices hair cortisol measurement is thought to be most fitting for researchers investigating the effects of distress, or the long-term effects of distress and long-term exposure to stressors which could potentiate allostatic overload resulting in reduced animal welfare. To continue monitoring response to stressors in the new exhibit, it is recommended that hair cortisol is collected annually during each animal's routine physical exam, as well as when there is a known change in health status. This non-invasive collection could alert zookeepers of fluctuations in long-term corticosteroid production and prove useful for determining the effects of future changes to exhibits such as addition of new animals, death of animals, or enrichment measures.

\subsection{Conclusions: Implications for animal welfare post-occupancy}

The new exhibit provided a habitat with a greater degree of complexity, which elicited more natural behaviors. Adaptations must be made for animals living in captivity and we can expect there to be a decrease in arboreal and foraging behaviors for zoo housed orangutans when compared to their wild counterparts. However, an increase in active locomotive behaviors, that allow 
animals to spend their time at higher elevations in locations off the ground are more desirable than inactive behaviors where animals spend the majority of their time at ground level. This noticeable increase in use of naturalistic behaviors by both Inji and Kutai, suggests that the move to the new exhibit improved animal welfare. 


\section{References}

Altmann, J. (1974). Observational study of behavior: sampling methods. Behaviour, 49(3): 227-267.

Ange-van Heugten, K. D, van Heugten, E., Timmer, S., Bosch, G., Elias, A., Whisnant, S. , Swartz, H. J. M., Ferket, P., \& Verstegen, M. W. A. (2009). Fecal and salivary cortisol concentrations in Woolly (Lagothrix ssp.) and spider monkeys (Ateles spp.). International Journal of Zoology. doi:10-1155/2009/127852.

Choudhury, A. (2009). Mann-Whitney U-Test. Retrieved 1 Aug. 2012 from Experiment Resources: http://www.experiment-resources.com/mann-whitney-u-test.html

Ben-Ari, E. T. (2001). What's new at the Zoo? BioScience, 51(3): 172-177.

Birke, L. (2002). Effects of browse, human visitors and noise on the behavior of captive orangutans. Animal Welfare, 11: 189-202.

Buckingham, J. C. (2006). Glucocorticoids: exemplars of multi-tasking. British Journal of Pharmacology, 147: S258-s268.

Buckley, C. (2003). Captive orangutans (Pongo pygmaeus) and environmental enrichment. Ratel, 30(1): 11-22.

Cawthon Lang K. A. (2005). Primate Factsheets: Orangutan (Pongo) Behavior . $<$ http://pin.primate.wisc.edu/factsheets/entry/orangutan/behav>. Accessed on January 17, 2012.

Chang, T. R., Forthman, D. L. \& Maple, T. L. (1999). Comparison of confined mandrill (Mandrillus sphinx) behavior in traditional and "ecologically representative" exhibits. Zoo Biology, 18: 163-176.

Condon, E. \& Wehnelt, S. (2003). Proceedings of zoo research Marwell Zoological Park annual symposium. Winchester, UK. pp: 53-58.

Cowan, T. (2010). The Animal Welfare Act: Background and Selected Legislation. Congressional Research Service. Report no. RS22493. 
Creel, S., Dantzer, B., Wolfgang, G., \& Rubenstein, D.R. (2012). The ecology of stress: Effects of the social environment. Functional Ecology. Cross, N., Pines, M. K. \& Rogers, L. J. (2004). Saliva sampling to assess cortisol levels in unrestrained common marmosets and the effect of behavioral stress. American Journal of Primatology, 62: 107-114.

Davenport, M. D., Tienfenbacher, S., Lutz, C. K., Novak, M. A., \& Meyer, J. S. (2006). Analysis of endogenous cortisol concentrations in the hair of rhesus macaques. General and Comparative Endocrinology, 147: 255-261.

Dedovic, K., Duchesne, A., Andrews, J., Engert, V., \& Pruessner, J.C. (2009) The brain and the stress axis: The neural correlates of cortisol regulation in response to stress. Neurolmage, 47: 864-871.

Delgato, R. A. \& van Schaik, C. P. (2000) The behavioral ecology and conservation of the orangutan (Pongo pygmaeus): A tale of two islands. Evolutionary Anthropology, 9: 201218.

Dellatore, D. F. (2007). Behavioral Health of Reintroduced Orangutans (Pongo abelii) in Bukit Lawang, Sumatra Indonesia. Master's Thesis, Oxford Brooks University.

Fraser, D. (2009). Assessing animal welfare: different philosophies, different scientific approaches. Zoo Biology, 28: 507-518.

Galdikas, B.M. (1978). Orangutan adaptation at Tanjung Putting Reserve, Central Borneo. Ph.D. dissertation, University of California, Los Angeles.

Goymann, W. \& Wingfield, J.C. (2004). Allostatic load, social status and stress hormones: the cost of social status matter. Animal Behavior, 67: 591-602.

Harrison, M. E. \& Chivers, D. J. (2006). The orang-utan mating system and the unflanged male: A product of increased food stress during the late Miocene and Pliocene? Journal of Human Evolution, 52(3): 275-293.

Hebert, P.L. \& Bard, K. (2000). Orangutan use of vertical space in an innovative habitat. Zoo Biology, 19: 239-251.

Hill, S. P., \& Broom, D. M. (2009). Measuring zoo animal welfare: Theory and Practice. Zoo 
Biology, 28: 531-544.

Hoff, M. P. \& Maple, T. L. (1995) Post-occupancy modifications of a lowland gorilla, Gorilla g.gorilla, enclosure at Zoo Atlanta. International Zoo Yearbook, 34: 153-160.

Hosey, G.R. (2005). How does the zoo environment affect the behavior of captive primates? Applied Animal Behaviour Science, 90: 107-129.

Jones, R. (2003). Effect of visitor numbers on orang-utan behavior. B.Sc. thesis, University of Manchester, UK.

Kirschbaum, C \& Hellhammer, D. H. (1989). Salivary cortisol in psychobiological research: An overview. Neuropsychobiology, 22: 150-169.

Koren, L., Mokady, O., Karaskov, T., Klein, J., Koren, G. \& Geffen, E. (2002) A novel method using hair for determining hormonal levels in wildlife. Animal Behaviour, 63: 403-406

Little, K. A. \& Sommer, V. (2002). Change of enclosure in langur monkeys: Implications for the evaluation of environmental enrichment. Zoo Biology, 21: 549-559.

MacKinnon, J. (1974). The behavior and ecology of wild orangutans (Pongo pygmaeus). Animal Behavior, 22: 3-74.

Maple, T. L. \& Finlay, T. W. (1987). Post-occupancy evaluation at the zoo. Applied Animal Behaviour Science, 18: 5-18.

Maple, T.L. \& Stine, W. (1982). Environmental variables and great ape husbandry. American Journal of Primatology Supplement, 1: 67-76

McEwen, B.S. \& Wingfield, J.C. (2003). The concept of allostasis in biology and biomedicine. Hormones and Behavior, 41(1): 2-15.

McEwen, B.S. \& Wingfield, J.C. (2010). What is in a name? Integrating homeostasis, allostasis and stress, Hormones and Behavior, 57: 105-111.

Mench, J. A. (1998). Environmental enrichment and the importance of exploratory behavior. In: Shepherdson, D. J., Mellen J. D., Hutchins, M., eds. Second Nature: Environmental Enrichment for Captive Animals. Washington DC: Smithsonian Institution. pp 30-46. Mitani, J.C. (1990). Experimental field studies of Asian ape social systems. International Journal of Primatology, 11(2): 103-126. 
Moberg, G.P. (1985). Biological response to stress: implications for animal welfare. In: Moberg GP, Mench JA, editors. The Biology of Animal Stress. Wallingford, UK: CAB International; 2000. pp. 1-21.

Moberg, G.P. (1987). Problems in defining stress and distress in animals. Journal of the American Veterinary Medical Association, 19(10): 1207-1211.

National Oceanic and Atmospheric Administration. (2012). Retrieved April 1, 2012 from: http://www.nws.noaa.gov/climate/xmacis.php?wfo=pqr

National Research Council (US) Committee on Recognition and Alleviation of Distress in Laboratory Animals (2008). Recognition and alleviation of distress in laboratory animals. Washington, DC: National Academies Press (US).

Perkins, L.A. (1992). Variables that influence the activity of captive orangutans. Zoo Biology, 11: 177-186 .

Pizzutto, C. S., Nichi, M., Sgair, M. G. F. G., Correa, S. H. R., Viau, P., Beresca, A. M., Alvarenga de Oliveira, C., Camanarut, B., \& Alcindo de Barros Vaz Guimaraes, M. (2008). Effect of environmental enrichment on behavioral and endocrine aspects of a captive orangutan (Pongo pygmaeus). Laboratory Primate Newsletter, 47(2): 10-14.

Rijksen, H.D. (1978). A field study of Sumatran orangutans (Pongo pygmaeus abelii Lesson 1827). H. Veenman \& Zonen, B.V., Wageningen.

Rodman, P.S. (1979). Individual activity patterns and the solitary nature of orangutans, pp. 235255 In: Hamburg, D.A; McCowan, E.R. (eds) The Great Apes pp. 235-255. Benjamin/Cummings: Menlo Park, CA

Ross, S.R., Wagner, K.E., Schapiro, S.J., Hau, J., and Lukas, K.E. (2011). Transfer and acclimatization effects on the behavior of two species of African great ape moved to a novel and naturalistic zoo environment. International Journal of Primatology, (32): 99117.

Sejian, V., Lakritz, J., Ezeji, T., \& Lal, R. (2011) Assessment methods and indicators of welfare. Asian Journal of Animal and Veterinary Advance, 6(4): 301-315. 
Shannon, C.E. and Weaver, W. (1949). The Mathematical Theory of Communication. Urbana Illinois, University of Illinois Press.

Shepherdson, D. J, Carlstead, K., Mellen, J. D., \& Seidensticker, J. (1993) Influence of Food Presentation on the behavior of small cats in confined environments. Zoo Biology, 12(2): 203-216.

Singleton, I., Wich, S. A. \& Griffiths, M. 2008. Pongo abelii. In: IUCN 2012. IUCN Red List of Threatened Species. Version 2012.1. <www.iucnredlist.org $>$. Downloaded on May, 172012.

Singleton, I., Supriatna, J. \& Wich, S. A. 2009. Sumatran orangutan Pongo abelii Lesson, 1827. In: R. A. Mittermeier et al., Primates in Peril: The World's 25 Most Endangered Primates 2008-2010, pp.65-67. IUCN/SSC Primate Specialist Group (PSG), International Primatological Society (IPS), and Conservation International (Cl), Arlington, VA.

Stoinski, T. S., Hoff, M. P., \& Maple, T. L. (2001). Habitat use and structural preferences of captive western lowland gorillas (Gorilla gorilla gorilla): Effects of environmental and social variables. International Journal of Primatology, 22(3):431-447.

Swaisgood, D. R. \& Shepherdson, D. J. (2005). Scientific approaches to enrichment and stereotypies in zoo animals: What's been done and where should we go next? Zoo Biology, 24:499-518.

Van Schaik, C.P. (1999) The socioecology of fission-fusion sociality in orangutans. Primates, 40(1):69-86.

von der Ohe \& C.G., Servheen, C. (2002) Measuring Stress in mammals using fecal glucocorticoids: opportunities and challenges. Wildlife Society Bulletin, $30(4): 1215-1225$

Warren, K. S., Verschoor, E. J., Langenhuijzen, S., Heriyanto, Swan, R. A., Vigilant, L. \& Heeney, J. L. (2001). Speciation and intrasubspecific variation of Bornean orangutans, Pongo pygmaeus pygmaeus. Molecular Biology and Evolution, 18: 472-480.

Whitten, P.L., Brockman, D.K., Stavisky, R.C. (1998) Recent advances in noninvasive 
techniques to monitor hormone-behavior interactions. Yearbook of Physical Anthropology, 41:1-23.

Wich, S.A., Utami-Atmoko, S.S., Mitra Setia, T., Rijksen, H.D.,Schurmann, C., van Hooff, J.A.R.A.M., van Schaik, C.P., (2004). Life history of wild Sumatran orangutans (Pongo abelii). Journal of Human Evolution, 47: 385-398.

Wich, S. A., Meijaard, E., Marshall, A. J., Husson, S., Ancrenaz, M., Lacy, R. C., van Schaik, C. P., Sugardjito, J., Simorangkir, T., Traylor-Holzer, K., Doughty, M., Supriantna, J., Dennis, R., Gumal, M., Knott, C. D., \& Singleton, I. (2008). Distribution and conservation status of the orang-utan (Pongo spp.) on Borneo and Sumatra: how many remain? Oryx, 42(3): 329-339.

Wright, B. W. (1995) Novel item enrichment program reduces lethargy in orangutans. Folia Primatologica 65: 214-218.

Wich, S. A., Shumaker, R. W., Perkins, L. \& De Vries, H. (2009). Captive and wild orangutans (Pongo sp.) survivorship: A comparison and the influence of management. American Journal of Primatology, 71:680-686. 


\section{Appendices}

\section{Appendix A}

\section{Orangutan new exhibit outdoor plant species}

\begin{tabular}{|c|c|}
\hline Botanical Name & Common Name \\
\hline Davidia incoluncrata & Dove Tree \\
\hline Fargesia spp. & Umbrella and Fountain Bamboo \\
\hline Magnolia grandiflora & Evergreen Magnolia \\
\hline Paulownia tomentosa & Empress Tree \\
\hline Photinis serratifolia & Chinese Photinia \\
\hline Phyllostachys spp. & Golden, Black, Giant Timber and Dwarf Fern Leaf Bamboo \\
\hline Stewartia pseudocamelia & Japanese Stewartia \\
\hline Trachycarpus fortune & Windmill Palm \\
\hline Ulmus parvifolia & Chinese Elm \\
\hline Abelia spp. & Confetti and Prostrata Glossy Abelia \\
\hline Arbutus unedo & Strawberry Tree \\
\hline Camellia sinensis & Tea Plant \\
\hline Clerodendron trichotomum & Harlequin Glorybower \\
\hline Fatsia japonica & Japanese Aralia \\
\hline Mahonia lomarifolia & Long Leaf Mahonia \\
\hline Miscanthus sinensis & Morning Light Silver Grass \\
\hline Musa basjoo & Japanese Banana \\
\hline Rhaphiolepis indica & India Hawthorne \\
\hline Sorbaria sorbifolia & False Spirea \\
\hline Viburnum carlesii & Koreanspice Viburnum \\
\hline Bergenia cordifolia & Heartleaf Bergenia \\
\hline Hakonechloa 'Aureola' & Japanese Forest Grass \\
\hline Pleioblastus viridistriatus & Dwarf Green-Stripe Bamboo \\
\hline Polystichum munitum & Western Sword Fern \\
\hline
\end{tabular}




\section{Appendix B}

\section{Orangutan Ethogram}

\begin{tabular}{|c|c|c|}
\hline Location & Modifiers & Description \\
\hline Out of sight & & Individual is not visible \\
\hline \multirow[t]{5}{*}{ On ground } & Nest 1 & Nest in front of exhibit, right corner of viewing window \\
\hline & Nest 2 & Nest along the wall of the exhibit, left side of viewing window \\
\hline & Window & In front of viewing window \\
\hline & Back door & $\begin{array}{l}\text { Within } 2 \text { meters of human access door in the back left of the } \\
\text { viewing window }\end{array}$ \\
\hline & Floor & Weight is supported by floor and no other location code applies \\
\hline \multirow[t]{5}{*}{ Not on Ground } & Nest 3 & Any wire nest in a climbing structure \\
\hline & Hammock & $\begin{array}{l}\text { Fabric hammock in the front of the exhibit, left of viewing } \\
\text { window }\end{array}$ \\
\hline & Doors & $\begin{array}{l}\text { Within } 2 \text { meters of holding area door in rear of exhibit on a } \\
\text { structure }\end{array}$ \\
\hline & Structure & $\begin{array}{l}\text { Weight is supported by climbing structure, not in the nest or } \\
\text { near door }\end{array}$ \\
\hline & Holding area & In or out of sight (can be inferred if animal is not on exhibit) \\
\hline
\end{tabular}

New Exhibit Locations

\begin{tabular}{|c|c|c|}
\hline Location & Modifiers & Description \\
\hline \multicolumn{2}{|l|}{ Out of sight } & Individual is not visible \\
\hline \multirow{8}{*}{$\begin{array}{l}\text { Outside } \\
\text { Zone } 1\end{array}$} & & The east yard from holding/east public window up to the log \\
\hline & & tunnel (not including tunnel) \\
\hline & Holding to outside door & Two doors with access from holding to outside. ${ }^{*}$ \\
\hline & Indoor to outside door & Two doors with access from inside to outside.* \\
\hline & Window wall & Window and wall between the indoor and outdoor exhibits. ${ }^{*}$ \\
\hline & Public window & Public viewing window.* \\
\hline & Enrichment tree & $\begin{array}{l}\text { Large gunite tree with portholes, centerpiece of the East yard. } \\
\star \star\end{array}$ \\
\hline & Sway pole & $\begin{array}{l}\text { Steel bamboo poles. Scored if pole(s) is supporting animal's } \\
\text { weight e.g. if animal uses pole for locomotion or is perched, } \\
\text { not if animal is merely touching it. }\end{array}$ \\
\hline \multicolumn{2}{|l|}{ Outside } & Middle of the yard, from the log tunnel (included) to the \\
\hline \multirow[t]{4}{*}{ Zone 2} & & stream/pool (not included) \\
\hline & Balcony & Keeper-access balcony to the west of the log tunnel. ${ }^{*}$ \\
\hline & Log tunnel & Hollow log allows public entrance to primate's area. ${ }^{*}$ \\
\hline & Platform Z2 & Wooden trapezoidal platform on metal beam. ${ }^{* *}$ \\
\hline \multicolumn{2}{|l|}{ Outside } & West side of the yard, from the stream/pool (included) to the \\
\hline \multirow[t]{5}{*}{ Zone 3} & & mesh near the Mandrill outdoor exhibit \\
\hline & Pool/stream & Water feature, scored if animal is in water or on the rockwork \\
\hline & Research hut & $\begin{array}{l}\text { Upper west-side public viewing area; covered deck with large } \\
\text { windows. Scored if animal is on or past the railing (including } \\
\text { mesh above railing) }\end{array}$ \\
\hline & Terrace & Elevated terrace planter along the building edge of the exhibit \\
\hline & Platform Z3 & Wooden trapezoidal platform on metal beam ${ }^{* *}$ \\
\hline \multicolumn{3}{|l|}{ Indoor Exhibit } \\
\hline & Holding & Animal is in holding \\
\hline
\end{tabular}




\begin{tabular}{|c|c|}
\hline Nest & Metal nest adjacent to west holding door \\
\hline Holding door & Two holding-to-indoors shift doors* \\
\hline In-out door & Two indoor-outdoors shift doors* \\
\hline Window wall & Window wall between indoor and outdoor exhibits* \\
\hline Public window & Public viewing window.* \\
\hline Upper keeper door & $\begin{array}{l}\text { Keeper door in the southwest corner of the exhibit, including } \\
\text { rock work above* }\end{array}$ \\
\hline Lower keeper door & Keeper door in the pit* \\
\hline Hammock & Fabric Hammock \\
\hline Window & Public viewing window.* \\
\hline Window wall & Window wall between indoor and outdoor exhibits* \\
\hline Mesh & $\begin{array}{l}\text { Perimeter side mesh. Scored if animal is within } 1 \mathrm{~m} \text {. at any } \\
\text { elevation }\end{array}$ \\
\hline Vertical log & $\begin{array}{l}\text { Vertical, upright logs and metal beam supports. Scored if } \\
\text { log/beam is supporting animal's weight }\end{array}$ \\
\hline Horizontal log & $\begin{array}{l}\text { Horizontal, slanted logs. Scored of log is supporting animal's } \\
\text { weight }\end{array}$ \\
\hline Rope & $\begin{array}{l}\text { Ropes connecting various structures. Scored if rope is } \\
\text { supporting subjects weight }\end{array}$ \\
\hline Ceiling & Ceiling mesh. \\
\hline \multirow[t]{4}{*}{ Floor } & $\begin{array}{l}\text { Animal is on the ground and not at any other specified } \\
\text { location }\end{array}$ \\
\hline & ${ }^{*}$ scored if animal is within $2 \mathrm{~m}$ \\
\hline & ${ }^{* *}$ scored if animal is in contact with \\
\hline & ${ }^{* * *}$ scored if supporting animals weight \\
\hline
\end{tabular}

Orangutan Locomotion

\begin{tabular}{ll}
\hline $\begin{array}{l}\text { Locomotion } \\
\text { Bipedal Walk }\end{array}$ & Description \\
Bipedal Run & $\begin{array}{l}\text { Bipedal walking without support } \\
\text { Bipedal running }\end{array}$ \\
Long arm-swing & Brachiation with $<4$ swings \\
Quadramanous & Lateral movement through the air using all four limbs \\
Climbing & Vertical movement up/down a structure \\
Hold-walking & Bipedal walking using upper limbs to grasp for objects for support \\
Hanging & Sitting upright, with the subject's weight not supported by anything else \\
Sitting &
\end{tabular}


Orangutan Activity

\begin{tabular}{ll}
\hline Activity & Description \\
\hline Eating & Includes chewing, oral holding and oral manipulation \\
Manipulating & Enrichment object is being altered by an orangutan action \\
Holding & Supporting or possessing enrichment object with limbs or body \\
Digging & In exhibit floor or through layer of enrichment \\
Contact & Passive touch with enrichment, being on, in or under objects \\
None & No contact with enrichment objects
\end{tabular}

Description of orangutan elevations

\begin{tabular}{ll}
\hline Elevation 1 & In contact with the ground \\
Elevation 2 & $<2$ meters above ground \\
Elevation 3 & $>2$ meters above ground \\
\hline
\end{tabular}


Appendix C

Behavioral data percent of observable interval totals

\begin{tabular}{clccc}
\hline $\begin{array}{l}\text { Elevation } \\
(\%)\end{array}$ & & $\begin{array}{c}\text { Elevation 1 } \\
\text { Ground level }\end{array}$ & $\begin{array}{c}\text { Elevation 2 } \\
<2 \mathrm{~m} \text { Above Ground }\end{array}$ & $\begin{array}{c}\text { Elevation } 3 \\
>2 \mathrm{~m} \text { Above Ground }\end{array}$ \\
\hline \multirow{2}{*}{ Inji } & Baseline & 96.8 & 1.3 & 3.8 \\
& Habituation & 67.8 & 7.1 & 30.6 \\
& Post-Occupancy & 84.0 & 13.9 & 5.3 \\
\multirow{3}{*}{ Kutai } & Baseline & 90.0 & 2.5 & 9.2 \\
& Habituation & 41.9 & 7.1 & 53.3 \\
& Post-Occupancy & 47.3 & 19.7 & 35.5 \\
\hline
\end{tabular}

Proximity

(\%)

\begin{tabular}{clcc} 
& & $<20 \mathrm{~m}$ & $>20 \mathrm{~m}$ \\
\hline \multirow{2}{*}{ Inji } & Baseline & 51.7 & 35.3 \\
& Habituation & 27.7 & 77.6 \\
& Post-Occupancy & 22.3 & 81.0 \\
\multirow{2}{*}{ Kutai } & Baseline & 52.7 & 31.7 \\
& Habituation & 27.1 & 75.9 \\
& Post-Occupancy & 22.3 & 81.0 \\
\hline
\end{tabular}

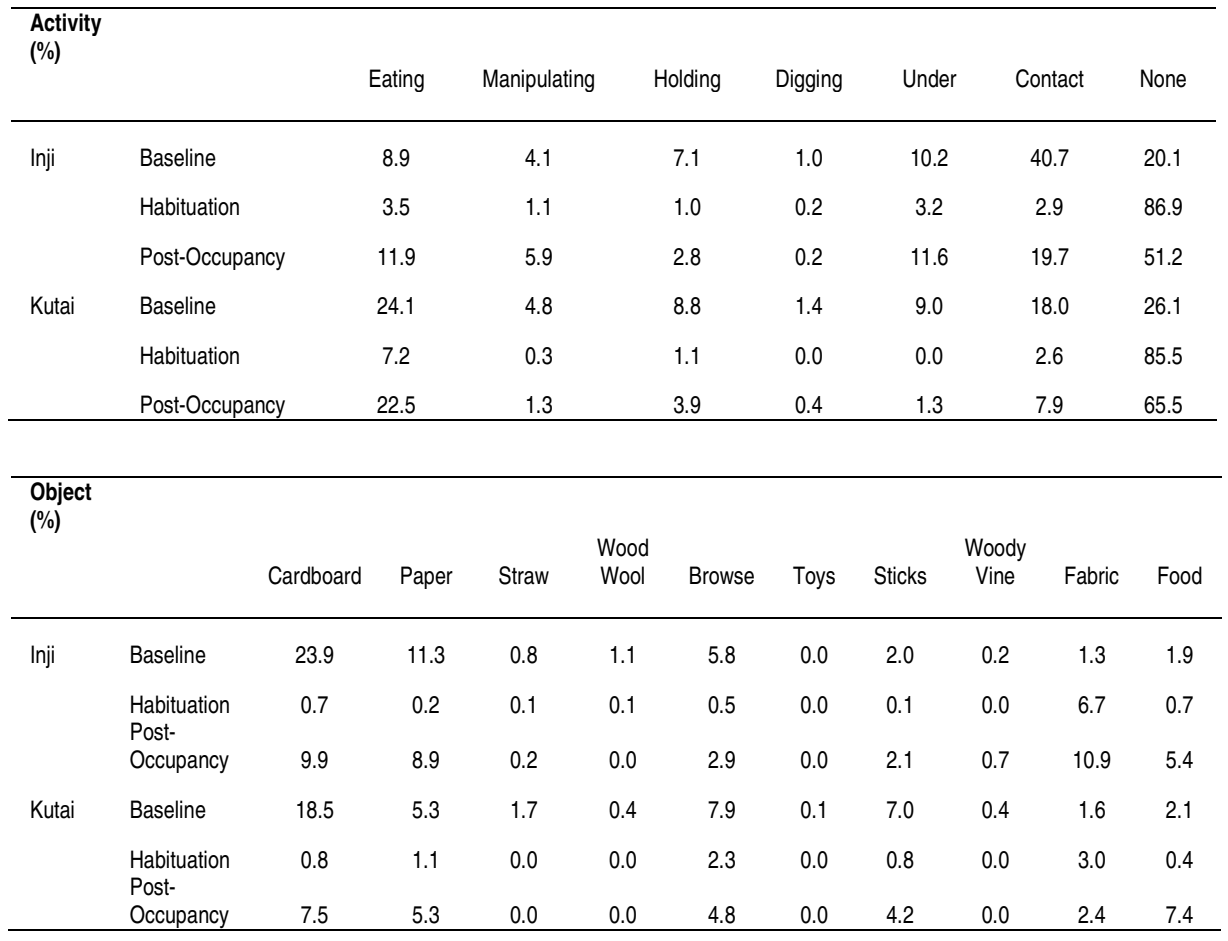




\begin{tabular}{|c|c|c|c|c|c|}
\hline \multirow[t]{2}{*}{$\begin{array}{l}\text { Object } \\
\text { (continued) } \\
(\%)\end{array}$} & & \multirow{2}{*}{ Bucket } & \multirow{2}{*}{ Bark } & \multirow{2}{*}{ Multiple } & \multirow[b]{2}{*}{ Unknown } \\
\hline & & & & & \\
\hline \multirow[t]{3}{*}{ Inji } & Baseline & 2.0 & 2.1 & 17.9 & 0.6 \\
\hline & $\begin{array}{l}\text { Habituation } \\
\text { Post- }\end{array}$ & 0.0 & 0.6 & 0.6 & 1.6 \\
\hline & Occupancy & 0.0 & 0.0 & 10.5 & 0.6 \\
\hline \multirow[t]{3}{*}{ Kutai } & Baseline & 2.0 & 3.8 & 10.6 & 2.1 \\
\hline & $\begin{array}{l}\text { Habituation } \\
\text { Post- }\end{array}$ & 0.0 & 0.0 & 0.2 & 2.5 \\
\hline & Occupancy & 0.0 & 1.3 & 3.5 & 0.8 \\
\hline
\end{tabular}

\begin{tabular}{|c|c|c|c|c|c|c|}
\hline \multicolumn{2}{|c|}{$\begin{array}{l}\text { Locomotion } \\
(\%)\end{array}$} & Knuckle walk & $\begin{array}{c}\text { Bipedal } \\
\text { Walk }\end{array}$ & $\begin{array}{l}\text { Bipedal } \\
\text { Run }\end{array}$ & $\begin{array}{l}\text { Short } \\
\text { Arm- } \\
\text { Swing }\end{array}$ & $\begin{array}{l}\text { Long } \\
\text { Arm- } \\
\text { Swing }\end{array}$ \\
\hline \multirow[t]{3}{*}{ Inji } & Baseline & 3.7 & 0.4 & 0.0 & 0.2 & 0.0 \\
\hline & $\begin{array}{l}\text { Habituation } \\
\text { Post- }\end{array}$ & 14.5 & 0.0 & 0.0 & 0.2 & 0.0 \\
\hline & Occupancy & 7.7 & 0.3 & 0.0 & 1.0 & 0.0 \\
\hline \multirow[t]{3}{*}{ Kutai } & Baseline & 3.0 & 1.0 & 0.1 & 0.3 & 0.1 \\
\hline & $\begin{array}{l}\text { Habituation } \\
\text { Post- }\end{array}$ & 12.9 & 0.0 & 0.0 & 0.5 & 0.2 \\
\hline & Occupancy & 11.3 & 0.6 & 0.0 & 0.5 & 0.0 \\
\hline
\end{tabular}

\begin{tabular}{|c|c|c|c|c|c|c|}
\hline \multicolumn{2}{|c|}{$\begin{array}{l}\text { Locomotion } \\
\text { (continued) } \\
(\%)\end{array}$} & Quadramanous & Climbing & $\begin{array}{l}\text { Hang- } \\
\text { Standing }\end{array}$ & Sitting & Inactive \\
\hline \multirow[t]{3}{*}{ Inji } & Baseline & 0.1 & 1.4 & 1.9 & 23.9 & 68.9 \\
\hline & $\begin{array}{l}\text { Habituation } \\
\text { Post- }\end{array}$ & 3.0 & 4.1 & 3.7 & 49.4 & 28.5 \\
\hline & Occupancy & 0.5 & 3.2 & 2.1 & 34.9 & 51.9 \\
\hline \multirow[t]{3}{*}{ Kutai } & Baseline & 0.1 & 1.0 & 4.0 & 36.4 & 53.8 \\
\hline & $\begin{array}{l}\text { Habituation } \\
\text { Post- }\end{array}$ & 0.8 & 2.6 & 5.1 & 55.9 & 19.7 \\
\hline & Occupancy & 0.9 & 9.9 & 1.6 & 32.8 & 43.9 \\
\hline
\end{tabular}

\begin{tabular}{lllll}
\hline \multicolumn{2}{c}{ Location : Window Use (\%) } & & & \\
& & Public Window & Wall Window & Window Total \\
\hline \multirow{2}{*}{ Inji } & Baseline & $\mathrm{n} / \mathrm{a}$ & $\mathrm{n} / \mathrm{a}$ & 25.5 \\
& Habitutation & 7.5 & 1.4 & 8.9 \\
& Post-Occupancy & 12.6 & 0.3 & 12.9 \\
\multirow{2}{*}{ Kutai } & Baseline & $\mathrm{n} / \mathrm{a}$ & $\mathrm{n} / \mathrm{a}$ & 11.3 \\
& Habitutation & 1.4 & 1.6 & 3.1 \\
& Post-Occupancy & 10.7 & 0.3 & 11.0 \\
\hline
\end{tabular}




\begin{tabular}{|c|c|c|c|c|c|c|c|c|c|}
\hline \multicolumn{10}{|c|}{ Location: Structure Use (\%) } \\
\hline & & Nest & Hammock & Structure* & Rope & Ceiling & Mesh & $\begin{array}{l}\text { Log } \\
\text { Tunnel }\end{array}$ & Tree \\
\hline \multirow[t]{3}{*}{ Inji } & Baseline & 0.60 & 0.05 & 3.50 & $\mathrm{n} / \mathrm{a}$ & $\mathrm{n} / \mathrm{a}$ & $\mathrm{n} / \mathrm{a}$ & $\mathrm{n} / \mathrm{a}$ & $\mathrm{n} / \mathrm{a}$ \\
\hline & $\begin{array}{l}\text { Habitutation } \\
\text { Post- }\end{array}$ & 1.24 & 0.06 & 18.21 & 1.90 & 0.56 & 0.85 & 0.56 & 4.90 \\
\hline & Occupancy & 10.28 & 0.00 & 10.99 & 5.80 & 0.82 & 0.33 & 0.15 & 0.55 \\
\hline \multirow[t]{3}{*}{ Kutai } & Baseline & 0.44 & 0.21 & 6.50 & $n / a$ & $\mathrm{n} / \mathrm{a}$ & $\mathrm{n} / \mathrm{a}$ & $\mathrm{n} / \mathrm{a}$ & $\mathrm{n} / \mathrm{a}$ \\
\hline & $\begin{array}{l}\text { Habitutation } \\
\text { Post- }\end{array}$ & 1.17 & 0.00 & 46.07 & 0.17 & 1.89 & 0.11 & 1.11 & 0.50 \\
\hline & Occupancy & 1.12 & 1.79 & 28.22 & 2.81 & 2.81 & 3.78 & 0.24 & 0.82 \\
\hline
\end{tabular}

*generic structure includes horizontal and vertical logs for the habituation and post-occupancy phases, see data below.

\begin{tabular}{|c|c|c|c|c|c|c|c|}
\hline \multicolumn{8}{|c|}{$\begin{array}{l}\text { Location: Structure Use (\%) } \\
\text { (continued) }\end{array}$} \\
\hline & & $\begin{array}{l}\text { Sway } \\
\text { pole }\end{array}$ & Platform & Terrace & Balcony & $\begin{array}{l}\text { Researcher } \\
\text { Hut }\end{array}$ & $\begin{array}{l}\text { Total } \\
\text { Structures }\end{array}$ \\
\hline \multirow[t]{3}{*}{ Inji } & Baseline & $\mathrm{n} / \mathrm{a}$ & $\mathrm{n} / \mathrm{a}$ & $\mathrm{n} / \mathrm{a}$ & $n / a$ & $\mathrm{n} / \mathrm{a}$ & 4.15 \\
\hline & $\begin{array}{l}\text { Habitutation } \\
\text { Post- }\end{array}$ & 0.56 & 0.06 & 0.28 & 0.23 & 0.06 & 29.47 \\
\hline & Occupancy & 0.06 & 0.00 & 0.00 & 0.00 & 0.00 & 28.98 \\
\hline \multirow[t]{3}{*}{ Kutai } & Baseline & $\mathrm{n} / \mathrm{a}$ & $\mathrm{n} / \mathrm{a}$ & $\mathrm{n} / \mathrm{a}$ & $\mathrm{n} / \mathrm{a}$ & $\mathrm{n} / \mathrm{a}$ & 7.15 \\
\hline & $\begin{array}{l}\text { Habitutation } \\
\text { Post- }\end{array}$ & 0.28 & 0.28 & 0.17 & 0.0 & 0.06 & 51.79 \\
\hline & Occupancy & 0.42 & 0.12 & 0.03 & 0.0 & 0.06 & 42.24 \\
\hline
\end{tabular}

\begin{tabular}{llrr}
\multicolumn{2}{l}{ Location: Log Use (\%) } & \multicolumn{2}{c}{ Horizontal log } \\
\hline \multirow{2}{*}{ Inji } & Habitutation & 1.8 & 16.4 \\
& Post-Occupancy & 3.4 & 7.6 \\
\multirow{2}{*}{ Kutai } & Habitutation & 8.7 & 37.3 \\
& Post-Occupancy & 16.4 & 11.8 \\
\hline
\end{tabular}

